FABIANO ROGÉRIO CORRÊA

\title{
GRADES DE EVIDÊNCIA COM VISÃO ESTÉREO OMNIDIRECIONAL PARA NAVEGAÇÃO DE ROBÔS MÓVEIS
}

\author{
Dissertação apresentada à Escola Politécnica \\ da Universidade de São Paulo para obtenção \\ do Título de Mestre em Engenharia.
}

SÃO PAULO 


\title{
FABIANO ROGÉRIO CORRÊA
}

\section{GRADES DE EVIDÊNCIA COM VISÃO ESTÉREO OMNIDIRECIONAL PARA NAVEGAÇÃO DE ROBÔS MÓVEIS}

\author{
Dissertação apresentada à Escola Politécnica \\ da Universidade de São Paulo para obtenção \\ do Título de Mestre em Engenharia. \\ Área de Concentração: \\ Engenharia Mecânica \\ Orientador: \\ Prof. Doutor \\ Jun Okamoto Junior
}

SÃO PAULO 


\section{FICHA CATALOGRÁFICA}

\section{Corrêa, Fabiano Rogério}

Grades de evidência com visão estéreo omnidirecional para navegação de robôs móveis / F.R. Corrêa. -- São Paulo, 2004. $81 \mathrm{p}$.

Dissertação (Mestrado) - Escola Politécnica da Universidade de São Paulo. Departamento de Engenharia Mecatrônica e de Sistemas Mecânicos.

1.Visão estéreo omnidirecional 2.Navegação de robôs móveis

3.Grades de evidência I.Universidade de São Paulo. Escola Politécnica. Departamento de Engenharia Mecatrônica e de Sistemas Mecânicos II.t. 
'The only way of finding the limits of the possible is going beyond them into the impossible'

- Arthur C. Clarke. 


\section{AGRADECIMENTOS}

Primeiramente ao CNPq pelo financiamento a este projeto permitindo-me dedicação exclusiva sem a qual os resultados não teriam sido os mesmos em tempo e qualidade.

Aos professores Anna Helena Reali Costa e Fabio Gagliardi Cozman que participaram da minha banca de qualificação e cujos apontamentos ajudaram-me muito a focar melhor o meu trabalho.

Ao meu orientador Jun Okamoto Junior pela oportunidade de trabalhar numa linha de pesquisa tão interessante e por ter me ajudado a planejar de maneira mais concreta meus estudos nos assuntos que me interessavam.

Ao engenheiro e colega de laboratório Marcus Pivatto que proporcionou ao longo de todo o desenvolvimento do trabalho um ambiente intelectualmente estimulante.

Aos meus colegas do LPA e da pós-graduação em geral por tornarem esse período do mestrado mais agradável. 


\section{RESUMO}

O problema da navegação de robôs móveis autônomos em ambientes internos, desconhecidos e não-estruturados ainda proporciona inúmeros desafios aos pesquisadores da área de Robótica e Inteligência Artificial. Neste trabalho foi proposta e implementada uma navegação utilizando-se apenas a informação adquirida por um sistema de visão omnidirecional, com um campo visual de $360^{\circ}$ ao redor do robô, e um algoritmo estéreo. Foi desenvolvido um modelo probabilístico específico para o sistema de visão estéreo omnidirecional para atualizar as Grades de Evidência, representação do ambiente que divide o espaço em células contendo suas respectivas probabilidades de estarem ocupadas. A abordagem probabilística visa incorporar os erros inerentes ao sensoriamento para a construção de um mapa do ambiente que possa ser utilizado para navegação. Sobre esta representação o robô planeja trajetórias para atingir locais pré-determinados. O cálculo da entropia da Grade de Evidência foi proposto e aplicado para quantificar a informação nela presente e determinar o momento de realizar o planejamento de trajetória. As Grades de Evidência também podem ser utilizadas como fonte auxiliar de informação para resolver os problemas de localização do robô ao longo da navegação. Alguns

resultados do mapeamento com o robô são apresentados, bem como com o planejador de trajetórias e a auto-localização para navegação autônoma. O modelo do sistema de visão estéreo omnidirecional mostrou-se adequado para a representação do ambiente de navegação. 


\begin{abstract}
The problem of navigation of autonomous mobile robots in indoor, unknown and unstructured environments still provides a challenge to the community of Robotics and Artificial Intelligence. In this work was proposed and implemented a navigation only with information from an omnidirectional vision system, with a field of view of 360 degrees around the robot, and a stereo algorithm. A probabilistic model specific to the omnidirectional stereo vision system was developed to update an Evidence Grid, a representation of the environment that tessellate space in cells containing its probability of being occupied. The probability approach incorporates errors inherent to sensor for construction of an environment map that could be utilized by a robot in a navigation task. Under this representation the robot plan its path to reach a goal. The calculus of the entropy of the Evidence Grids was proposed and applied to quantify the information in it and to determine the instant to plan. The Evidence Grid can be used as another source of information to solve the problem of localization. Some results are presented in mapping with the robot and with the path-planner and self-localization for an autonomous navigation. The model of omnidirectional stereovision system showed itself adequate to represent navigational environment.
\end{abstract}




\section{SUMÁRIO}

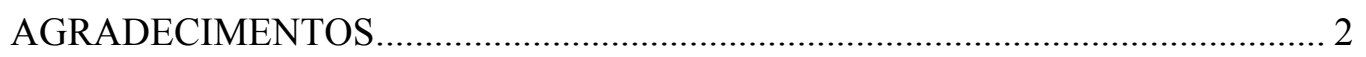

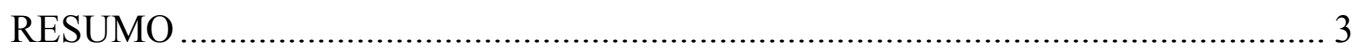

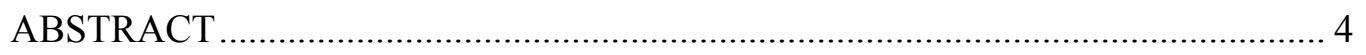

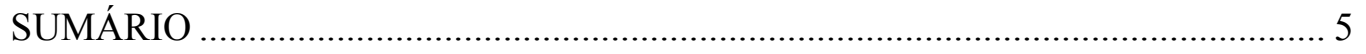

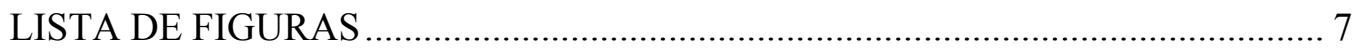

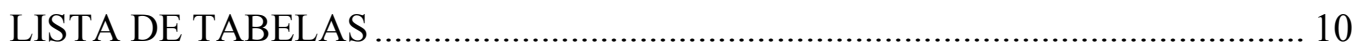

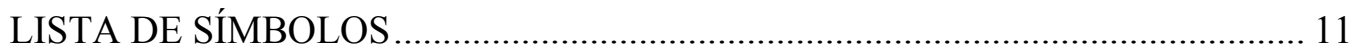

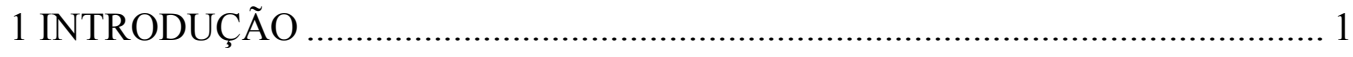

2 VISÃO OMNIDIRECIONAL APLICADA A ROBÔS MÓVEIS........................... 5

2.1 Sistemas de visão omnidirecional....................................................... 5

2.2 Aplicações em tarefas de navegação ....................................................... 8

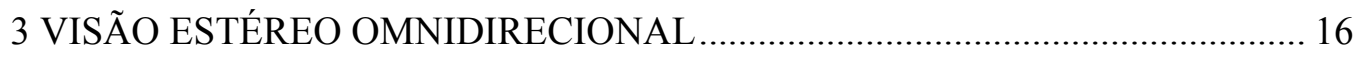

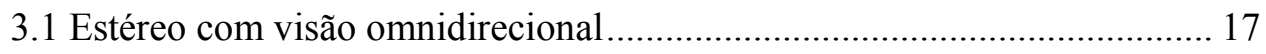

3.2 Extração de características..................................................................... 19

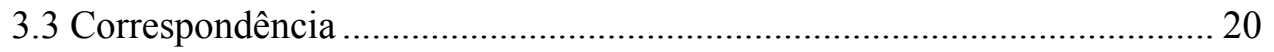

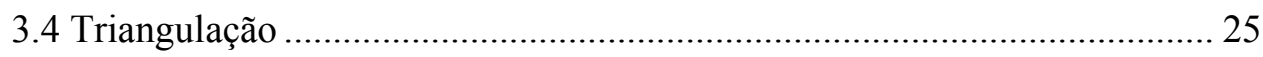

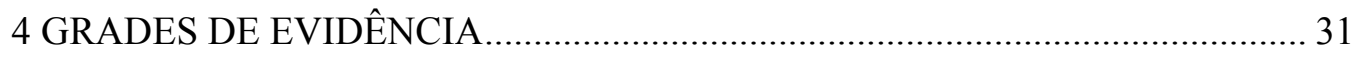

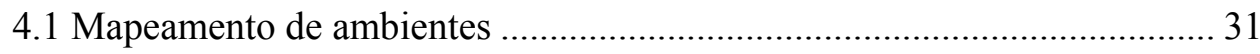




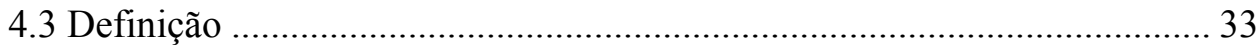

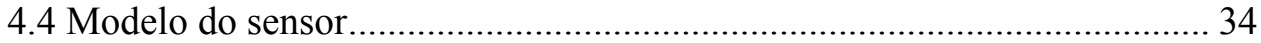

4.5 Modelo Bayesiano para estimação do mundo ............................................ 40

4.6 Atualização da Grade de Evidência ............................................................. 41

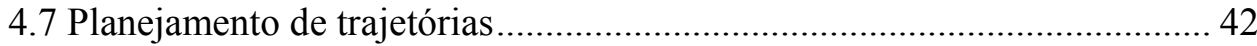

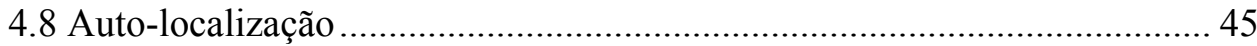

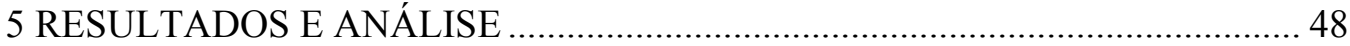

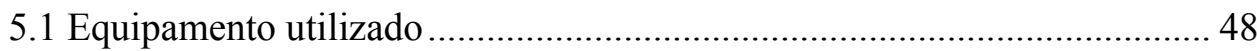

5.2 Experimentos com a visão estéreo omnidirecional ................................. 49

5.3 Experimentos de mapeamento com as Grades de Evidência ..................... 54

5.4 Experimentos de navegação autônoma com planejamento de trajetória .... 63

5.5 Experimentos de auto-localização com as Grades de Evidência................. 72

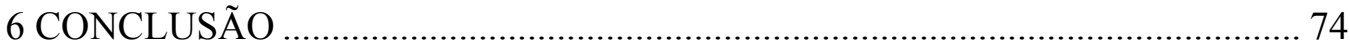

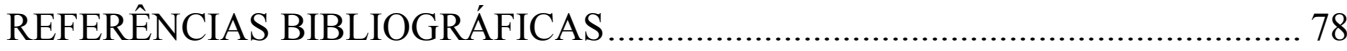




\section{LISTA DE FIGURAS}

Figura 1 - Exemplo de uma imagem omnidirecional.

Figura 2 - Exemplo de uma imagem panorâmica obtida a partir de uma imagem

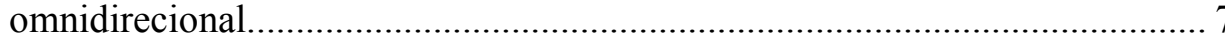

Figura 3 - Exemplo de uma imagem perspectiva obtida de uma região da imagem omnidirecional............................................................................. 7

Figura 4 - Classificação dos trabalhos em navegação................................................... 8

Figura 5 - Diagrama dos problemas em navegação..................................................... 9

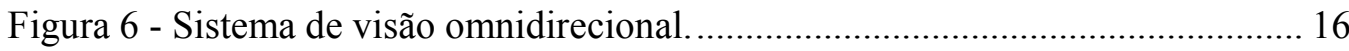

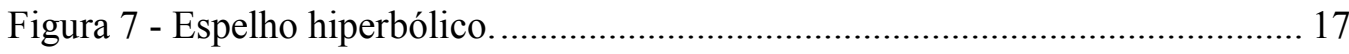

Figura 8 - Imagem omnidirecional após processamento do gradiente e posterior transformação em imagem binária............................................................... 20

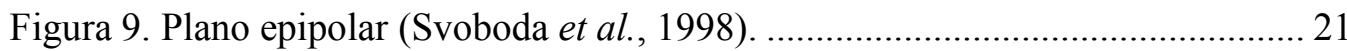

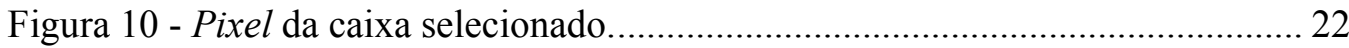

Figura 11 - Curva epipolar correspondente ao ponto selecionado na primeira

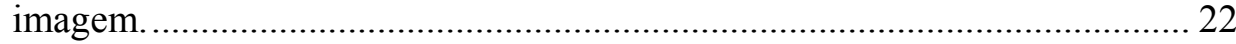

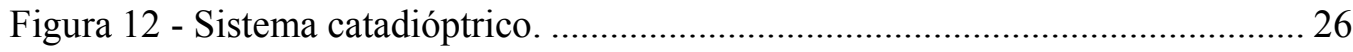

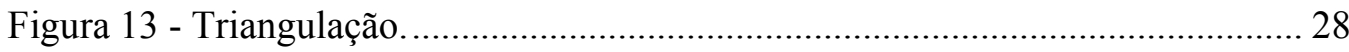

Figura 14 - Exemplo de um mapa de distâncias feito a partir de informação estéreo omnidirecional. ............................................................................. 30

Figura 15 - Seqüência para construção da Grade (Elfes, 1989)................................. 34

Figura 16 - Modelo probabilístico do ultra-som (Elfes, 1989). ................................ 36 
Figura 17. Princípio físico de formação da imagem omnidirecional.

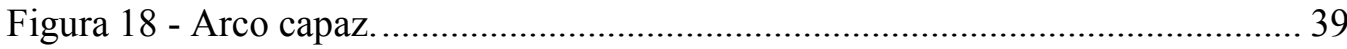

Figura 19 - Modelo probabilístico do sistema de visão estéreo omnidirecional........ 40

Figura 20. Funcionamento do algoritmo Frente de onda......................................... 44

Figura 22 - Base Móvel construída no LPA. ....................................................... 48

Figura 23. Objeto preparado para o teste de localização de distância. ....................... 50

Figura 24. Primeira imagem do par estéreo......................................................... 50

Figura 25. Segunda imagem do par estéreo....................................................... 51

Figura 26. Primeira imagem binária do par. ..................................................... 51

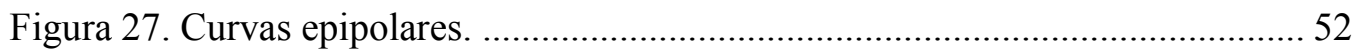

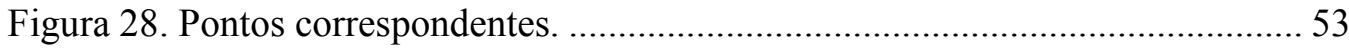

Figura 29. Resultado obtido das distâncias calculadas com a posição da caixa destacada pelo retângulo preto.................................................................... 53

Figura 30 - Ampliação da Grade de Evidência, após todas as atualizações feitas durante o mapeamento, com a caixa em destaque no centro. ....................... 58

Figura 31 - Outra maneira de representação das Grades............................................ 59

Figura 32 - Análise quantitativa da Grade de Evidência......................................... 59

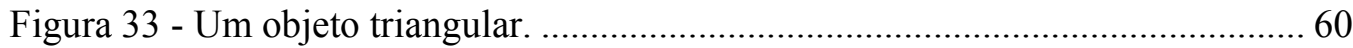

Figura 34 - Triângulo mapeado com as Grades de Evidência. ................................. 60

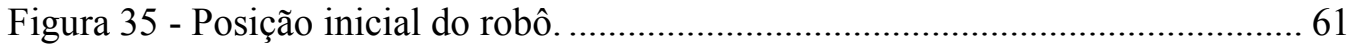

Figura 36 - Posição final do robô.......................................................................... 61

Figura 37 - Informação do algoritmo estéreo na última posição. .............................. 62 


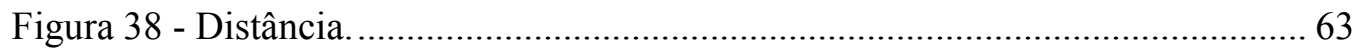

Figura 39 - Posições inicial e de chegada do robô. ................................................... 63

Figura 40 - Posição onde o robô possui informação suficiente para navegar............. 64

Figura 41 - Posição intermediária na navegação.................................................... 65

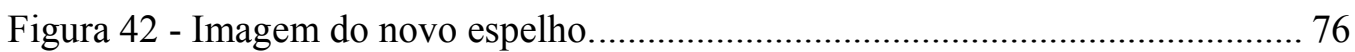

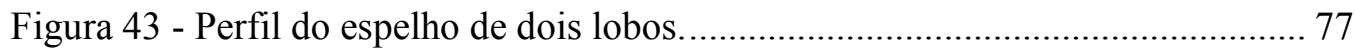




\section{LISTA DE TABELAS}

Tabela 1 - Usos da visão omnidirecional em robôs móveis....................................... 14

Tabela 2 - Atualizações da Grade de Evidência....................................................... 54

Tabela 3 - Atualizações na Grade de Evidência durante navegação autônoma.......... 65

Tabela 4 - Planejamento da trajetória durante navegação autônoma......................... 69

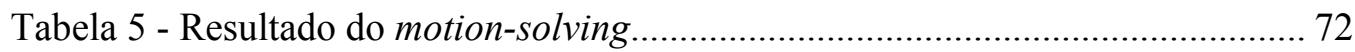




\section{LISTA DE SÍMBOLOS}

b(i,j) Valor em nível de cinza do pixel $(i, j)$ numa imagem omnidirecional

$p_{i} \quad$ Gradiente na direção i da imagem

$p_{j} \quad$ Gradiente na direção j da imagem

$P(i, j) \quad$ Gradiente de Prewitt

$\mathrm{C}_{1} \quad$ Posição da câmera ao adquirir a primeira imagem

$\mathrm{C}_{2} \quad$ Posição da câmera ao adquirir a segunda imagem

$\pi \quad$ Plano epipolar

$\mathrm{F}_{1}$ Foco do espelho hiperbólico na posição 1

$\mathrm{F}_{2}$, Foco do espelho hiperbólico na posição 2

X Ponto no espaço

$\mathrm{Xh}_{1} \quad$ Vetor que aponta na direção do ponto $\mathrm{X}$ e tem magnitude igual à distância entre o foco e o ponto na superfície do espelho hiperbólico correspondente ao pixel $\mathrm{q}_{1}$

$\mathrm{Xh}_{2} \quad$ Vetor que aponta na direção do ponto $\mathrm{X}$ e tem magnitude igual à distância entre o foco e o ponto na superfície do espelho hiperbólico correspondente ao pixel $\mathrm{q}_{2}$

$\mathrm{q}_{1} \quad$ Pixel corresponde à projeção de $\mathrm{X}$ na primeira imagem

$\mathrm{q}_{2} \quad$ Pixel corresponde à projeção de $\mathrm{X}$ na segunda imagem 
$\mathrm{e}_{1}, \mathrm{e}_{1}, \quad$ Epipolos na primeira imagem

$\mathrm{e}_{2}, \mathrm{e}_{2}, \quad$ Epipolos na segunda imagem

t vetor de translação entre a posição 1 e 2

$S S D(i, j)$ Função para correspondência

$\left(i_{0, j_{0}}\right) \quad$ Coordenadas em pixel do centro da janela para correspondência

$(i, j) \quad$ Coordenadas em pixel de um ponto na janela para correspondência

$I_{1}(i, j) \quad$ Nível de cinza do pixel de coordenadas $(i, j)$ na primeira imagem

$I_{2}(i, j) \quad$ Nível de cinza do pixel de coordenadas $(i, j)$ na segunda imagem

$W \quad$ Janela de busca na imagem para determinação do ponto correspondente

$\left(\mathrm{i}_{1}, \mathrm{j}_{1}\right) \quad$ Coordenadas em pixel de um ponto na primeira imagem

$\left(i_{2}, j_{2}\right) \quad$ Coordenadas em pixel do ponto correspondente a $\left(i_{1}, j_{1}\right)$ na segunda imagem

$\rho_{i} \quad$ Raio em coordenadas polares de um pixel na imagem

$l \quad$ Raio de luz que passa pelo pixel de raio $\rho$

$(\mathrm{x}, \mathrm{z}) \quad$ Sistema de coordenadas fixo em F'

f Distância focal da câmera

$\rho \quad$ Coordenada $\mathrm{x}$ da intersecção entre o raio de luz $l$ e a superfície do espelho

$a, b \quad$ Parâmetros do espelho hiperbólico

$e \quad$ Raiz quadrada da soma dos quadrados de $a$ e $b$

$h \quad$ Superfície hiperbólica do espelho 
C Foco da câmera que coincide com o outro foco $\mathrm{F}$ da hipérbole $\mathrm{h}$

Xh Ponto na superfície do espelho

t Módulo do vetor translação t entre a aquisição das imagens do par estéreo

$\alpha \quad$ Ângulo da direção do vetor translação $\mathbf{t}$

$r \quad$ Reta que passa pelo foco do espelho na posição 1 e pelo ponto $\mathrm{X}$ no espaço

$s \quad$ Reta que passa pelo foco do espelho na posição 2 e pelo ponto X no espaço

d Distância da projeção do objeto no plano com relação à segunda posição do robô

$\lambda \quad$ Parâmetro da equação da reta $r$

$\beta \quad$ Parâmetro da equação da reta $s$

$\mathrm{x}_{1} \quad$ Coordenada $\mathrm{x}$ do sistema de referência no foco do espelho na primeira posição

$\mathrm{y}_{1} \quad$ Coordenada y do sistema de referência no foco do espelho na primeira posição

$\mathrm{z}_{1} \quad$ Coordenada $\mathrm{z}$ do sistema de referência no foco do espelho na primeira posição

$\mathrm{x}_{2}$ Coordenada $\mathrm{x}$ do sistema de referência no foco do espelho na segunda posição

$\mathrm{y}_{2}$ Coordenada y do sistema de referência no foco do espelho na segunda posição

$\mathrm{z}_{2} \quad$ Coordenada $\mathrm{z}$ do sistema de referência no foco do espelho na segunda posição 
$\mathrm{C}_{\mathrm{i}} \quad$ Célula $i$ da Grade de Evidência

$\mathrm{E}\left(\mathrm{C}_{\mathrm{i}}\right) \quad$ Valor da Grade de Evidência na célula $\mathrm{C}_{\mathrm{i}}$

$\mathrm{s}\left(\mathrm{C}_{\mathrm{i}}\right) \quad$ Variável aleatória binária

OCC Ocupada

EMP Livre

S Leitura do sensor

M Configuração do mundo

o Distância da câmera à um objeto no ambiente

$\delta($ S-o) Função delta ou impulso

$\theta \quad$ Ângulo num sistema de coordenadas polares cujo raio é $z$

$\sigma_{s}^{2} \quad$ Variância na distância

$\sigma_{\theta}^{2} \quad$ Variância no ângulo $\theta$

$\mathrm{S}_{\mathrm{t}} \quad$ Leitura do sensor no instante $\mathrm{t}$

$\mathrm{S}_{\mathrm{t}+1} \quad$ Leitura do sensor no instante $\mathrm{t}+1$

$\gamma \quad$ Ângulo entre o raio de luz e um objeto no ambiente formando uma região de sombra

$\mathrm{h}_{\mathrm{O}} \quad$ Altura do objeto no ambiente

$\mathrm{d}_{\mathrm{S}} \quad$ Tamanho da sombra que um objeto produz no ambiente segundo o sistema de visão omnidirecional

$\mathrm{d}_{\mathrm{K}} \quad$ Número de células ocupadas pela sombra que um objeto produz no ambiente segundo o sistema de visão omnidirecional 
$v(x, y) \quad$ Modelo do sistema de visão estéreo omnidirecional na forma de uma distribuição de probabilidades

$\mu_{x} \quad$ Valor médio na direção $\mathrm{x}$ correspondendo à medida do sensor

$\mu_{y} \quad$ Valor médio na direção y correspondendo à medida do sensor

n Célula da Grade de Evidência

f*(n) Função estimada de custo para o planejamento de trajetória sobre a Grade de Evidência

g(n) Função do custo entre a posição inicial do robô na Grade de Evidência e a posição atual

h*(n) Função estimada do custo entre a posição atual e a posição final segundo uma heurística dada

U Entropia da Grade de Evidência $\mathrm{E}\left(\mathrm{C}_{\mathrm{i}}\right)$

T Matriz de rotação estendida para transformação da Grade de Evidência

$\varphi \quad$ Ângulo de rotação do sistema de coordenadas do robô entre duas atualizações da Grade de Evidência

$\mathrm{t}_{\mathrm{x}}$ Translação do robô na direção $\mathrm{x}$ entre duas atualizações da Grade de Evidência

ty Translação do robô na direção y entre duas atualizações da Grade de Evidência

IP Índice de desempenho na registro entre duas Grades de Evidência 
Capitulo 1

\section{INTRODUÇÃO}

As dificuldades presentes numa navegação autônoma em ambientes desconhecidos ainda são um desafio para as áreas de Robótica Móvel e Inteligência Artificial. Uma tarefa de navegação autônoma consiste em, partindo-se de um determinado ponto do ambiente, atingir outro previamente estabelecido. Durante a realização da tarefa o robô precisa se auto-localizar em certos intervalos de tempo, identificando a posição do seu objetivo, e planejar uma trajetória ou adotar uma estratégia de movimentação capaz de levá-lo à posição final desviando-se dos obstáculos à sua frente. Para isso, o robô é equipado com sensores que permitem a aquisição de informações sobre o ambiente onde ele se encontra, podendo também dispor de um conhecimento a priori como um modelo ou mapa do local da navegação. No caso da navegação em ambientes desconhecidos, o robô não possui nenhum conhecimento a priori, embora possa criar com suas informações sensoriais uma representação interna do ambiente.

Os ambientes de navegação podem ser classificados em internos e externos. No caso de ambientes internos, a possibilidade de utilização ou construção de um mapa é bem maior que nos ambientes externos devido a simplicidade de um com relação ao outro; compare o piso plano de um laboratório com o terreno irregular de um parque. Além desta classificação, alguns ambientes possuem uma certa estrutura, como corredores em prédios, da qual pode-se tirar proveito durante a navegação desenvolvendo algoritmos específicos. Neste caso, fala-se em ambientes estruturados e na ausência desta estrutura em não-estruturados.

Muitas soluções foram propostas ao longo do desenvolvimento das pesquisas na área de navegação. Elas podem ser agrupadas em arquiteturas distintas segundo o modo de se abordar o problema. A arquitetura de um robô evidencia a maneira como suas três características primitivas (percepção, planejamento e ação) estão relacionadas (Murphy, 2000). 
Desde que começaram a aparecer os primeiros robôs móveis em 1967 até o final dos anos 80 , a arquitetura mais utilizada era a hierárquica. Nesta arquitetura, as três primitivas estão ordenadas em seqüência: o robô percebe o ambiente através dos seus sensores e do processamento dos dados obtidos, criando um modelo do ambiente; sobre este modelo, o robô planeja uma trajetória para atingir o seu alvo; o robô então atua sobre o ambiente segundo o planejamento realizado.

Neste período, uma outra arquitetura estava sendo elaborada visando suprir as limitações da hierárquica, principalmente o tempo de resposta em ambientes dinâmicos. Esta arquitetura baseava-se no estudo do comportamento de animais e recebeu o nome de reativa. Segundo esta abordagem, o robô é dotado de comportamentos que fazem com que ele reaja às leituras de seus sensores. Os comportamentos são agrupados de maneira a influenciarem-se e combinarem-se para dar uma característica ou comportamento global ao robô permitindo que ele realize a sua tarefa. O planejamento foi completamente abandonado e a percepção foi ligada diretamente na ação.

No final dos anos 80, apesar dos avanços da arquitetura reativa, percebeu-se a necessidade de reincorporar alguma forma de planejamento ou deliberação no sistema. Assim, surgiu a arquitetura híbrida deliberativa/reativa. A percepção continuava ligada diretamente a atuação, mas existia um planejamento em paralelo que mandava informações ao robô em determinadas situações.

Dependendo do tipo de arquitetura, pode-se caracterizar um tipo de navegação mais apropriada. As arquiteturas reativas são mais adequadas à navegação topológica, onde o posicionamento do robô é mais qualitativo e as representações do ambiente assemelham-se à grafos. As arquiteturas que possuem alguma forma de deliberação ou planejamento são empregadas na navegação métrica onde o posicionamento do robô é quantitativo e a representação do ambiente é um modelo geométrico (Murphy, 2000).

Em qualquer navegação autônoma é indispensável a constante obtenção de informações por meio dos sensores sobre o ambiente no qual o robô se encontra. Assim, o robô é capaz de interagir de maneira adequada com o ambiente baseando-se 
nestas informações. Sistemas de visão têm sido largamente utilizados para esta tarefa. DeSouza et al. (2002) realizou um estudo compreendendo os últimos vinte anos de avanço na área de visão computacional utilizada em navegação. Sensores como os ópticos e os acústicos costumam estar presentes ao redor dos robôs móveis para adquirir informações em todas as direções. Em robôs que dependem apenas do sistema de visão, estes necessitam de um amplo campo visual para não ficarem limitados em seus planejamentos e atuações. Os sistemas de visão omnidirecional possibilitam um campo visual de $360^{\circ}$ ao redor do robô. Sistemas deste tipo têm sido propostos e construídos de formas diferentes, oferecendo uma alternativa à visão tradicional (Yagi,1999). Em particular, os sistemas catadióptricos são compostos por uma câmera e um espelho convexo.

O sistema de visão pode ser utilizado para calcular as distâncias entre o robô e os objetos no ambiente por meio de um algoritmo de estéreo. Com estas informações, o próprio robô constrói representações espaciais ou mapas do ambiente no qual se encontra. No entanto, estas representações devem incorporar a incerteza presente no sensoriamento e na movimentação do robô para que o mapa resultante tenha alguma utilidade. Nestes casos, a maior parte das representações utilizadas são modelos probabilísticos, alguns dos quais unem tanto localização quanto mapeamento (Thrun, 2000).

Pode-se representar ambientes através de mapas métricos, modelos em duas ou três dimensões que armazenam as distâncias entre os objetos presentes no ambiente e o robô. Um exemplo de mapa métrico é a Grade de Evidência (Moravec et al., 1985). Esta representação tem este nome pois armazena a evidência da ocupação de cada célula no qual o espaço foi dividido. Com esta representação muitos dos problemas de navegação, como a auto-localização e o planejamento de trajetória, podem ser resolvidos (Elfes, 1989).

Neste trabalho é proposta e implementada uma tarefa de navegação para um robô móvel num ambiente interno, desconhecido, estático e não-estruturado. A navegação métrica segundo uma arquitetura hierárquica é baseada exclusivamente na informação obtida através do sistema de visão omnidirecional. Este sistema é 
composto por uma câmera convencional e um espelho hiperbólico. O processamento estéreo das imagens omnidirecionais produzem informações sobre as distâncias dos objetos presentes no ambiente. Para o algoritmo são utilizadas duas imagens adquiridas pelo robô que se desloca para compor o par estéreo. A informação é representada através das Grades de Evidência, que incorporam as incertezas inerentes ao sensoriamento através de um modelo probabilístico do mesmo. São apresentados resultados de mapeamento e navegação autônoma com planejamento de trajetória e auto-localização sobre a Grade de Evidência.

O presente trabalho foi desenvolvido no Laboratório de Percepção Avançada (LPA) do Departamento de Engenharia Mecatrônica e de Sistemas Mecânicos da Escola Politécnica da USP. O laboratório possui dois robôs móveis e sistemas de visão omnidirecional para implementação dos resultados deste trabalho, além de uma infraestrutura de comunicação para processamento da informação obtida pela visão e para envio de sinais de controle para o robô. O LPA vem conduzindo diversos estudos em áreas ligadas a robôs móveis e sistemas de visão. 
Capitulo 2

\section{VISÃO OMNIDIRECIONAL ${ }^{1}$ APLICADA A ROBÔS MÓVEIS}

\subsection{Sistemas de visão omnidirecional}

Muito tem-se feito com relação ao desenvolvimento de sistemas de visão omnidirecional e sua utilização como fonte de informação para robôs móveis em diversas tarefas. Um sistema de visão omnidirecional produz imagens que representam um campo visual de $360^{\circ}$ ao redor do robô. Para construí-lo pode-se utilizar uma câmera rotativa ou múltiplas câmeras fixas, uma lente especial como a “olho de peixe” ou arranjos entre câmeras e espelhos convexos (Yagi, 1999).

Uma câmera rotativa gira com velocidade angular constante em torno de um eixo vertical fixo adquirindo imagens em diversas direções. $O$ tempo necessário para mover a câmera, estabilizar o foco, adquirir as imagens e depois compô-las todas numa panorâmica inviabiliza a utilização deste sistema na navegação em tempo real, principalmente em ambientes dinâmicos. As múltiplas câmeras fixas encontram-se num mesmo plano e estão dispostas em diferentes direções cobrindo um campo visual de $360^{\circ}$. Em ambos os casos, a imagem omnidirecional é formada pela sobreposição de imagens adquiridas em diferentes direções. Embora as imagens possuam alta resolução, não são sistemas adequados para robôs móveis seja pela portabilidade (múltiplas câmeras) ou pela funcionalidade (câmera rotativa).

Uma câmera convencional com uma lente com amplo campo visual como a "olho de peixe" é uma solução de alto custo. A imagem obtida possui boa resolução no centro que representa as características menos relevantes para aplicações em robótica, como o teto se a câmera estiver apontada para cima ou o próprio robô se apontada para

\footnotetext{
${ }^{1}$ Segundo o dicionário Houaiss, o prefixo omni não existe na língua portuguesa escrita no Brasil, apenas em Portugal; o termo correto seria onidirecional. Entretanto para evitar confusão no meio científico que já adota o termo omnidirecional em diversas publicações na área, optou-se por manter esta grafia.
} 
baixo. Os objetos presentes no ambiente encontram-se na periferia da imagem onde a resolução é muito baixa.

A utilização conjunta de espelho convexo e câmera mostra-se adequada pois permite a obtenção do campo de visão de $360^{\circ}$, em montagens relativamente compactas, sem que seja necessário mover a câmera ou o espelho para a obtenção das imagens e são de custo inferior à solução com lentes olho de peixe. Estes sistemas são conhecidos como catadióptricos.

Os sistemas catadióptricos normalmente requerem um processamento adicional da imagem caso se deseje obter uma imagem panorâmica a partir da omnidirecional, que é o mapeamento de pixels para retirar as distorções provocadas pelo espelho. Este pré-processamento é muito utilizado para a posterior aplicação de outros métodos tradicionais em visão computacional. No entanto, é possível o processamento e a extração das informações desejadas diretamente da imagem omnidirecional, sem que haja a necessidade da conversão da imagem omnidirecional em uma imagem plana.

Uma propriedade de algumas combinações entre espelhos e câmeras é o centro único de projeção que simplifica os cálculos das projeções perspectivas. Possuem esta propriedade câmeras ortográficas com espelhos parabólicos e câmeras convencionais com espelhos hiperbólicos. A Figura 1 mostra uma imagem adquirida por um sistema de visão catadióptrico formado por uma câmera convencional e um espelho hiperbólico. As figuras seguintes mostram outra imagem omnidirecional processada em tempo real para obtenção das imagens panorâmica (Figura 2) e perspectiva (Figura 3). Esta imagem panorâmica é obtida por meio de um mapeamento dos pixels da imagem omnidirecional num cilindro segundo a equação de forma do espelho, compensado as distorções. A imagem perspectiva é determinada por uma câmera virtual apontando num direção específica que determina que região da imagem omnidirecional deve ser mapeada. 


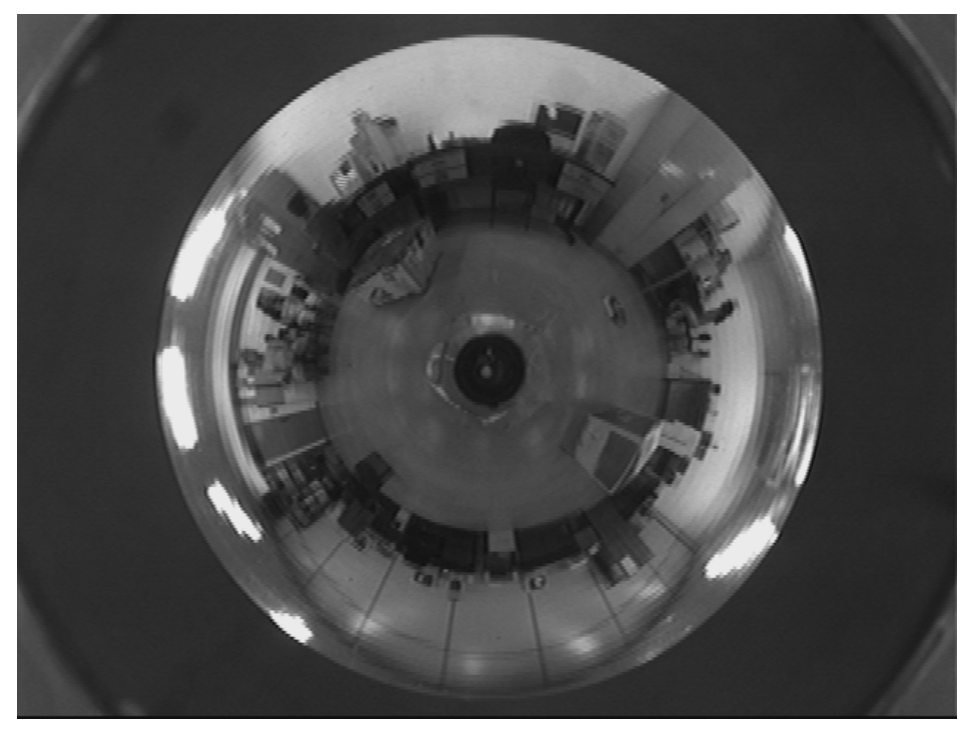

Figura 1 - Exemplo de uma imagem omnidirecional.

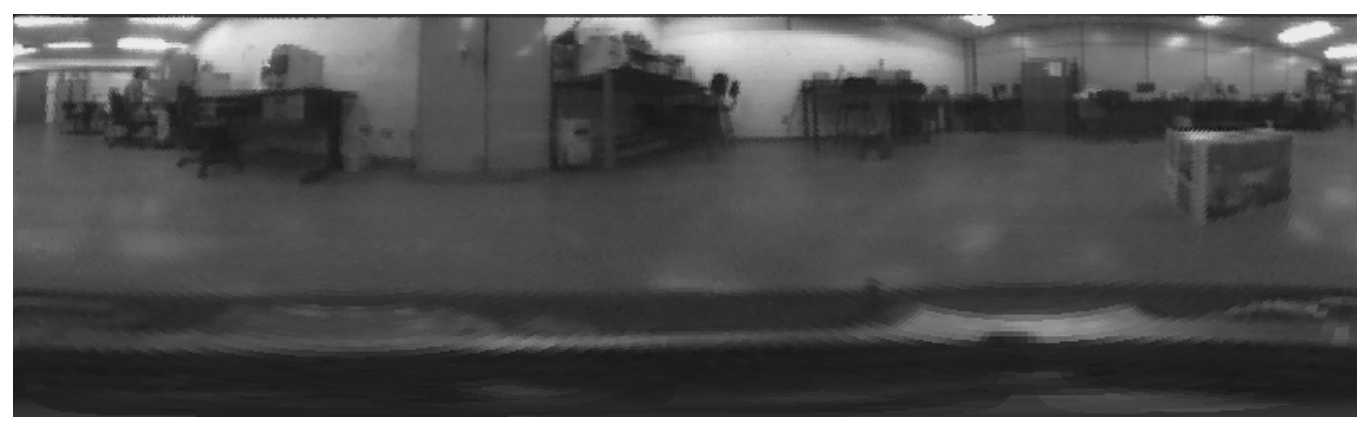

Figura 2 - Exemplo de uma imagem panorâmica obtida a partir de uma imagem omnidirecional.

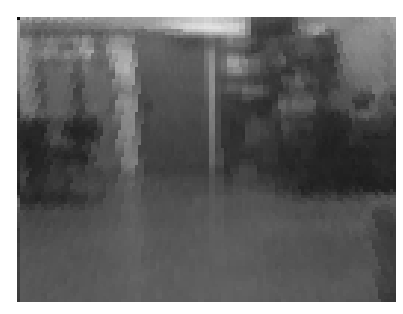

Figura 3 - Exemplo de uma imagem perspectiva obtida de uma região da imagem omnidirecional. 


\subsection{Aplicações em tarefas de navegação}

Sistemas de visão omnidirecional vêm sendo muito utilizados em robôs móveis. Alguns trabalhos nesta área de navegação com auxílio de visão omnidirecional foram analisados e dispostos a seguir de maneira a evidenciar as abordagens mais adotadas e suas soluções específicas.

Dentro da ampla área de navegação de robôs móveis, faz-se aqui a distinção entre aqueles que utilizam conhecimento a priori e aqueles que não. Dentro de cada uma delas, a navegação foi dividida entre métrica e topológica. Outra subdivisão de cada uma destas navegações foi entre navegação estritamente visual e com a utilização de outros sensores. A Figura 4 mostra esta disposição em forma de árvore, com o nome do primeiro autor do artigo como referência ao trabalho da equipe.

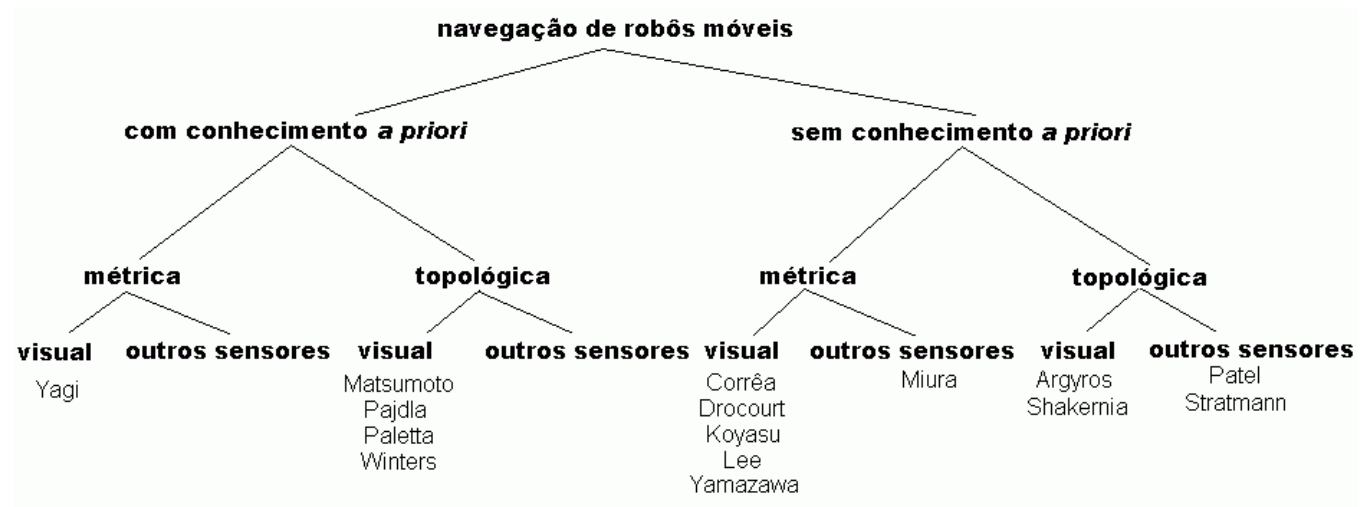

Figura 4 - Disposição dos trabalhos em navegação.

Na Figura 4 é aparente a concentração de trabalhos em navegação estritamente visual. Isso mostra que os sistemas de visão omnidirecionais, presentes em todos os trabalhos, são fontes suficientes de informação para a maior parte das tarefas de navegação. Apenas alguns trabalhos em navegação que não possuem conhecimento $a$ priori fazem uso de outros sensores além da visão omnidirecional. Mas vale ressaltar que nem todos estes trabalhos resolvem todos os problemas de uma navegação, como será mostrado a seguir. 
A Figura 5 leva em consideração os problemas de navegação resolvidos por cada um dos trabalhos. A auto-localização é uma maneira de obter a posição do robô durante uma navegação. O uso da odometria, de um sensor nas rodas do robô, não é suficiente para obter uma estimativa precisa da movimentação do robô quando a trajetória é da ordem de 100 m (Thrun, 2000). Na Figura 5, com relação à autolocalização, foram considerados algoritmos diferentes ou complementares à odometria do robô.

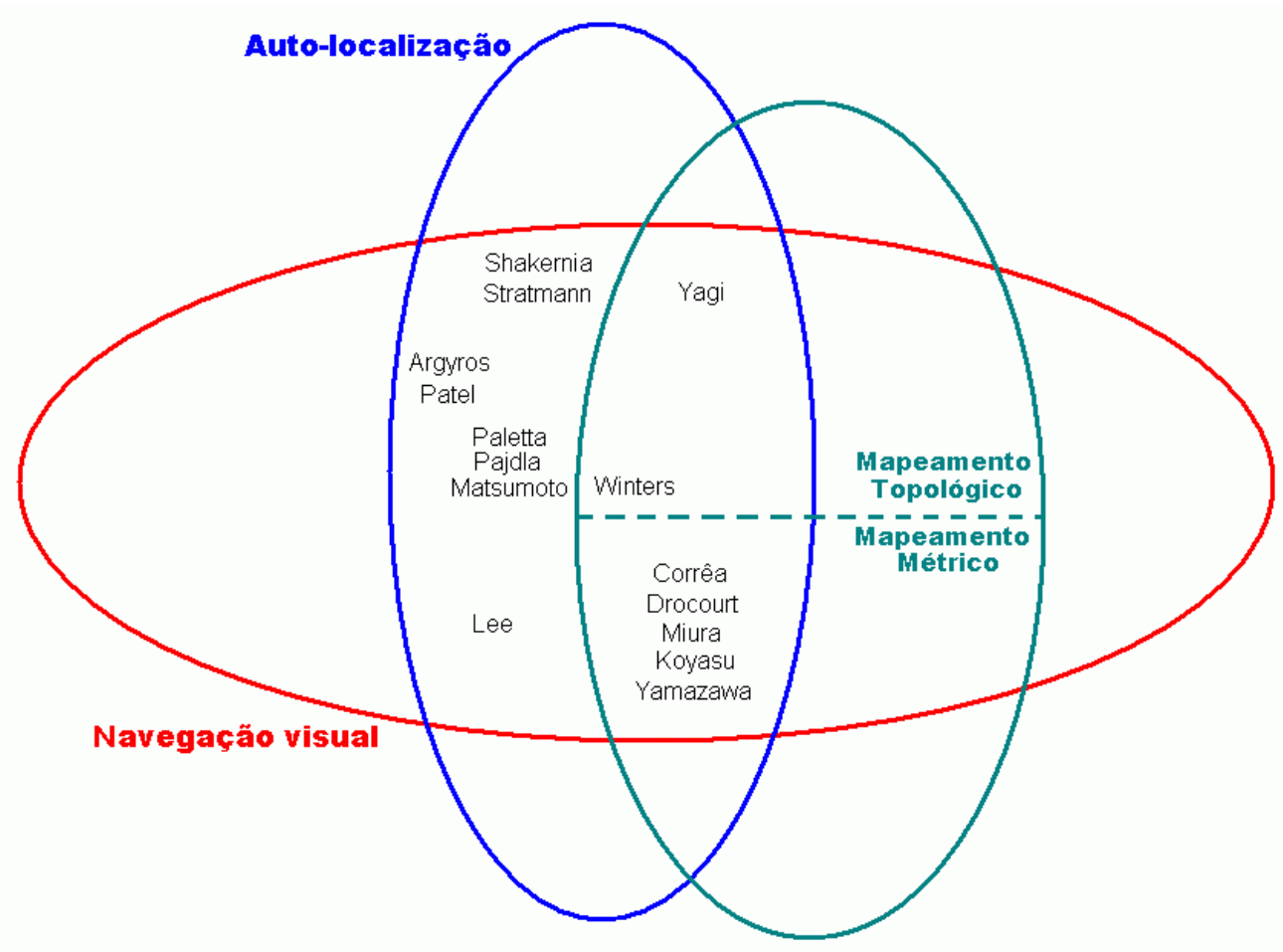

Figura 5 - Diagrama dos problemas em navegação.

A Figura 5 mostra que muito tem-se feito para obter o deslocamento do robô utilizando apenas as imagens obtidas por sistemas de visão. Qualquer tentativa de realizar uma navegação acaba por utilizar uma maneira complementar à odometria para estimar a real posição do robô. Os trabalhos que apenas resolvem o problema de auto-localização não realizam uma navegação completa. Os trabalhos que, além da auto-localização, abordam também uma forma de mapeamento são aqueles em que o robô tem um objetivo a atingir e realiza uma navegação pelo ambiente. 
A seguir os trabalhos são divididos segundo a presença ou ausência de conhecimento a priori e são apresentados em mais detalhes e agrupados segundo seu objetivo principal na tarefa de navegação.

\subsubsection{Navegação com conhecimento a priori}

Uma forma de navegação visual é aquela em que o robô compara as imagens que vai obtendo ao longo da trajetória com um conjunto de imagens obtidas anteriormente durante a tele-operação do robô pelo mesmo ambiente. Pajdla (1998) propõe uma navegação baseada em visão similar a realizada por insetos. Ele utiliza um sistema de visão omnidirecional cujas imagens são projetadas num cilindro. A auto-localização ou egomotion é feita comparando-se imagens obtidas durante a navegação com um banco de dados adquirido anteriormente. As imagens são armazenadas segundo uma critério de invariância de deslocamento. As comparações são feitas no espaço dos auto-vetores. Matsumoto et al. (1999) realiza uma navegação que tem por base a aquisição de imagens e comparação com imagens teste utilizando um sistema omnidirecional para se auto-localizar no ambiente. Esta solução é adequada principalmente para navegação em corredores. Faz-se assim auto-localização, controle do robô, e detecção de obstáculos. As imagens constituindo uma rota prévia são imagens omnidirecionais transformadas em projeções cilíndricas com resolução reduzida pois as imagens omnidirecionais apresentam muitas distorções para serem utilizadas na correspondência. A correspondência é feita em dois níveis baseadas nas imagens memorizadas. Paletta et al. (2001) trata do problema de localização na navegação de um robô móvel em ambientes internos. A localização é feita comparando-se imagens obtidas durante a navegação com imagens arquivadas durante uma fase de treinamento. É uma navegação baseada em visão que usa um mapa topológico do ambiente. As imagens omnidirecionais são transformadas em panorâmicas e estas são particionadas em pedaços correspondendo a uma direção. É utilizada a estimação Bayesiana para determinar a posição do robô. As imagens de treinamento são adquiridas segundo uma grade e permite determinar a posição do robô durante a navegação. Winters et al. (2000) utiliza um sistema de visão omnidirecional para duas modalidades de navegação: topológica e através da localização visual de marcos no ambiente. Na navegação topológica, o principal 
problema é a localização global do robô, que neste caso é feita com uma coletânea de imagens omnidirecionais adquiridas num estágio de treinamento. A navegação realizada através da localização de marcos no ambiente é feita para controlar o robô de maneira precisa ao longo de uma trajetória pré-definida. As imagens omnidirecionais são adequadas para este tipo de navegação que necessita de meios para localizar marcos, pois estes marcos permanecem visíveis em todas as imagens. O trabalho de Winters utiliza uma câmera CCD apontada para um espelho esférico. Além disso, é feita uma transformação conhecida com Bird's Eye View que é uma projeção ortográfica do plano do chão para corrigir distorções da imagem omnidirecional.

Yagi et al. (1995) exibe uma navegação com visão omnidirecional baseada no cálculo do azimuth de cada objeto na imagem. Utiliza um sensor denominado COPIS (COnic Projection Image Sensor) que consiste de um sensoriamento passivo do

ambiente em tempo real. É formado por uma câmera, uma lente e um espelho convexo, e realiza uma projeção do ambiente num plano. Este sensor é utilizado para cálculo do ângulo que os objetos projetados fazem com a direção da trajetória do robô e permite a localização precisa do mesmo através da estimação de sua posição. Ele também é capaz de desviar de obstáculos desconhecidos, já que a navegação é feita por comparação dos ângulos encontrados com o mapa fornecido a priori. A movimentação do robô é assumida conhecida.

\subsubsection{Navegação sem nenhum conhecimento a priori}

Em muitos casos de navegação sem conhecimento a priori, aparecem demonstrações de como o robô conseguiria adquirir informações sobre o ambiente através de seu sistema de visão, localizando-se nele quando tele-operado. Yamazawa et al. (1995) desenvolve um sistema de visão omnidirecional para estimar a movimentação do robô e encontrar obstáculos desconhecidos no ambiente. O sistema de visão omnidirecional, conhecido como HyperOmni Vision, é formado por uma câmera convencional e um espelho hiperbólico. A característica de interesse nas imagens omnidirecionais são as retas radiais que correspondem a retas verticais no ambiente, como em portas e mesas. O ângulo destas retas na imagem é utilizado para estimar a 
distância deste objeto ao robô baseando-se nas propriedades do sistema de visão. A posição é estimada através da correspondência entre imagens sucessivas adquiridas pelo robô. A correspondência é feita sobre uma projeção perspectiva da imagem omnidirecional, chamada de floor map, que é invariante quanto à escala dos objetos. As retas verticais são eliminadas das imagens utilizadas na correspondência. Antes da correspondência as imagens são processadas segundo o operador diferencial ou gradiente, e posteriormente são transformadas em imagens binárias. As características que não tiveram correspondentes são considerados objetos desconhecidos.

O cálculo do fluxo óptico para obtenção de informação sobre o deslocamento do robô durante uma navegação, além da obtida por odometria, é foco de diversos trabalhos devido à importância desta informação. O fluxo óptico é o cálculo da movimentação dos pixels em imagens seqüenciais. Shakernia et al. (2003) utiliza o fluxo óptico para estimar a movimentação do robô. Ele propõe uma alternativa ao cálculo do fluxo óptico comumente implementado, onde as imagens são projetadas numa esfera. Com a geometria das câmeras panorâmicas centrais, ele cria o backpropagation flow. Stratmann et al. (2003) utiliza um sistema de visão omnidirecional com espelho esférico. O sistema é usado para estimar a posição do robô baseado no cálculo do fluxo óptico das imagens e em características do sistema de visão e da movimentação presentes na imagem. A estimação usa também informação vinda de um giroscópio. Lee et al. (2000) propõe a estimação de movimentação da câmera, recuperando tanto a rotação quanto a translação da mesma. Para isso é utilizado um sistema de visão omnidirecional com um espelho esférico. A estimação é baseada na correspondência de características nas imagens. Como cada imagem representa todo o ambiente, não existe o problema de falta de informação em grandes deslocamentos da câmera. Um Implícito Filtro de Kalman Extendido é usado de maneira recursiva, obtendo estimação utilizando apenas algumas características por vez da imagem.

A capacidade do robô de retornar à posição inicial, também conhecida como homing, após realizar uma navegação foi desenvolvida em alguns trabalhos. Argyros et al. (2001) implementa este comportamento num robô móvel. O robô possui um sistema de visão omnidirecional que é a única fonte de informação para esta tarefa. $O$ 
comportamento consiste numa lei de controle do robô baseada em características destacadas nas imagens panorâmicas. Durante a navegação o robô armazena imagens em posições intermediárias (IPS) segundo um algoritmo de rastreamento de características. Esse algoritmo determina as características que serão rastreadas de maneira a garantir que pelo menos três características, necessárias para o funcionamento da lei de controle do robô, apareçam entre IPs consecutivas. Em determinado momento, o comportamento para retornar à posição inicial é ativado. A partir das características destacadas nas imagens panorâmicas, é determinado o ângulo em que elas se encontram no ambiente, e a partir de duas características, um setor circular é formado e utilizado na lei de controle. A lei de controle determina um vetor de movimentação para o robô de modo a que os setores circulares correspondentes tenham o mesmo tamanho angular. A orientação do robô pode ser estimada a partir do deslocamento horizontal de uma característica entre duas imagens panorâmicas. $\mathrm{O}$ robô atinge sua posição inicial com precisão de milímetros e a técnica é independente da extensão do percurso realizado durante a navegação.

A navegação topológica baseada em visão é uma das possíveis abordagens para sistemas de visão omnidirecionais. Patel et al. (2002) desenvolveu um sistema para navegação de veículos não-holonômicos. Um veículo deste tipo não possui simetria em todas as direções e as manobras necessárias para se atingir determinada posição do ambiente têm de ser consideradas. O sistema de visão omnidirecional é montado numa cadeira de rodas motorizada, que possui também um sensor de distância a laser e um odômetro. A tarefa é atravessar uma porta definida pelo usuário através de uma interface visual. As imagens utilizadas são panorâmicas e nestas imagens uma porta é identificada como duas retas verticais. A navegação é baseada num controle servovisual. Duas restrições são aplicadas ao controle baseado na imagem: campo de visão limitado, a fim de manter uma das extremidades da porta sempre visível na imagem; e as características geométricas da cadeira de rodas. A combinação de informação dos sensores permite a auto-localização e a determinação da porta por meio de uma descontinuidade nos dados de distâncias. O laser é utilizada para determinar as distâncias dos objetos ao redor da cadeira e aciona um algoritmo para desviar de obstáculos. 
Os sistemas omnidirecionais são utilizados também como fonte de informação de distâncias para navegação métrica. Koyasu et al. (2002) usa-se um sistema para detecção de obstáculos móveis com um sistema de visão omnidirecional, com dois sistemas catadióptricos alinhados verticalmente. Com estas imagens o robô usa um algoritmo estéreo e cria um mapa com espaços livres e estima sua posição localizando objetos móveis por meio da correspondência entre os mapas atuais e anteriores. Miura et al. (2002) propõe uma navegação com visão omnidirecional e um sensor de distância baseado em laser. O sistema constrói grades de evidência separadas para cada sensor e depois as integra segundo uma lógico que incorpora as características de cada sensor. Este mapa é utilizado para um planejamento de trajetória. O sistema omnidirecional proposto é formado por duas câmeras alinhadas verticalmente e dois espelhos convexos, uma para cada câmera. O laser fica na parte da frente do robô. Drocourt et al. (2001) apresenta-se um sistema para localização dinâmica do robô num ambiente estruturado. É baseado em dois sensores: um odômetro e um sistema de visão omnidirecional que fornece uma referência segundo um conjunto de marcos ativos. Para a fusão de dados dos dois sensores, é utilizado um filtro de Kalman estendido. O robô é capacitado para navegar num ambiente industrial. Navegação métrica, visão estéreo, auto-localização e mapeamento.

Tabela 1 - Usos da visão omnidirecional em robôs móveis. 


\begin{tabular}{|c|c|c|c|c|}
\hline & $\begin{array}{l}\text { Uso da visão } \\
\text { omnidirecional }\end{array}$ & $\begin{array}{l}\text { Outros } \\
\text { Sensores }\end{array}$ & $\begin{array}{l}\text { Conhecimento } \\
\text { a priori }\end{array}$ & Tarefa \\
\hline $\begin{array}{l}\text { Winters } \\
\text { Gaspar, Lacey } \\
\text { Santos-Victor } \\
(\mathbf{2 0 0 0 )}\end{array}$ & $\begin{array}{l}\text { Controle servo- } \\
\text { visual e } \\
\text { rastreamento de } \\
\text { marcos. }\end{array}$ & Nenhum. & $\begin{array}{ll}\text { Imagens } & \text { do } \\
\text { ambiente. } & \end{array}$ & $\begin{array}{l}\text { Navegação em } \\
\text { corredores. }\end{array}$ \\
\hline $\begin{array}{l}\text { Matsumoto } \\
\text { Ikeda, Inaba } \\
\text { Inoue (1999) }\end{array}$ & $\begin{array}{l}\text { Correlação com } \\
\text { imagens. }\end{array}$ & Nenhum. & $\begin{array}{l}\text { Imagens do } \\
\text { ambiente. }\end{array}$ & $\begin{array}{l}\text { Navegação } \\
\text { visual. }\end{array}$ \\
\hline $\begin{array}{l}\text { Yagi, } \\
\text { Nishizawa } \\
\text { Yachida (1995) }\end{array}$ & $\begin{array}{l}\text { Detecção das } \\
\text { retas verticais } \\
\text { do ambiente. }\end{array}$ & Nenhum. & $\begin{array}{ll}\text { Mapa } & \text { do } \\
\text { ambiente. } & \end{array}$ & $\begin{array}{l}\text { Mapeamento do } \\
\text { ambiente. }\end{array}$ \\
\hline Pajdla (1998) & $\begin{array}{l}\text { Correlação com } \\
\text { imagens. }\end{array}$ & Nenhum. & $\begin{array}{ll}\begin{array}{l}\text { Imagens } \\
\text { ambiente. }\end{array} & \\
\end{array}$ & Egomotion. \\
\hline $\begin{array}{l}\text { Paletta,Fintrop } \\
\text { Hertzberg } \\
(\mathbf{2 0 0 1 )}\end{array}$ & $\begin{array}{l}\text { Correlação com } \\
\text { imagens. }\end{array}$ & Nenhum. & $\begin{array}{l}\text { Imagens do } \\
\text { ambiente. }\end{array}$ & $\begin{array}{l}\text { Auto- } \\
\text { localização. }\end{array}$ \\
\hline $\begin{array}{l}\text { Yamazawa } \\
\text { Yagi } \\
\text { Yashida (1995) }\end{array}$ & $\begin{array}{l}\text { Detecção das } \\
\text { retas verticais } \\
\text { do ambiente. }\end{array}$ & Nenhum. & Nenhum. & $\begin{array}{l}\text { Auto- } \\
\text { localização e } \\
\text { determinação de } \\
\text { objetos } \\
\text { desconhecidos. }\end{array}$ \\
\hline $\begin{array}{l}\text { Stratmann } \\
\text { Solda }(2003)\end{array}$ & $\begin{array}{l}\text { Cálculo do } \\
\text { fluxo óptico. }\end{array}$ & Giroscópio. & Nenhum. & Egomotion. \\
\hline $\begin{array}{l}\text { Shakernia } \\
\text { Vidal, Sastry } \\
(\mathbf{2 0 0 3 )}\end{array}$ & $\begin{array}{l}\text { Cálculo do } \\
\text { fluxo óptico. }\end{array}$ & Nenhum. & Nenhum. & Egomotion. \\
\hline $\begin{array}{l}\text { Lee, ou } \\
\text { Neumann } \\
(2000) \\
\end{array}$ & $\begin{array}{l}\text { Estimação de } \\
\text { grandes } \\
\text { deslocamentos. }\end{array}$ & Nenhum. & Nenhum. & Egomotion. \\
\hline $\begin{array}{l}\text { Patel, Jung, } \\
\text { Ostrowski,Rao, } \\
\text { Taylor (2002) }\end{array}$ & $\begin{array}{lr}\text { Controle } & \text { servo- } \\
\text { visual } & \mathrm{e} \\
\text { estimação } & \mathrm{de} \\
\text { posição. } & \\
\end{array}$ & Laser. & Nenhum. & $\begin{array}{ll}\text { Atravessar } & \text { uma } \\
\text { porta } & \text { com } \\
\text { veículo } & \text { não- } \\
\text { holonômico. } & \\
\end{array}$ \\
\hline $\begin{array}{l}\text { Argyros,Bekris } \\
\text { Orphanoudakis } \\
(2001) \\
\end{array}$ & $\begin{array}{l}\text { Rastreamento } \\
\text { de } \\
\text { características. }\end{array}$ & Nenhum. & Nenhum. & $\begin{array}{l}\text { Retornar à } \\
\text { posição inicial. }\end{array}$ \\
\hline $\begin{array}{l}\text { Koyasu, Miura } \\
\text { Shirai (2002) }\end{array}$ & Estéreo. & Nenhum. & Nenhum. & $\begin{array}{ll}\text { Detecção de } \\
\text { obstáculos } \\
\text { móveis. }\end{array}$ \\
\hline $\begin{array}{l}\text { Drocourt } \\
\text { Delahoche } \\
\text { Brassart } \\
\text { Cauchois } \\
(2001) \\
\end{array}$ & Estéreo. & Nenhum. & Nenhum. & $\begin{array}{l}\text { Mapeamento e } \\
\text { localização. }\end{array}$ \\
\hline $\begin{array}{l}\text { Miura, Negishi } \\
\text { Shirai (2002) }\end{array}$ & Estéreo. & Laser. & Nenhum. & $\begin{array}{l}\text { Mapeamento do } \\
\text { ambiente. }\end{array}$ \\
\hline $\begin{array}{l}\text { Corrêa } \\
\text { Okamoto } \\
(\mathbf{2 0 0 4 )} \\
\end{array}$ & Estéreo & Nenhum. & Nenhum. & $\begin{array}{l}\text { Mapeamento do } \\
\text { ambiente. }\end{array}$ \\
\hline
\end{tabular}


Capitulo 3

\section{VISÃO ESTÉREO OMNIDIRECIONAL}

Neste trabalho é utilizado um sistema catadióptrico de visão omnidirecional. Grassi Jr. et al. (2001) construiu o sistema que é composto por uma câmera convencional alinhada com o eixo óptico de um espelho hiperbólico. Os componentes deste sistema de visão são mostrados na Figura 6. A construção mecânica do sistema procurou garantir o alinhamento preciso das partes. A combinação deste tipo de câmera e espelho, assim como o de câmeras ortográficas com espelhos parabólicos, possui a propriedade do centro único de projeção, que simplifica a projeção perspectiva a partir da imagem omnidirecional para construção de imagens panorâmicas. O espelho hiperbólico mostrado na Figura 7 foi usinado no laboratório NUMA em São Carlos, num torno de ultra-precisão. Este sistema de visão é montado sobre um robô móvel que locomove-se sem a rotação do seu corpo, mantendo assim a câmera sempre num sistema de coordenadas que é apenas transladado.

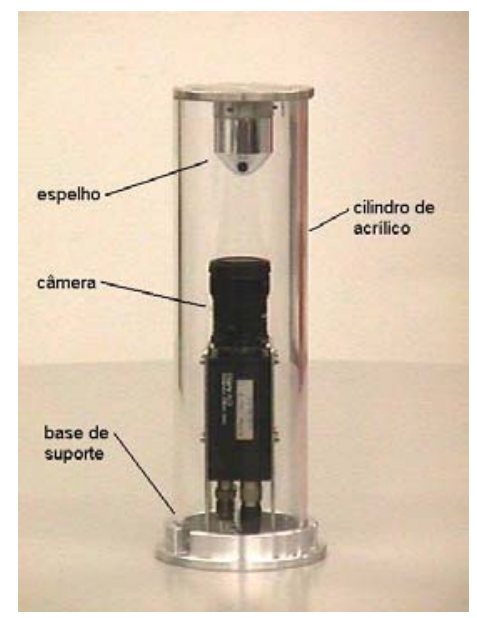

Figura 6 - Sistema de visão omnidirecional. 


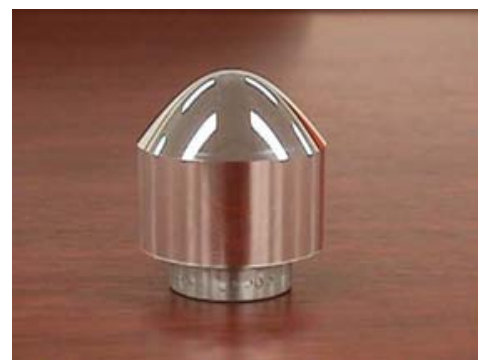

Figura 7 - Espelho hiperbólico.

\subsection{Estéreo com visão omnidirecional}

A informação extraída das imagens adquiridas por sistemas de visão pode ser utilizada para construir um mapa do ambiente e para resolver outros problemas de navegação. O sistema de visão descrito acima é usado na obtenção da informação das distâncias entre os objetos presentes nas imagens e a câmera. As distâncias são obtidas por meio do processamento das imagens com um algoritmo estéreo.

Um algoritmo estéreo combina informação adquiridas de posições diferentes para compor um quadro global. No caso da visão, são necessárias duas ${ }^{2}$ ou mais imagens, adquiridas em posições próximas uma da outra, para reconstruir o ambiente em três dimensões projetado no plano das imagens. A distância entre a aquisição das imagens é chamada de linha de base. O cálculo final das distâncias utiliza as propriedades geométricas do sistema de visão.

Basicamente, um algoritmo estéreo pode ser dividido em três processos:

- Extração de característica: Uma característica é um elemento da imagem referente ao qual a distância com relação a câmera será calculada. Podem ser pontos, curvas ou áreas da imagem. Cada característica exige um processamento de imagem específico. Estas características são utilizadas nos processos seguintes;

\footnotetext{
${ }^{2}$ Existe uma exceção para o caso de uma imagem obtida com uma câmera alinhada a um espelho formado por duas superfícies diferentes. Neste caso, como parte do ambiente é retratado diferentemente na mesma imagem segundo cada uma das superfícies, é possível utilizar o algoritmo estéreo com apenas uma imagem.
} 
- Correspondência: Consiste em relacionar as características destacadas numa imagem com suas projeções correspondentes nas outras imagens. Para isso é feita uma busca para cada característica destacada na primeira imagem nas outras imagens adquiridas para compor o estéreo. Existem diversas restrições a serem aplicadas nesta busca para tornar o algoritmo mais eficiente. No espaço de busca, uma função é escolhida para determinar o melhor entre os candidatos à correspondência de cada característica baseado na maximização ou minimização desta função;

- Triangulação: Com cada par de características correspondentes, é possível calcular a distância da mesma até à câmera. Para isso, utilizam-se as propriedades do sistema de visão e semelhança de triângulos formados pelos raios que ligam as câmeras às características e pela linha de base;

Os processos utilizados em estéreo foram desenvolvidos em sua grande maioria para imagens convencionais. Na literatura, os trabalhos encontrados que realizam estéreo com imagens omnidirecionais transformam-nas em panorâmicas, segundo a equação de forma do espelho, para utilizá-las diretamente com os processos largamente difundidos. No entanto, neste trabalho optou-se por desenvolver um algoritmo estéreo que funcionasse sobre as próprias imagens omnidirecionais mostrando que é possível obter informações de distância deste tipo de imagem.

Na seqüência é apresentado, num nível mais detalhado e específico, cada processo do algoritmo estéreo (Corrêa et al. 2003) aperfeiçoado neste trabalho. O par de imagens necessário para compor a visão estéreo é obtido intercalando-se deslocamentos de magnitude conhecida e capturas de imagens pelo robô móvel.

$\mathrm{O}$ algoritmo desconsidera parte da imagem omnidirecional. Neste tipo de imagem, os pixels do centro para a periferia da imagem representam os ângulos de incidência dos raios de luz sobre o espelho num sentido crescente. Ângulos maiores que noventa graus identificam objetos maiores que o robô. Como o mapa do ambiente que se deseja obter é bidimensional, estes pontos não são relevantes. Assim, o limite de utilização da imagem é determinado pelos pontos no ambiente cujos raios de luz incidem paralelos ao solo no espelho hiperbólico. Os resultados obtidos com o 
algoritmo estéreo e a velocidade de processamento são melhores pois os pontos descartados são os que apresentam maior erro nos processos.

\subsection{Extração de características}

Basicamente, os tipos de características com as quais pode-se trabalhar são três: pontos, curvas ou áreas. Dentro de cada tipo, existe ainda uma diferença quanto ao que cada característica representa, como pontos da borda de um objeto, retas verticais do ambiente ou a área ocupada por um objeto específico. Com o processamento adequado de imagem pode-se extrair tais características.

As características usadas no algoritmo estéreo deste trabalho são os pontos nos contornos dos objetos. O par de imagens omnidirecionais é processado para que as bordas sejam realçadas. Para isso, usa-se o gradiente de Prewitt. Representando uma imagem pela função b(i,j), tem-se o operador de Prewitt:

$$
\begin{aligned}
p_{i}= & {[\mathrm{b}(\mathrm{i}-1, \mathrm{j}+1)+\mathrm{b}(\mathrm{i}, \mathrm{j}+1)+\mathrm{b}(\mathrm{i}+1, \mathrm{j}+1)] } \\
& -[\mathrm{b}(\mathrm{i}-1, \mathrm{j}-1)+\mathrm{b}(\mathrm{i}, \mathrm{j}-1)+\mathrm{b}(\mathrm{i}+1, \mathrm{j}-1)] \\
p_{j}= & {[\mathrm{b}(\mathrm{i}-1, \mathrm{j}-1)+\mathrm{b}(\mathrm{i}-1, \mathrm{j})+\mathrm{b}(\mathrm{i}-1, \mathrm{j}+1)] } \\
& -[\mathrm{b}(\mathrm{i}+1, \mathrm{j}-1)+\mathrm{b}(\mathrm{i}+1, \mathrm{j})+\mathrm{b}(\mathrm{i}+1, \mathrm{j}+1)]
\end{aligned}
$$

Prewitt: $P(i, j)=\sqrt{p_{i}^{2}+p_{j}^{2}}$

A imagem com as bordas realçadas é transformada numa imagem binária escolhendo-se um limiar. O limiar é um tom de cinza que escolhido adequadamente transforma as bordas realçadas em 1, e o resto em 0 . É uma escolha empírica que influencia o funcionamento do algoritmo, pois existe um compromisso entre a quantidade de ruído na imagem e as bordas dos objetos realçadas.

A Figura 8 mostra uma imagem após o processo de extração de características, mostrando a qualidade e quantidade das bordas realçadas. 


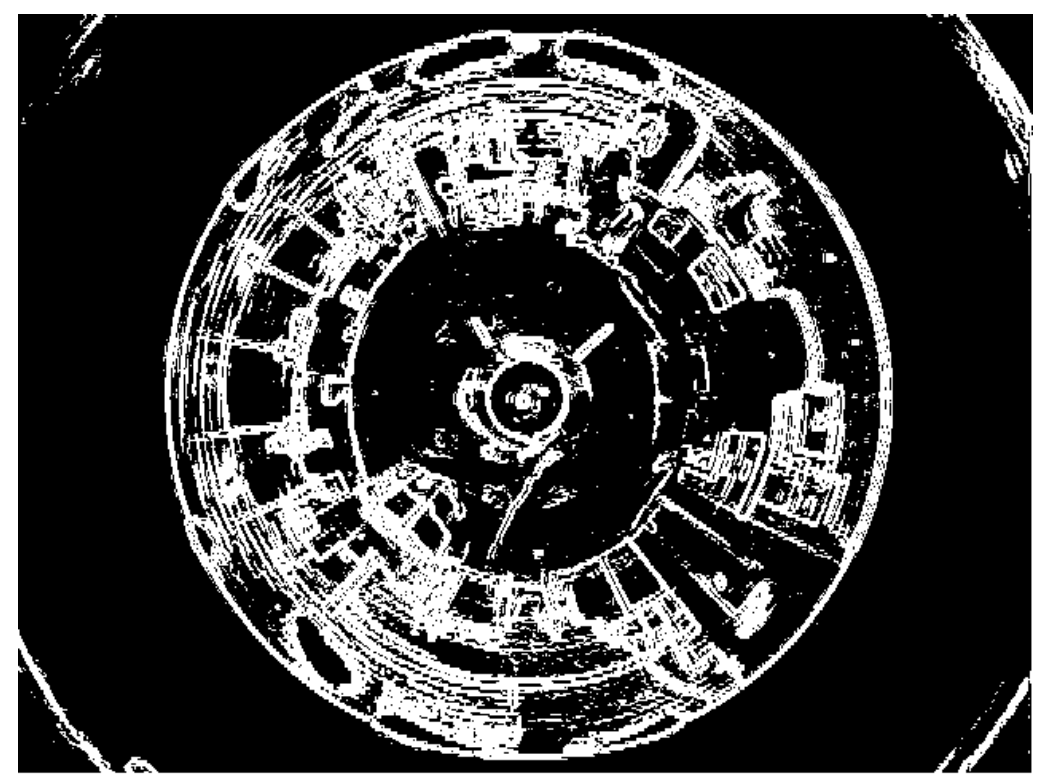

Figura 8 - Imagem omnidirecional após processamento do gradiente e posterior transformação em imagem binária.

\subsection{Correspondência}

A correspondência é a parte mais importante e suscetível a erros de todo algoritmo estéreo. Consiste em relacionar cada característica extraída na primeira imagem com outra na segunda. Restrições são necessárias para reduzir e simplificar a busca dos pontos candidatos.

Uma das restrições mais usadas é a geometria epipolar (Faugeras, 1999). Ela determina que a característica procurada está num lugar geométrico específico da outra imagem. Assim a busca é reduzida de duas dimensões, o plano da imagem, para uma dimensão, uma curva. Em imagens convencionais as curvas epipolares são retas dependendo do arranjo de câmeras. Nas imagens omnidirecionais, são cônicas. O cálculo das curvas epipolares para sistemas omnidirecionais foi feito por Svoboda et al., 1998.

Em sistemas catadióptricos com centro único de projeção, onde as câmeras estão posicionadas nos pontos $\mathrm{C}_{1}$ e $\mathrm{C}_{2}$, o plano epipolar $\pi$ é determinado por três pontos: os focos $F_{1}$ ' e $F_{2}$ ' dos espelhos nas duas posições onde as imagens são adquiridas e o 
ponto X no ambiente representado na imagem como os pixels $\mathrm{q}_{1}$ e $\mathrm{q}_{2}$, na primeira e segunda imagem respectivamente. Os vetores $\mathrm{Xh}_{1} \mathrm{e} \mathrm{Xh}_{2}$ tem como origem o foco do espelho e apontam na direção do ponto X no espaço. O plano epipolar intercepta os espelhos e a projeção desta intersecção define na imagem a curva epipolar, uma cônica, como mostra a Figura 9. Todas as curvas epipolares de uma imagem passam pelos epipolos, os pontos $\mathrm{e}_{\mathrm{i}} \mathrm{e}_{\mathrm{i}}{ }^{\prime}$, determinados pelo vetor $\mathbf{t}$ que une os dois sistemas.

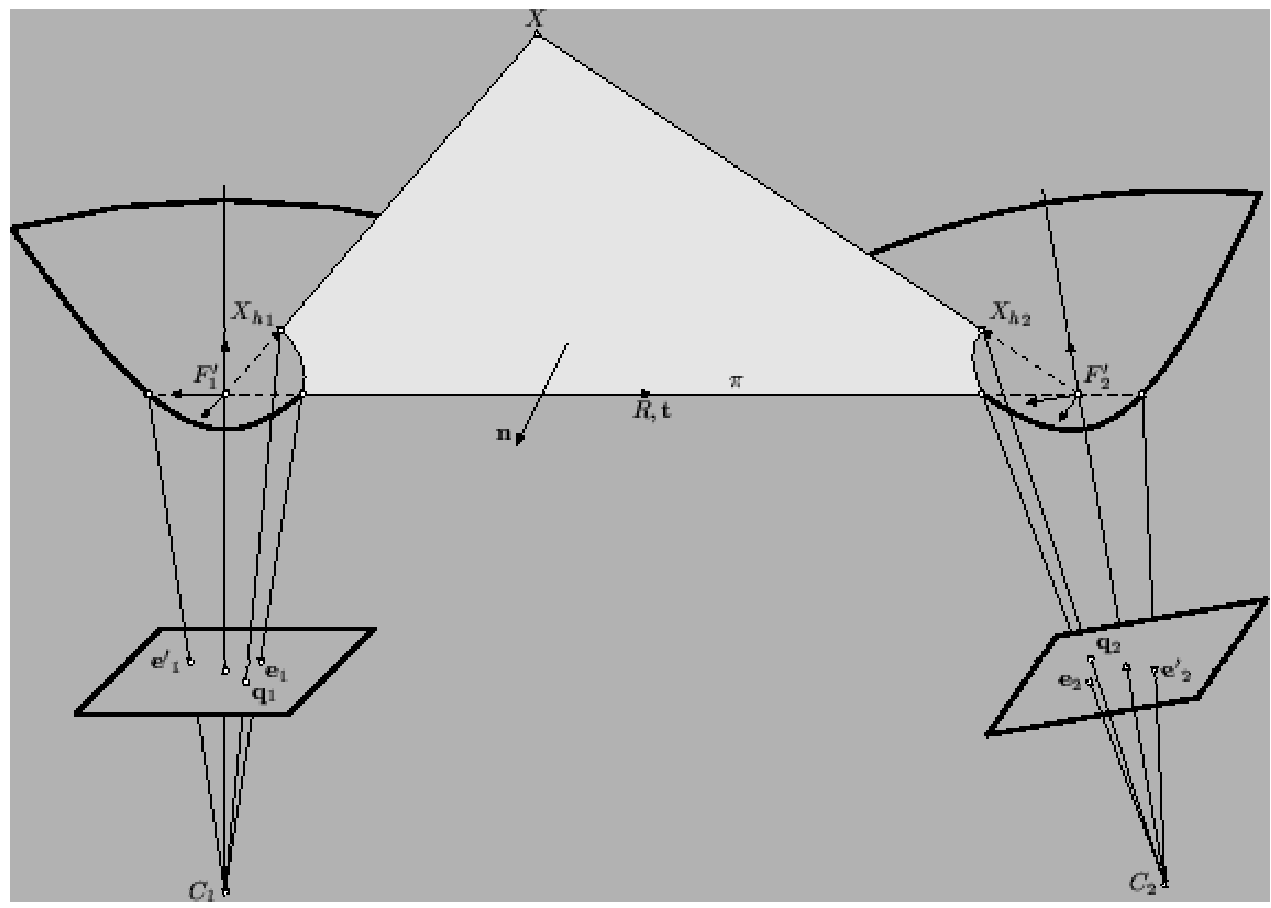

Figura 9. Plano epipolar (Svoboda et al., 1998).

A Figura 10 mostra a primeira imagem do par estéreo com um ponto marcado em verde sobre a caixa que está no ambiente. A Figura 11 mostra a curva epipolar na segunda imagem do par, correspondente ao ponto da quina superior da caixa presente na cena. Como pode-se verificar, a curva desenhada na segunda imagem passa pelo ponto correspondente. Para cada característica extraída na primeira imagem, uma curva epipolar é calculada na segunda imagem restringindo o espaço de busca pelo correspondente. 


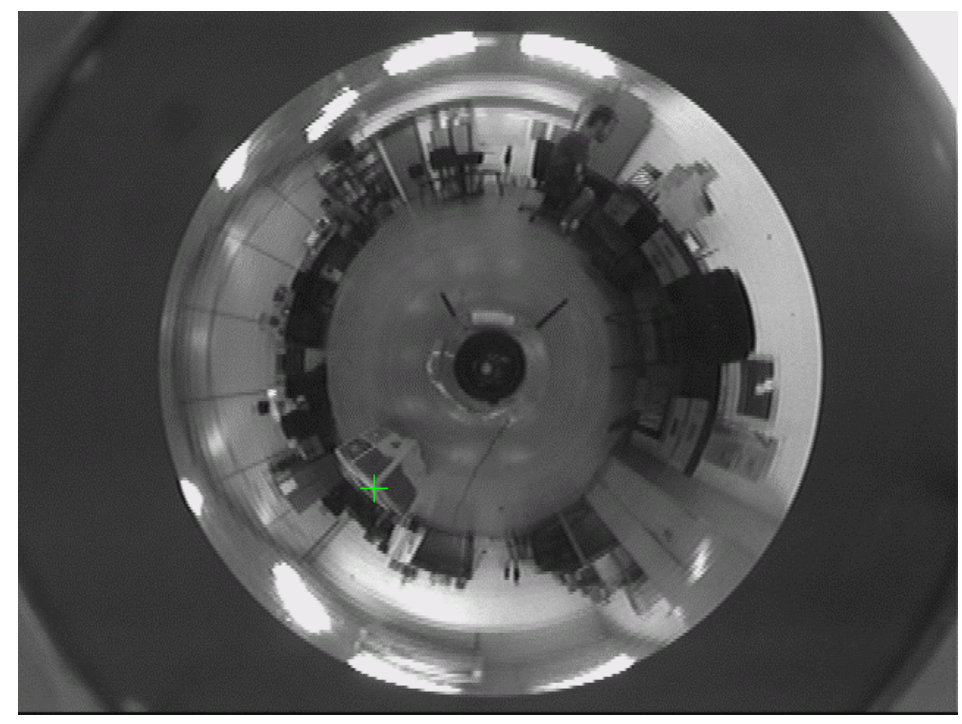

Figura 10 - Pixel da caixa selecionado.

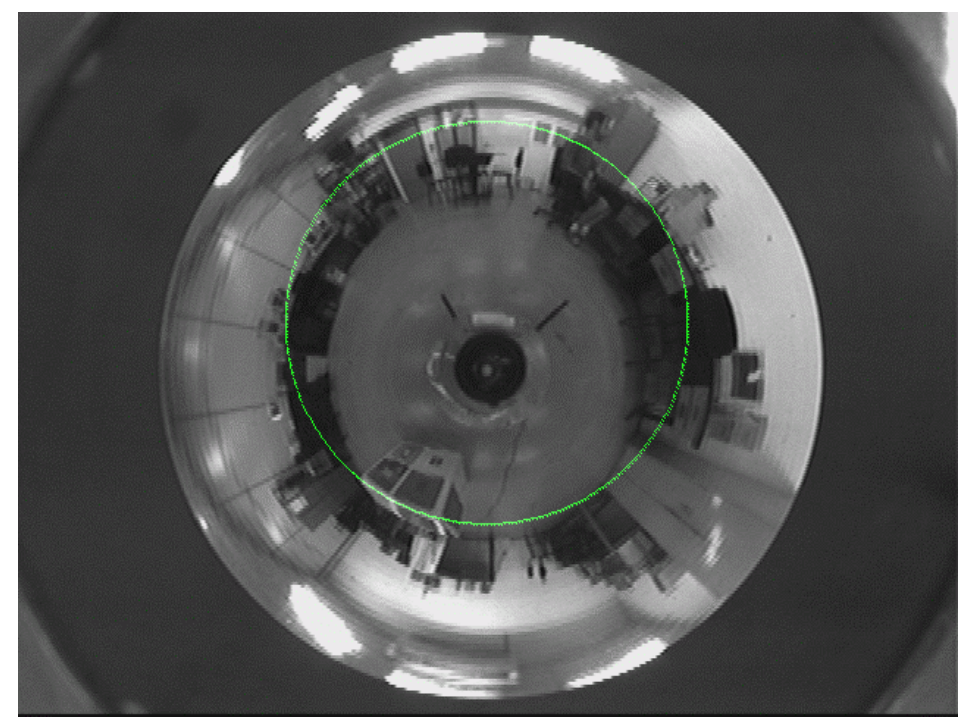

Figura 11 - Curva epipolar correspondente ao ponto selecionado na primeira imagem.

Como as imagens são adquiridas com uma pequena translação do sistema de visão, a maior parte dos pontos correspondentes encontram-se nas vizinhanças do pixel onde a característica foi extraída na primeira imagem. Assim, apenas um trecho da curva epipolar é considerado na busca. O tamanho deste trecho pode descartar pontos que 
estão muito próximos da câmera e se deslocam muito de uma imagem para outra e precisa ser bem escolhido.

Estabelecidas as restrições, a correspondência é feita pelo método baseado numa área da imagem. Uma janela retangular é centrada sobre cada pixel da curva epipolar na segunda imagem e comparada com uma janela de mesmo tamanho centrada no pixel que representa a característica na primeira imagem. O tamanho desta janela é uma escolha empírica. Uma pequena janela numa região sem muita textura não proporciona informação suficiente para encontrar o pixel correspondente enquanto que uma janela maior pode gerar ambigüidades ou falsos correspondentes.

As hipóteses feitas para o emprego deste método são restritivas, partindo do princípio de que as superfícies que aparecem na imagem são normais ao eixo óptico da câmera. Esse não é o caso da maior parte dos sistemas de visão estéreo, e menos ainda dos sistemas omnidirecionais. O emprego das janelas retangulares na correspondência pode causar erros no mapa de distâncias, pois um retângulo numa imagem não corresponde a um retângulo na outra. Ollis, et al. (1999) propõe a utilização de janelas distorcidas para se fazer a correspondência. Uma tabela contendo um mapeamento dos pixels segundo a geometria do espelho seria utilizada para evitar o constante cálculo complexo da forma das janelas. Para evitar a utilização de janelas não-retangulares, a maior parte da comunidade de pesquisa transforma a imagem omnidirecional em panorâmica através da projeção cilíndrica. Moriya et al. (2000) constata que a projeção cilíndrica utilizada nas imagens omnidirecionais na correspondência apresenta distorções. Ele propõe outros métodos de projeções locais segundo a geometria epipolar do sistema de visão.

Svoboda et al. (2001) afirma que o maior problema na utilização de janelas retangulares em imagens omnidirecionais é que em largas rotações a correspondência fica comprometida. As janelas utilizadas tem a forma de segmentos de setores circulares baseados na geometria do espelho. No caso deste trabalho, em que o sistema de visão não rotaciona, não é utilizado nenhum critério adicional para tratar melhor a correspondência. 
Para determinar o ponto correspondente entre os candidatos, uma função, calculada nestas janelas, é escolhida. A função utilizada é o SSD (Sum of Squared Differences) que calcula a diferença entre os pixels dentro das janelas nas duas imagens, de acordo com a seguinte expressão:

$$
\operatorname{SSD}\left(i_{0}, j_{0}\right)=\sum_{(i, j) \in W\left(i_{0}, j_{0}\right)}\left(I_{1}(i, j)-I_{2}(i, j)\right)^{2},
$$

onde $S S D\left(i_{0}, j_{0}\right)$ é o valor encontrado pelo algoritmo com uma janela $W$ centrada em $\left(\mathrm{i}_{0}, \mathrm{j}_{0}\right) ; I_{1}$ e $I_{2}$ são os níveis de intensidade dos pixels na imagem 1 e 2 respectivamente; $i_{0}$ e $j_{0}$ são os índices do pixel central da janela na segunda imagem, e $i$ e $j$ são os índices dos pixels dentro das janelas na imagem 1 e 2 . Note que a janela na primeira imagem é centrada na característica extraída e a na segunda imagem é centrada em todos os pixels ao longo da curva epipolar. Obviamente para cada pixel na curva epipolar na segunda imagem é calculado um valor de SSD. O mínimo valor ao longo desta curva indica o correto correspondente, isto é, a posição na segunda imagem que corresponde à característica na primeira. A idéia por trás do SSD é aumentar através do quadrado da diferença as diferenças entre as cenas dentro das janelas.

Existe um compromisso da distância entre a aquisição das imagens e a qualidade do resultado da correspondência. Deslocamentos menores entre as posições da câmera não alteram muito a iluminação na imagem mas dificultam a triangulação por causa do pequeno ângulo. Maiores deslocamentos resultam numa melhor triangulação mas também em maiores alterações das cenas. Para este sistema de visão utiliza-se deslocamentos da ordem de 200-300 mm.

Como o resultado dos algoritmos de correspondência apresentam um alto número de falsos correlatos, é necessário tratar este resultado de alguma maneira. Svoboda et al. (2001) desenvolve um algoritmo para eliminar os falsos correlatos baseado na matriz fundamental que implica numa condição a ser satisfeita pelos pontos correspondentes. Wei et al. (2001) utiliza programação dinâmica para fazer a 
correspondência de pontos com janelas distorcidas. Estes algoritmos exigem um grande poder computacional.

\subsection{Triangulação}

A reconstrução do ambiente presente nas imagens omnidirecionais, ou no caso mais simples das distâncias dos objetos em cena para o sistema de visão formando um mapa de duas dimensões, depende apenas da geometria do sistema de visão e da maneira de composição do par estéreo. A derivação para o presente sistema de visão estéreo omnidirecional foi desenvolvida neste trabalho e é apresentada a seguir. A hipótese utilizada na dedução baseia-se no alinhamento entre câmera e espelho. Este alinhamento é verificado nos resultados do desenho das curvas epipolares.

Tendo as características extraídas de uma imagem e seus respectivos correspondentes na outra é possível calcular a distância entre estas características no mundo real e a câmera. Na triangulação deve-se fazer o processo inverso do raio de luz que sensibiliza os foto-sensores no CCD da câmera. Com os pixels da imagem pode-se calcular a direção do vetor cuja origem está no foco do espelho e a outra extremidade na superfície do espelho onde o ponto do ambiente é refletido. A projeção deste vetor num plano paralelo ao solo é a distância procurada. Primeiro, a partir das imagens e das propriedades geométricas do sistema catadióptrico, encontra-se este vetor (Svoboda et al., 1998). Segundo, tendo os dois vetores, em cada uma das posições de aquisição de imagem, a distância é calculada por meio da intersecção espacial das retas formadas por estes vetores.

Os pontos correspondentes encontrados, $\left(\mathrm{i}_{1}, \mathrm{j}_{1}\right)$ e $\left(\mathrm{i}_{2}, \mathrm{j}_{2}\right)$, representam as coordenadas em pixels na imagem 1 e 2, respectivamente. Faz-se uma transformação de coordenadas para transportar a origem dos sistemas de coordenadas na imagem omnidirecional para o centro da mesma. Depois, transforma-se estas coordenadas de pixels para milímetros, por meio dos parâmetro intrínsecos da câmera. Estas novas coordenadas são utilizadas nos cálculos abaixo. 
Para encontrar os vetores apontando para o objeto real no espaço, a partir do pixel na imagem, o problema a ser resolvido é o sistema de equações que modela a intersecção entre uma reta (o raio de luz) e uma hipérbole (a superfície do espelho).

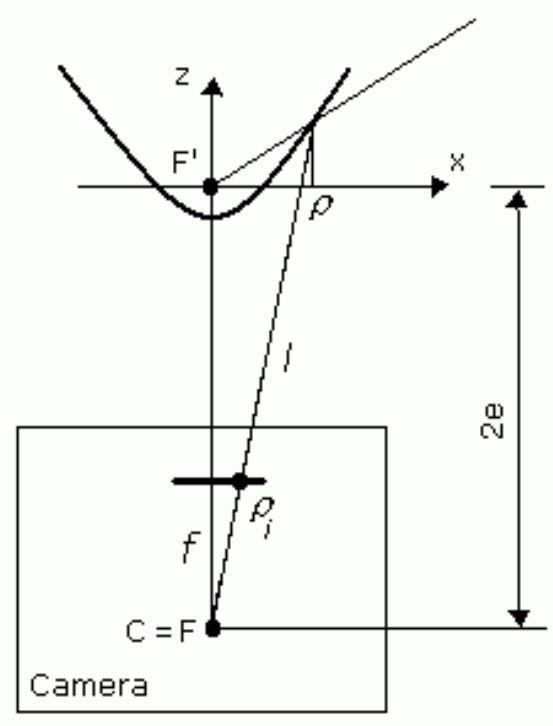

Figura 12 - Sistema catadióptrico.

A reta $l$ representa o raio de luz que reflete na superfície do espelho e vai ao foco da câmera assim marcando um pixel no plano da imagem é,

$l: z=\frac{f}{\rho_{i}} \rho-2 e$

onde $\rho_{\mathrm{i}}$ é a raiz quadrada da soma dos quadrados das coordenadas do pixel no plano da imagem transformados em $\mathrm{mm}, f$ é a distância focal da câmera em $\mathrm{mm}$, e $e=\sqrt{a^{2}+b^{2}}$, onde $a$ e $b$ são parâmetros geométricos do espelho (Svoboda et al., 1998). Todo equacionamento desta parte é feito num sistema de coordenadas tal que o pixel escolhido encontra-se no eixo x deste sistema. Calculado o valor de $\rho$, é feita a sua decomposição segundo o sistema de coordenadas fixo no foco do espelho a partir das coordenadas do pixel na imagem. 
A hipérbole $h$ é a superfície do espelho e é representada por,

$h: z=\sqrt{a^{2}\left(1+\frac{\rho^{2}}{b^{2}}\right)}-e$

A intersecção da reta $l$ com a hipérbole $h$ nos dá um ponto que unido à origem do sistema de coordenadas fixo no foco do espelho representa o vetor que aponta para o ponto real no ambiente. A intersecção é obtida através da substituição de z da eq.(5) na eq.(6). Resolvendo para $\rho$, obtêm-se:

$\rho=\frac{\frac{f}{\rho_{i}} \cdot e \pm a \sqrt{\left(\frac{f}{\rho_{i}}\right)^{2}+1}}{\left(\frac{f}{\rho_{i}}\right)^{2}-\left(\frac{a}{b}\right)^{2}}$

A altura z pode ser obtida substituindo $\rho$ obtido na eq.(7) na eq.(6). Com a direção dos vetores cujas origens estão no foco do espelho nas duas posição de aquisição de imagem para compor o par estéreo, e que apontam para um ponto específico do espaço é possível calcular a intersecção deles determinando a distância d do ponto $\mathrm{X}$ projetado no plano x-y. É conhecido o deslocamento entre as duas posições do robô dados por $t$ e $\alpha$, que são o módulo e a direção do vetor $\mathbf{t}$. 


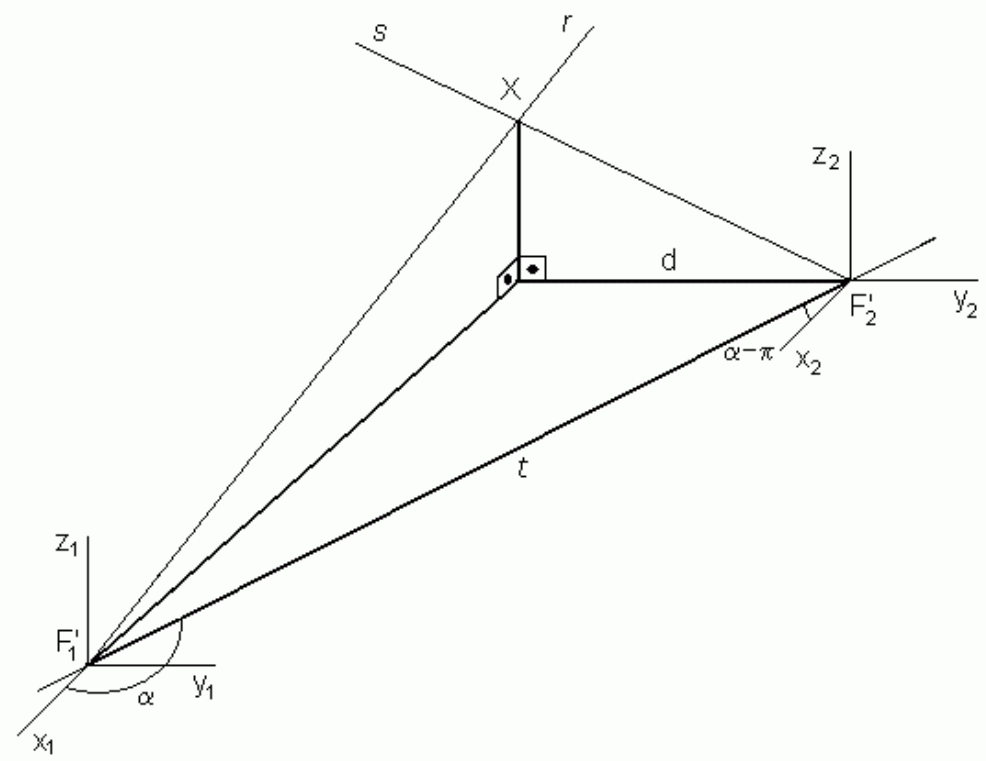

Figura 13 - Triangulação.

Montando as equações das retas $r$ e $s$ da Figura 13, segundo o sistema de coordenadas $\left(\mathrm{O}_{2}, \mathrm{x}_{2}, \mathrm{y}_{2}, \mathrm{z}_{2}\right)$ fixo no foco do espelho, na posição final do robô, tem-se:

$$
\begin{aligned}
& r: \mathrm{X}=\left(\begin{array}{c}
t \cdot \cos (\alpha-\pi) \\
t \cdot \operatorname{sen}(\alpha-\pi) \\
0
\end{array}\right)+\lambda \cdot\left(\begin{array}{l}
x_{1} \\
y_{1} \\
z_{1}
\end{array}\right) \\
& s: \mathrm{X}=\beta\left(\begin{array}{l}
x_{2} \\
y_{2} \\
z_{2}
\end{array}\right)
\end{aligned}
$$

Da intersecção entre as retas $r$ e $s$, tem-se:

$$
\left(\begin{array}{c}
t \cdot \cos (\alpha-\pi) \\
t \cdot \operatorname{sen}(\alpha-\pi) \\
0
\end{array}\right)+\lambda \cdot\left(\begin{array}{l}
x_{1} \\
y_{1} \\
z_{1}
\end{array}\right)-\beta \cdot\left(\begin{array}{l}
x_{2} \\
y_{2} \\
z_{2}
\end{array}\right)=0
$$

Como $\lambda=\beta \frac{y_{2}}{y_{1}}-\frac{t}{y_{1}} \operatorname{sen}(\alpha-\pi)$, resolvendo o sistema para $\beta$, tem-se: 


$$
\beta=t .\left(\frac{\operatorname{sen}(\alpha-\pi) \cdot \frac{x_{1}}{y_{1}}-\cos (\alpha-\pi)}{y_{2} \cdot \frac{x_{1}}{y_{1}}-x_{2}}\right)
$$

Substituindo o valor de $\beta$ calculado na eq.(11), na eq.(9), obtém-se as coordenadas do ponto $\mathrm{X}$ no espaço. No entanto, as informações referentes à altura dos pontos no espaço não são utilizadas. Apenas a distância d (ver Figura 13) é utilizada para a construção do mapa de distâncias. Assim, para cada característica extraída na imagem é obtida a distância, no plano $\mathrm{x}-\mathrm{y}$, do ponto no espaço correspondente com relação à câmera na segunda posição.

A Figura 14 é uma forma de representar um mapa das distâncias calculadas a partir de um par de imagens omnidirecionais. Este mapa é uma vista superior do ambiente onde o robô encontra-se na coordenada $(0,0)$. Todas as distâncias são medidas com relação ao robô na sua posição final, após a aquisição da segunda imagem do par estéreo. As regiões com maior concentração de pontos representam a existência de objetos no ambiente. $\mathrm{O}$ resto dos pontos espalhados por todo o mapa são erros devido principalmente às falsas correspondências. 


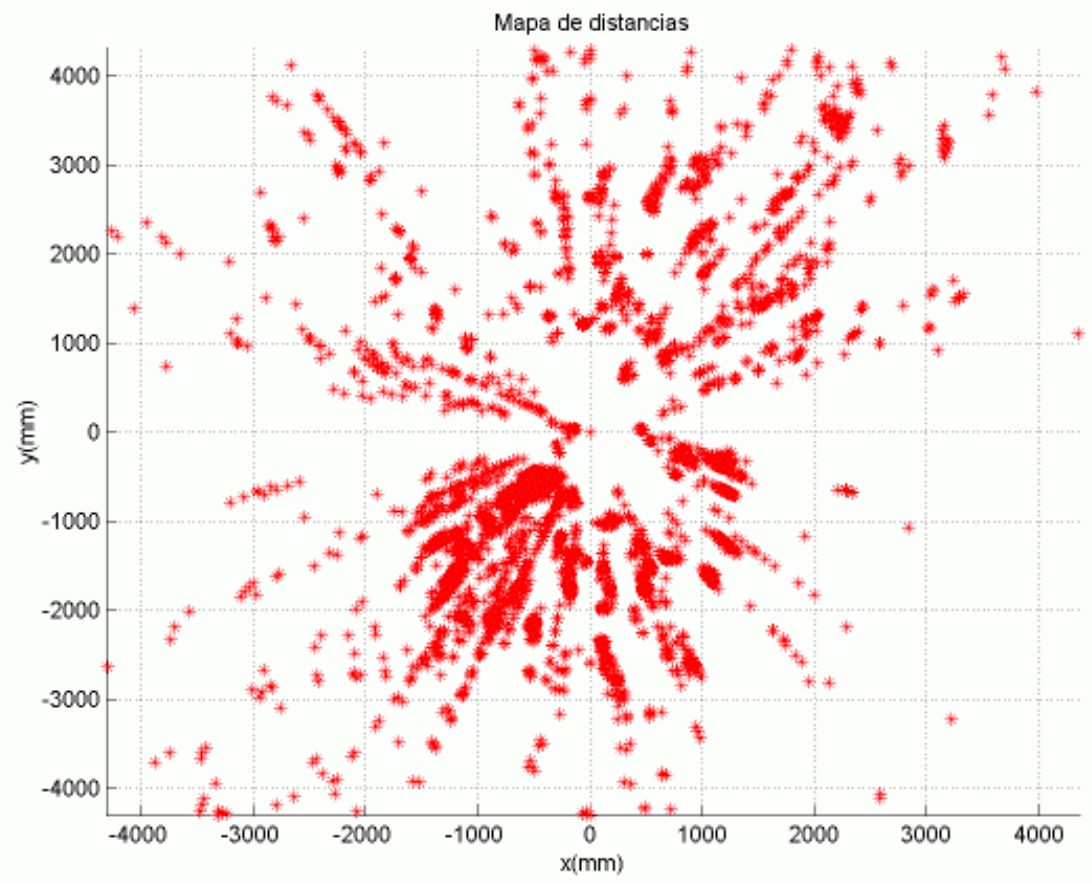

Figura 14 - Exemplo de um mapa de distâncias feito a partir de informação estéreo omnidirecional.

Como pode ser observado na Figura 14, o resultado produzido pelo algoritmo estéreo, sem nenhum tratamento posterior, não produz uma representação do ambiente suficientemente detalhada para que o robô possa navegar baseado-se apenas nela. Este trabalho propõe a representação das informações de distâncias através das Grades de Evidência, que é uma abordagem probabilística bastante adequada para tarefas de navegação (Elfes, 1989). As grades são atualizadas por modelos de sensores na forma de distribuições de probabilidade com parâmetros a serem ajustáveis. 
Capitulo 4

\section{GRADES DE EVIDÊNCIA}

\subsection{Mapeamento de ambientes}

Um robô pode ser capaz de, através da informação obtida por seus sensores, criar um modelo espacial do ambiente e utilizá-lo em tarefas de planejamento e autolocalização. A construção deste modelo pode ser feita por meio da exploração do ambiente, onde o robô procura apenas preencher o seu modelo com o máximo de informação possível, ou até mesmo durante a própria navegação. Esta tarefa é denominada de mapeamento. Com um mapa previamente fornecido ou elaborado ao longo da tarefa, um robô pode interagir de maneira coerente com o ambiente.

O problema do mapeamento é considerado como um dos mais importantes na busca da criação de robôs completamente autônomos (Thrun, 2000). Atualmente existem métodos robustos para mapeamento de ambientes estáticos, estruturados e de tamanho reduzido, mas é ainda um problema em aberto o mapeamento de ambientes não-estruturados, dinâmicos e de larga escala.

Entre as décadas de 80 e 90, este campo de pesquisa em mapeamento por robôs móveis era dividido em abordagens métricas e topológicas. Os mapas métricos capturam as propriedades geométricas do ambiente, enquanto os topológicos, descrevem a forma como diversos lugares do ambiente estão conectados ou relacionados. A distinção entre um tipo e outro não é muito precisa, pois o mapa topológico baseia-se em informações métricas também; na prática, os mapas métricos possuem maior resolução que os topológicos, tendo por isso um custo computacional maior embora possibilitem a solução de várias tarefas complicadas como o problema de correspondência ou registro, onde é preciso uma quantidade de informação suficiente para determinar um posicionamento preciso. 
A partir de 1990, este campo foi dominado por técnicas probabilísticas e atualmente o estado da arte está quase que completamente nestes tipos de algoritmo. Uma série de trabalhos seminais, como o de Cheeseman et al. (1990), introduziram uma poderosa fundamentação estatística para resolver simultaneamente os problemas de mapeamento e de localização do robô no próprio mapa em construção.

O mapeamento é realizado com a informação dos sensores que o robô possui, que estão sujeitos a erros. Os sensores também apresentam limitações de alcance que torna necessário que o robô se locomova pelo ambiente durante a construção do modelo do mesmo. A movimentação do robô é de extrema importância para a criação deste modelo, mas também está sujeita a erros sendo a odometria do robô insuficiente para determinar sua real posição no ambiente.

Um dos desafios propostos pelo problema do mapeamento está relacionado à natureza dos erros nas informações de distância que são estatisticamente dependentes, pois o deslocamento do robô, por exemplo, é utilizado para interpretar as leituras do sensor e compor o mapa do ambiente. Para acomodar este tipo de erro, os algoritmos de mapeamento tendem a ser complexos tanto do ponto de vista matemático quanto de implementação.

\subsection{Histórico das Grades de Evidência}

As Grades de Evidência foram propostas por Moravec et al. (1985) como uma alternativa às abordagens anteriores para tratamento da informação vinda dos sensores para navegação autônoma. Neste trabalho foi implementada a Grade de Evidência atualizada com o sistema de visão estéreo omnidirecional.

Entre os anos 70 e 80, a abordagem utilizada no Mobile Robot Lab da Carnegie Mellon University (CMU) era a de extrair diversas características das imagens do ambiente obtidas por câmeras dispostas ao longo do mesmo em diferentes posições (Martins et al. 1996). As imagens destas câmeras eram arranjadas segundo múltiplos pares para serem usadas em algoritmos estéreo. As distâncias destas características com relação às câmeras eram calculadas e utilizadas por um robô móvel para desviar dos obstáculos durante uma navegação pelo ambiente. Algumas técnicas baseadas 
em consistência geométrica eram utilizadas para verificar possíveis inconsistências nos dados enviados ao robô. Mas por mais que o sistema tenha sido aperfeiçoado ao longo do tempo, percebeu-se que era uma maneira inadequada de modelar as incertezas presentes no sensoriamento. Mostrava-se suscetível a falhas devido ao acúmulo de falsas características detectadas que passavam pela verificação e produzia estimativas de navegação erradas. Esta abordagem era conhecida como o paradigma geométrico.

Em 1983, começou-se o desenvolvimento de uma outra abordagem e optou-se pela utilização de sensores de ultra-som de baixo custo. Com o conhecimento das características deste tipo de sensor como a baixa resolução angular, elaborou-se um modelo probabilístico do mesmo. Para utilizar este modelo, criou-se o que atualmente é conhecido com Grades de Evidência (inicialmente era conhecido como Occupancy Grids, depois sendo denominado Certainty Grids e finalmente Evidence Grids) capaz de representar de maneira implícita as imprecisões probabilísticas das distâncias obtidas e lidar com leituras erradas obtida pelo sensor. Estas grades dividem o espaço em células e as leituras dos sensores determinam a probabilidade de cada célula estar ocupada ou vazia. Os primeiros testes foram surpreendentes mesmo com a determinação dos modelos do sensor por métodos ad hoc. Desenvolvimentos posteriores levaram a uma fundamentação das grades baseada na Teoria de Probabilidade. Atualmente, trabalha-se com a fusão de informações de diversos sensores numa mesma grade, com grades em três dimensões, e com o desenvolvimento de um método de aprendizagem de modelos para diferentes sensores.

\subsection{Definição}

A Grade de Evidência pode ser definida como um processo estocástico de estados discretos definido sobre um espaço segmentado:

$\mathrm{E}\left(\mathrm{C}_{\mathrm{i}}\right)=\mathrm{P}\left[\mathrm{s}\left(\mathrm{C}_{\mathrm{i}}\right)=\mathrm{OCC}\right]\left(\mathrm{C}_{\mathrm{i}}\right)$

onde $\mathrm{C}_{\mathrm{i}}$ representa as células nas quais o espaço é dividido e $\mathrm{s}\left(\mathrm{C}_{\mathrm{i}}\right)$ é a variável aleatória binária que assume o valor OCC (ocupado) ou EMP (livre). 
A Figura 15 mostra a seqüência do processo de cálculo da Grade de Evidência. Para se construir esta representação faz-se uma transformação do espaço dos parâmetros (Estado do mundo), que são as distâncias dos objetos no ambiente que serão calculadas, para o espaço de observação, que são as informações obtidas dos sensores, através de um modelo probabilístico que incorpora as incertezas na leitura do sensor e de todo o processo envolvido na obtenção das distâncias. Este modelo é uma função densidade de probabilidade condicional. Do espaço de observação, com as leituras obtidas pelo sensor, é possível reproduzir o estado do mundo através de um modelo para a estimação. Este processo de inferência pode ser feito por meio de um modelo de estimação Bayesiana. Assim, é criada a Grade de Evidência.

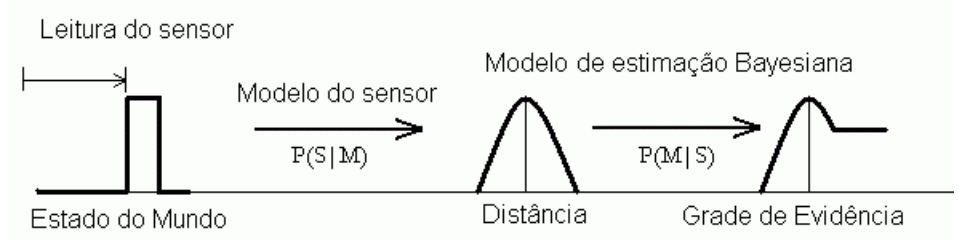

Figura 15 - Seqüência para construção da Grade (Elfes,1989).

O processo é realizado para cada leitura dos sensores e as células são calculadas uma a uma, como variáveis aleatórias independentes (equivalente a Campos de Markov de ordem zero). Ou seja, os estados de uma célula não influenciam nas outras. Esta hipótese reduz as combinações exponenciais que surgiriam inviabilizando a utilização do método. As diversas etapas do processo serão discutidas a seguir.

\subsection{Modelo do sensor}

Toda forma de sensoriamento apresenta incertezas quanto à informação obtida. $\mathrm{Na}$ presença de informação vinda de posições ou sensores diferentes, esta incerteza pode ser estimada para obtenção de resultados mais precisos. Como um robô adquire informação sobre o seu ambiente através dos sensores que possui é preciso entender melhor as características próprias e as aplicações específicas de cada tipo de sensor. Por exemplo, o ultra-som apresenta baixa resolução angular e erros devido às múltiplas reflexões ou reflexões especulares devido às superfícies irregulares dos 
objetos, enquanto que a visão estéreo detecta e localiza os contornos dos objetos, mas não encontra o interior de superfícies com pouca ou nenhuma textura.

As Grades de Evidência são apropriadas para integrar as informações de distância vindas de vários tipos de sensores e de diversas leituras de cada um deles. O modelo do sensor representa a forma como este obtém informações de distância no ambiente em que está inserido e incorpora o tipo de erro presente nas leituras que é inerente ao tipo de sensor utilizado. Este modelo é formado por uma função densidade de probabilidade utilizada para efetuar o cálculo da Grade de Evidência. Por serem de mesma natureza, estes modelos são facilmente integráveis para complementar a informação espacial vinda de diversos sensores.

O modelo do sensor consiste de uma função densidade de probabilidade que melhor caracterize o sistema, ou seja, uma probabilidade condicionada de como são as leituras do sensor dado uma configuração de mundo ou ambiente, $\mathrm{p}(\mathrm{S} \mid \mathrm{M})$ - onde "S" indica uma leitura do sensor e "M", uma configuração de mundo. Para um sensor ideal tem-se:

$\mathrm{p}(\mathrm{S} \mid \mathrm{o})=\delta(\mathrm{S}-\mathrm{o})$

Esta é a representação para o caso unidimensional de grade, que indica que a probabilidade de, dado o, ou seja, a distância real de um objeto, obter-se a leitura $S$ do sensor que apenas é diferente de zero quando a célula a ser calculada é a célula na qual o objeto se encontra. Mas como todo sensor possui incerteza em suas leituras, é possível modelar este fenômeno através de, por exemplo, um ruído gaussiano, uma distribuição normal com média e variância ajustadas adequadamente:

$$
\mathrm{p}(\mathrm{S} \mid \mathrm{o}, \theta)=\frac{1}{2 \pi \sigma_{S} \sigma_{\theta}} \exp \left[-\frac{1}{2}\left(\frac{(S-o)^{2}}{\sigma_{S}^{2}}+\frac{\theta^{2}}{\sigma_{\theta}^{2}}\right)\right]
$$

Este é o modelo para o caso de uma grade bidimensional com média dada pela distância encontrada pelo sensor, e variâncias $\sigma_{\mathrm{s}}^{2}$ e $\sigma_{\theta}{ }^{2}$ para as variáveis $\mathrm{S}$ e $\theta$, 
evidenciando tanto uma incerteza quanto à direção do objeto localizado quando da distância estimada.

Estas funções são utilizadas para o cálculo da grade modelando um tipo particular de sensor. O modelo para o ultra-som elaborado por Elfes (1989) é mostrado na Figura 16. Este modelo incorpora as principais características dos sensores de ultra-som. Conforme um objeto é localizado pelo sensor, a grade é atualizada com uma distribuição de probabilidades centrada na medida obtida e com maior incerteza quanto à direção perpendicular à emissão do ultra-som devido à baixa resolução angular. As células dentro do raio visível ao sensor e anteriores ao objeto localizado são atualizados segundo outra distribuição representando a probabilidade do espaço estar vazio já que o objeto foi localizado mais adiante.

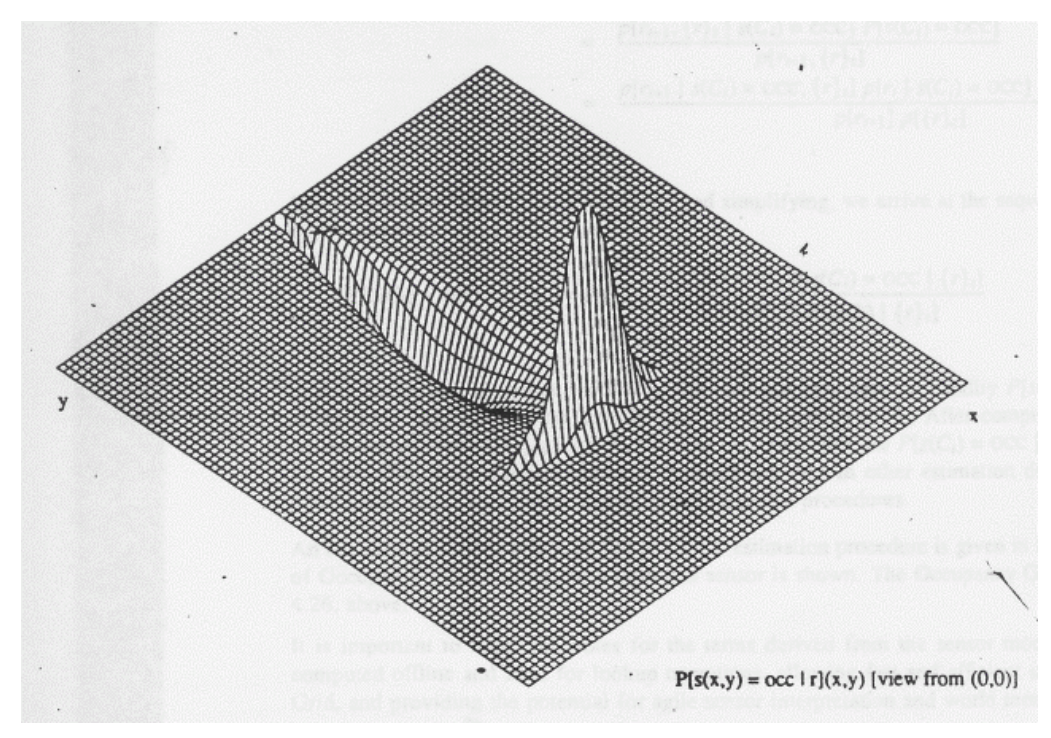

Figura 16 - Modelo probabilístico do ultra-som (Elfes, 1989).

As Grades de Evidência foram criadas para serem atualizadas com dados vindos de sensores de ultra-som. Como esta representação de grades é adequada para fusão de informação sensorial, logo foram criados modelos para outros tipos de sensores, como os sistemas de visão. Moravec (1996) apresenta um modelo para um sistema de visão estéreo com um par de câmeras com lentes de amplo campo visual para Grades de Evidência em três dimensões. Não se tem conhecimento de nenhum 
modelo desenvolvido para um sistema de visão estéreo catadióptrico como o deste trabalho.

\subsubsection{Modelo do sistema de visão estéreo omnidirecional}

O sistema de visão omnidirecional em conjunto com o algoritmo estéreo foram modelados probabilisticamente buscando incorporar as características do sistema e os erros produzidos por ele. A primeira característica deste sistema de visão estéreo omnidirecional é que para a obtenção da informação estéreo, já que o robô possui apenas uma câmera, é necessário deslocar o sistema entre a aquisição de uma e outra imagem do par estéreo.

A Figura 17 mostra o princípio de formação da imagem com o sistema de visão omnidirecional. Além da característica bem adequada da visão omnidirecional de adquirir informação em todas as direções, apresenta ainda pouco problema com relação à obstrução do espaço por obstáculos uns à frente dos outros. Dependendo do campo visual do sistema e da altura dos objetos no ambiente, é possível ter uma visão praticamente desobstruída.

Dada a altura do objeto mais próximo ao robô, é possível determinarmos o cone de sobra que ele projeta atrás de si, calculando a distância em que os objetos atrás serão visíveis.

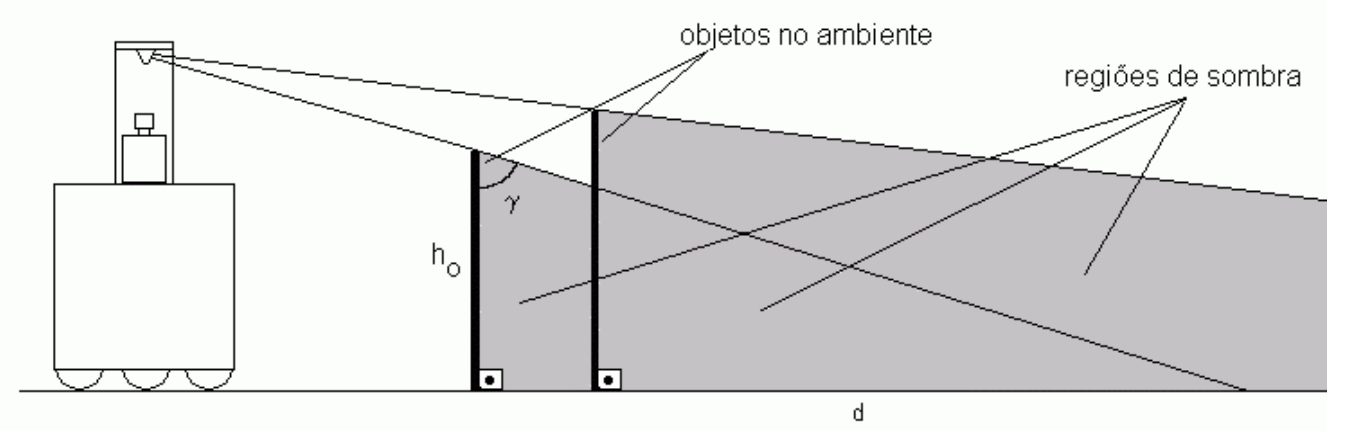

Figura 17. Princípio físico de formação da imagem omnidirecional. 
$d_{S}\left(h_{O}, \gamma\right)=\frac{h_{O}}{\operatorname{tg}\left(\frac{\pi}{2}-\gamma\right)}(\mathrm{mm})$

$d_{k}=\frac{d_{S}\left(h_{O}, \gamma\right)}{\text { tamanho da célula }}$ (células)

A precisão do algoritmo estéreo está relacionada com a distância real dos pontos no ambiente. Quanto mais longe este ponto está do sistema de visão, menor é o ângulo que ele forma com as duas posições da câmera na aquisição do par estéreo de imagens. O tamanho deste ângulo também depende do deslocamento do robô para compor o par estéreo, ou seja do tamanho da linha de base. Um ângulo muito pequeno torna os cálculos baseado em semelhança de triângulos muito impreciso. Este ângulo está relacionado com um lugar geométrico conhecido como arco capaz. Dados dois pontos quaisquer num plano o arco capaz é o lugar geométrico que corresponde a um arco de circunferência onde todos os pontos formam o mesmo ângulo quando ligados aos dois pontos dados. A Figura 18 ilustra alguns arcos capazes formados a partir das duas posições (extremos da linha preta mais grossa na figura) necessárias para aquisição de informação estéreo. Os pontos $\mathrm{A}, \mathrm{B}$ e $\mathrm{C}$ na figura estão num mesmo arco capaz e portanto o ângulo que formam com a linha de base do estéreo é o mesmo. O ponto D que pertence a um arco capaz maior forma um ângulo menor com a linha de base. Os arcos capazes de ângulos muito pequenos dificultam o cálculo de distâncias na semelhança de triângulos. Como o ângulo está vinculado a uma certa distância, é necessário limitá-los na representação por Grades de Evidência. Em regiões próximas a do deslocamento para composição do estéreo também ocorre o mesmo problema, mas por causa de ângulos muito grandes. 


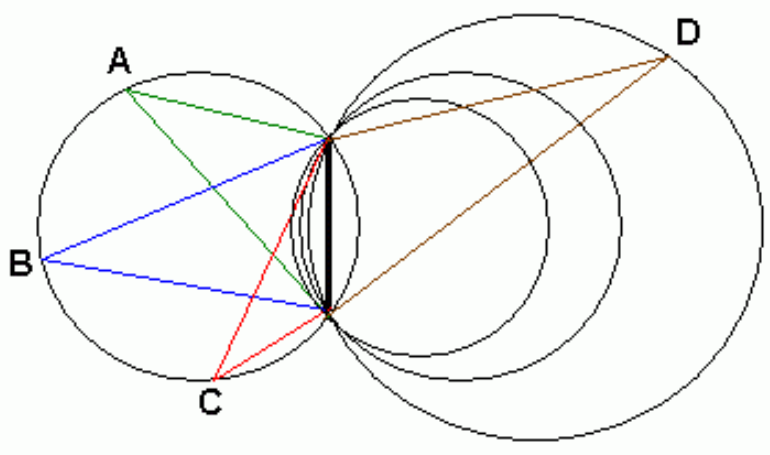

Figura 18 - Arco capaz.

Qualquer objeto nesta região visível é representado por uma distribuição normal de probabilidade. Esta distribuição bidimensional é representada até três desvios padrões. No caso de sobreposição, a maior probabilidade prevalece, sendo o mais seguro. A distribuição utilizada é:

$$
v(x, y)=0,6 \cdot \exp \left(-\frac{\left(x-\mu_{x}\right)^{2}}{2 \cdot \sigma_{x}{ }^{2}}-\frac{\left(y-\mu_{y}\right)^{2}}{2 \cdot \sigma_{y}{ }^{2}}\right)
$$

As outras porções do espaço não ocupadas dentro do espaço visível do sensor recebem o valor 0.2 , uma evidência baixa de que o espaço está ocupado. Os locais onde o robô se desloca recebem o valor 0 , pois como o robô passou por lá, é garantido que o espaço correspondente está vazio.

Os parâmetros desta distribuição são dependentes do ângulo que o ponto calculado forma com as duas posições onde as imagens do par estéreo foram adquiridas. Conseqüentemente, dependem do arco capaz. Conforme este arco aumenta, o ângulo diminui e os resultados calculados da distância deste ponto torna-se menos confiável. Ângulos entre uma faixa determinada experimentalmente têm os parâmetros da distribuição de probabilidade calculados segundo uma função do segundo grau. Ângulos muito pequenos tendem ao completo desconhecimento sobre aquela região do ambiente pelo robô e portanto a os valores de probabilidade tendem a 0,5. Conforme o ângulo aumenta, a probabilidade de ocupação também aumenta 
proporcionalmente até atingir um certo valor máximo que abrange a área onde o sensor nos dá informação mais precisa.

A Figura 19 representa o modelo do sistema de visão estéreo omnidirecional para as Grades de Evidência. Nota-se na figura a região visível pelo sensor que corresponde a uma distância limite no qual a precisão do cálculo é aceitável. As regiões em azul indicam probabilidade baixa de ocupação, as regiões em verde locais de incerteza, e as amarelas e vermelhas regiões com evidência maior que 0,5 de ocupação.

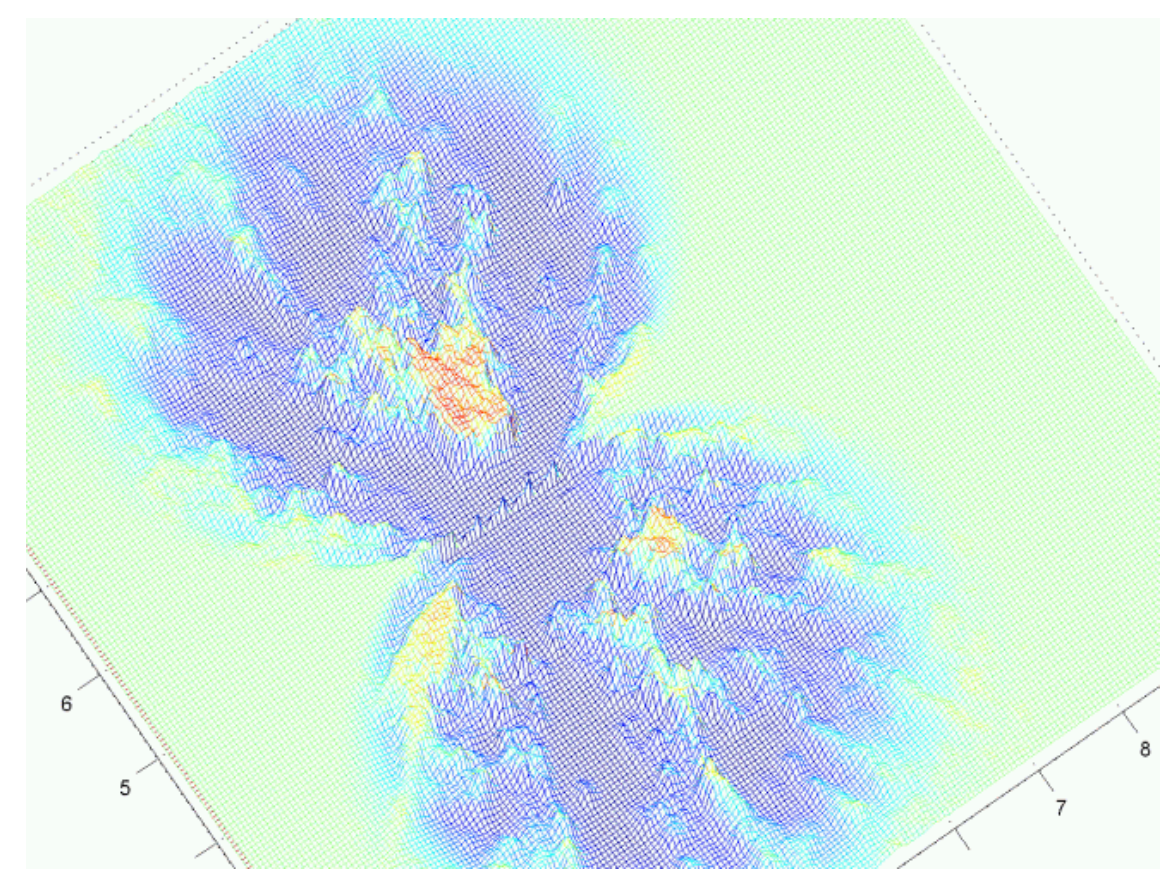

Figura 19 - Modelo probabilístico do sistema de visão estéreo omnidirecional.

\subsection{Modelo Bayesiano para estimação do mundo}

A partir das leituras do sensor, que adquirem informações sobre o ambiente, é possível utilizar um modelo para tentar reconstruir o ambiente a partir destas informações.

Como é possível apenas conhecer o ambiente ao redor do robô por meio do sensor, tem-se apenas uma função densidade de probabilidade da qual é extraída a probabilidade de que cada célula da Grade de Evidência esteja ocupada ou livre. Para 
isto, é necessário um processo de estimação. O processo Bayesiano estima o valor $a$ posteriori a partir de uma função densidade de probabilidade. Esta probabilidade é obtida através do teorema de Bayes:

$p\left(s\left(C_{i}\right)=O C C \mid S\right)=\frac{p\left(S \mid s\left(C_{i}\right)=O C C\right) \cdot P\left(s\left(C_{i}\right)=O C C\right)}{\sum_{s\left(C_{i}\right)} p\left[S \mid s\left(C_{i}\right)\right] \cdot P\left[s\left(C_{i}\right)\right]}$

O termo $\mathrm{P}\left(\mathrm{s}\left(\mathrm{C}_{\mathrm{i}}\right)=\mathrm{OCC}\right)$ representa a probabilidade das configurações a priori, é o seu conhecimento do ambiente antes de uma nova leitura do sensor. Como a intenção é trabalhar com ambientes desconhecidos, não se tem conhecimento algum a priori, estabelecendo-se que $\mathrm{P}\left(\mathrm{s}\left(\mathrm{C}_{\mathrm{i}}\right)=\mathrm{OCC}\right)=\mathrm{P}\left(\mathrm{s}\left(\mathrm{C}_{\mathrm{i}}\right)=\mathrm{EMP}\right)=0,5$, o que significa utilizar a probabilidade de máxima entropia. Levando em consideração o fato de que as células da grade são variáveis aleatórias independentes, é possível escrever que pelo teorema de Kolmogoroff:

$p\left[S \mid s\left(C_{i}\right)=O C C\right]=\sum_{\left\{G_{s\left(c_{i}\right)}\right\}} p\left[S \mid s\left(C_{i}\right)=O C C, G_{s\left(C_{i}\right)}\right] P\left[G_{s\left(C_{i}\right)} \mid s\left(C_{i}\right)=O C C\right]$,

onde $P\left[G_{s\left(C_{i}\right)} \mid s\left(C_{i}\right)=O C C\right]=\prod_{\forall j, j \neq i} P\left[s\left(C_{j}\right)=s_{j}\right]=\frac{1}{2^{N-1}}$, sendo $\mathrm{N}$ a dimensão da

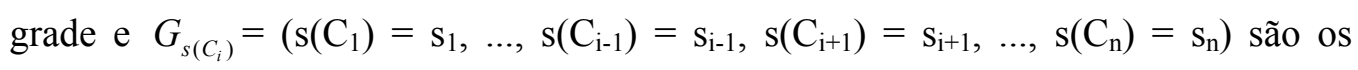
possíveis estados da grade, desconsiderando a célula $\mathrm{C}_{\mathrm{i}}$.

A probabilidade $p\left[S \mid s\left(C_{i}\right)=O C C, G_{s\left(C_{i}\right)}\right]$ é retirada do modelo de interpretação espacial.

\subsection{Atualização da Grade de Evidência}

As Grades de Evidência armazenam informação espacial e temporal obtida através do(s) sensor(es) do robô. O contínuo sensoriamento faz com que as incertezas inerentes ao(s) sensor(es) e as ambigüidades obtidas nas leituras se reduzam conforme a informação vai se acumulando na grade. 
Por meio de derivações da Regra de Bayes (Murphy, 2000), obtém-se uma Regra de Bayes recursiva para ser utilizada na atualização das grades. Nesta regra iterativa é utilizada a nova leitura do sensor juntamente com a informação da última Grade de Evidência. A Regra de Bayes recursiva é dada por:

$$
p\left(O C C \mid\left\{S_{t+1}\right\}\right)=\frac{p\left(\left\{S_{t+1}\right\} \mid O C C\right) \cdot P\left(O C C \mid\left\{S_{t}\right\}\right)}{p\left(\left\{S_{t+1}\right\} \mid O C C\right) \cdot P\left(O C C \mid\left\{S_{t}\right\}\right)+p\left(\left\{S_{t+1}\right\} \mid E M P\right) \cdot P\left(E M P \mid\left\{S_{t}\right\}\right)}
$$

A informação a priori neste caso vem da Grade de Evidência mais atual antes da obtenção de nova informação sensorial, mostrando que o resultado não depende diretamente de todo o histórico das leituras obtidos pelo sensor.

Sobre uma representação como as Grades de Evidência, um robô autônomo pode solucionar alguns dos problemas que surgem durante uma navegação, como o planejamento de trajetória e a auto-localização.

\subsection{Planejamento de trajetórias}

Um planejador de trajetórias é um algoritmo que, baseado numa representação do ambiente, determinará o caminho que o robô deverá percorrer para chegar a um local pré-determinado desviando-se das áreas consideradas ocupadas.

É uma das partes deliberativas de uma arquitetura. O planejador busca um caminho ótimo segundo um critério pré-estabelecido. No entanto, como o planejador não tem a sua disposição uma representação a priori do mundo e realiza os cálculos sobre um modelo incompleto e com incertezas, as soluções obtidas são sub-ótimas. Os planejadores de trajetória para navegação métrica possuem duas partes: representação e algoritmo. A representação é o modelo do ambiente que o robô possui ou constrói, e o algoritmo é a maneira como as informações da representação são utilizadas para a obtenção da trajetória. A trajetória produzida por planejadores deste tipo é muitas vezes cheias de "cotovelos", devido a discretização da representação. Como todas as partes de uma abordagem deliberativa, tem-se os problemas de representação do mundo, a dinâmica do ambiente, o aparecimento de situações não modeladas, e a complexidade computacional dos algoritmos. 
As representações podem ser divididas em grafos (Meadow maps ou Grafos de Voronoi generalizados) ou grades (grades regulares ou quadtrees) (Murphy, 2000). Os meadow maps são construídos sobre um mapa conhecido a priori ligando-se os vértices dos objetos e paredes do ambiente, formando-se triângulos em cujo perímetro pode-se navegar de modo seguro. Os grafos de Voronoi generalizados traçam linhas eqüidistantes de todos os obstáculos. Um grade regular é a divisão do ambiente em células do mesmo tamanho que marcam se aquele espaço está ou não ocupado por algum obstáculo, como o caso das Grades de Evidência. Uma quadtree é uma grade que possui diferentes resoluções locais: em espaços vazios, existe uma célula grande; em espaços ocupados, a grade é refinada, para incorporar uma melhor precisão do local exato do objeto.

Os algoritmos para o planejamento sobre os mapas métricos do tipo grades podem ser de dois (Murphy, 2000): o $\mathrm{A}^{*}$ e o wave front.

Algoritmos do tipo frente de onda, utilizam-se do princípio análogo à transferência do calor baseado na condutividade do material. Cada célula da grade possui uma condutividade baseada na sua ocupação. A Figura 20 mostra como o algoritmo funciona. O caminho vai se formando conforme uma frente de onda vai se expandindo, partindo-se do ponto inicial, em vermelho na figura, até o ponto final, verde. A expansão segue a idéia da propagação do calor sobre materiais com diferentes coeficientes de condução. Cada quadro na figura mostra uma iteração do algoritmo. Em cada iteração, os vizinhos de cada uma das células da nova frente de onda que está propagando-se são preenchidas nesta iteração. A nova frente de onda é desenhada em amarelo claro e as células já visitadas vão ficando amarelo escuras. $\mathrm{Na}$ grade, estes coeficientes são as próprias probabilidades das células. Quanto maior a probabilidade da célula estar ocupada mais lentamente ele será incorporada a trajetória. 


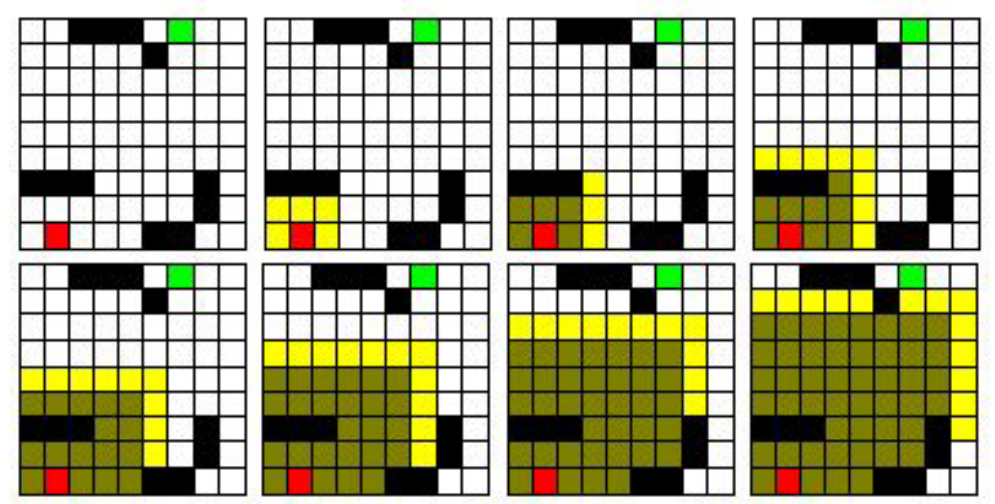

Figura 20. Funcionamento do algoritmo Frente de onda.

O planejamento pode ser feito também com um algoritmo $A^{*}$, utilizando a probabilidade de ocupação das células como custo para atravessar o ambiente. $\mathrm{O}$ algoritmo busca minimizar o custo da trajetória. Conforme o robô navega e adquire mais informações sobre o ambiente, a trajetória é replanejada. A forma geral destes algoritmos é:

$f *(n)=g(n)+h *(n)$,

onde $\mathrm{h}^{*}(\mathrm{n})$ é uma função heurística do custo entre um ponto dado e o alvo que deve ser a menor possível para a consistência da estimação, mantendo o resultado otimizado (consiste na distância euclidiana); g(n) é o custo do caminho percorrido do ponto inicial até um ponto dado.

Para que as Grades de Evidência possam ser utilizadas para o planejamento de trajetória, e o robô possa ser tratado como um ponto material, utiliza-se um algoritmo de crescimento de região sobre as probabilidades que indicam ocupação.

Um dos problemas em se realizar uma navegação autônoma baseada nas Grades de Evidência é que os mapas iniciais contém muito pouca informação sobre a ocupação do ambiente. O maior problema está na qualidade da informação vinda do algoritmo estéreo. Os erros presentes na leitura do sensor são atenuados no mapa global após algumas iterações entre leitura e criação/atualização das grades. A quantidade de iterações necessárias varia segundo o grau de sobreposição entre a nova informação 
obtida do sistema de visão e o mapa global disponível. A partir de um determinado número de atualizações, com sobreposição maior que $90 \%$ entre a informação sensorial e a representação atual do ambiente, de três a quatro significando uma trajetória de mais ou menos um metro numa determinada direção, é que os objetos do ambiente começam a se definir sobre a grade e o robô pode planejar trajetórias mais confiáveis.

A solução para este problema é a utilização de um cálculo para determinar a quantidade de informação, ou mais precisamente a entropia das grades. Quando a entropia diminuir até um certo grau, a trajetória pode ser planejada. Quando o planejador ainda não está sendo empregado, o robô faz uma trajetória perpendicular à reta que o une ao local a ser atingido na navegação.

A entropia $U$ pode ser calculada da seguinte maneira:

$U=\sum_{i=0}^{n^{2}}-E\left(C_{i}\right) \cdot \log E\left(C_{i}\right)$

onde $\mathrm{E}\left(\mathrm{C}_{\mathrm{i}}\right)$ é o valor de uma célula da Grade de Evidência. Dado o tamanho da Grade de Evidência, determinam-se as entropias máxima e mínima, correspondendo respectivamente a incerteza completa e a determinação completa da estrutura do ambiente. $\mathrm{O}$ valor a ser utilizado para determinar quando o planejador pode ser usado é escolhido de modo empírico através de testes feitos com o mapeamento do laboratório. Mas não são necessários mais que três atualizações na grade ou pouco mais de meio metro para que as Grades tenham informação suficiente para serem utilizadas para planejar sobre ela a trajetória do robô.

\subsection{Auto-localização}

A representação do ambiente na forma de Grades de Evidência criada a partir das informações de distâncias obtidas pelo sistema de visão estéreo omnidirecional incorpora as incertezas presentes no sensoriamento relacionadas ao algoritmo estéreo e ao próprio sistema de visão. A incerteza no deslocamento do robô não foi considerada até o momento. Conforme ele se move em direção ao seu objetivo, os 
erros de movimentação vão acumulando-se a ponto de invalidar o mapeamento realizado por ele. Sabe-se que com apenas a leitura do odômetro dos motores em percursos da ordem de 100 m não é possível realizar um mapeamento ou navegação baseada em informação métrica (Thrun, 2000). É necessária uma outra maneira de obter uma melhor estimativa da posição real do robô. Como a navegação proposta não faz uso de informações a priori, soluções que buscam marcos no ambiente para identificar posições conhecidos são descartadas. A técnica que será utilizada para a obtenção de uma melhor estimativa da posição do robô é uma forma de motionsolving baseada na correlação entre Grades de Evidência. Esta técnica procura pelo registro ótimo entre a nova informação sensorial e o mapa global.

A estimação da posição do robô dada pelo odômetro dos motores é utilizada como ponto central da procura pela correlação. A correlação é feita entre as células do mapa local, que corresponde à nova informação sensorial modelada probabilisticamente, que indicam ocupação e o mapa global. Um vetor $A$ com a posição de todas as células ocupadas no mapa local é transformado segundo $T$ no vetor $B$ segundo uma rotação de um ângulo $\varphi$ e uma translação $\left(\mathrm{t}_{\mathrm{x}}, \mathrm{t}_{\mathrm{y}}\right)$ e correlacionado com o mapa global. A transformação é dada por:

$\mathrm{B}=\mathrm{T}$.A, onde $T=\left[\begin{array}{ccc}\cos \varphi & \operatorname{sen} \varphi & t_{x} \\ -\operatorname{sen} \varphi & \cos \varphi & t_{y}\end{array}\right]$

$A=\left[\begin{array}{l}x \\ y \\ 1\end{array}\right]$ e $B=\left[\begin{array}{l}x^{\prime} \\ y^{\prime}\end{array}\right]$

A correlação é calculada da seguinte maneira:

$I P=\sum_{i=1}^{m}\left(E_{t-1}\left(C_{i}\right) \cdot E_{t}\left(C_{i}\right)\right)$,

onde $\mathrm{C}_{1 \mathrm{i}}$ é o valor da célula da Grade $\mathrm{j}$. O maior valor de IP determina a melhor estimação para a movimentação do robô. 
A qualidade desta estimativa depende muito do quanto sobrepõem-se a nova informação com o mapa global. Para otimizar esta correlação pode-se usar múltiplas correlações com grades de diferentes resoluções. Adquire-se novas grades a partir dos mapas locais e globais, com menores resoluções. As grades de menor resolução são correlacionadas inicialmente e o resultado é utilizado como posição inicial para a busca nas grades de maior resolução. A diferença de resolução entre as grades é feita numa escala logarítmica. 


\section{RESULTADOS E ANÁLISE}

\subsection{Equipamento utilizado}

O sistema de visão omnidirecional utilizado neste trabalho foi montado na Base Móvel (Figura 21), um robô móvel construído por alunos do laboratório. Este robô pode ser considerado holômico pois apenas as rodas mudam de direção enquanto o sistema de visão mantém a mesma.

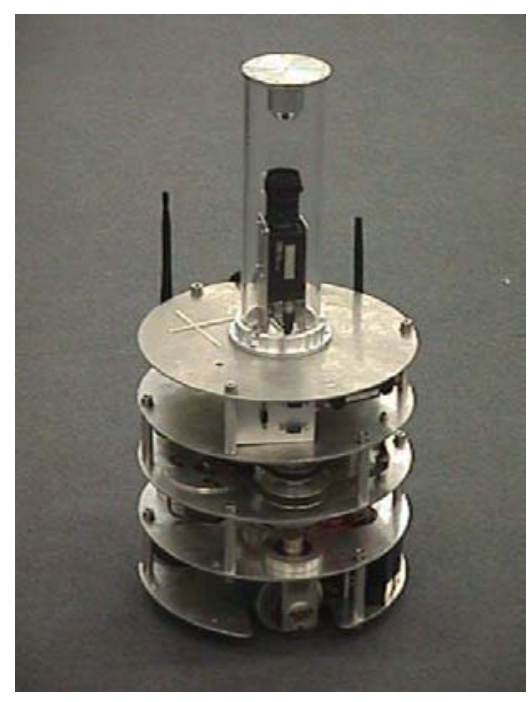

Figura 21 - Base Móvel construída no LPA.

O robô é dotado de três rodas que se movem simultaneamente (a translação é feita por um motor DC controlado em malha fechada com o auxílio de um encoder; e a rotação é feita por um motor de passo controlado em malha aberta com interface PWM), sendo capaz de locomover-se num plano. Tem o formato cilíndrico, dividido em cinco níveis sobrepostos. Esquematicamente, no nível superior, encontra-se o sistema de visão omnidirecional, composto por uma câmera apontando para um espelho hiperbólico, ambos encerrados num cilindro de acrílico. Abaixo, encontra-se o nível responsável pela comunicação externa - um link de vídeo e outro de Ethernet 
- e o computador padrão PC104 que faz a comunicação entre a rede externa de computadores e o controlador que se localiza no penúltimo nível. No nível intermediário está o sistema mecânico, formado por correias e engrenagens. No nível inferior encontram-se as rodas e as baterias que lhe garantem certa autonomia.

As imagens obtidas pelo sistema de visão são processadas por um computador externo ao robô que opera com sistema operacional Linux com uma placa de aquisição de imagens (framegrabber) Matrox Meteor. A transmissão das imagens do robô para esse computador externo é feita através de um link de rádio que transporta o vídeo.

Neste computador externo é realizado todo o processamento das imagens obtidas, a criação da Grade de Evidência e a determinação do próximo movimento do robô. Esta última informação pode ser enviada do computador externo para o robô através de comunicação por Ethernet. Essa comunicação é feita entre um access point wireless conectado a rede Ethernet, e um link Ethernet de rádio conectado a interface de rede do PC104 embarcado no robô. O PC104, por sua vez, envia através de uma interface RS-232c, a informação para o hardware de controle interno do robô.

Os códigos dos algoritmos estéreo e das Grades de Evidência estão em linguagem C e C++. Está sendo utiliza a biblioteca XVision descrita em Hager; Toyama (1998), para a aquisição e processamento das imagens.

A seguir são apresentados alguns experimentos realizados para analisar a implementação da visão estéreo omnidirecional e das Grades de Evidência para mapeamento, planejamento de trajetória e auto-localização.

\subsection{Experimentos com a visão estéreo omnidirecional}

Os resultados da visão estéreo são mostrados para um experimento onde o robô contorna uma caixa no centro do laboratório (Figura 22). 


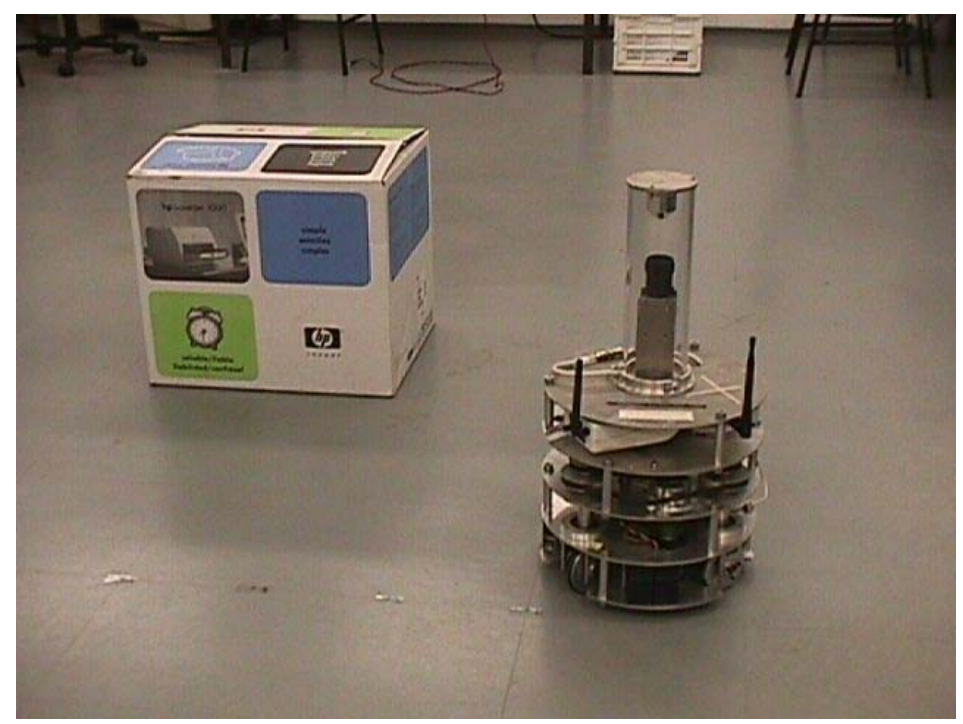

Figura 22. Objeto preparado para o teste de localização de distância.

A Figura 23 mostra a primeira imagem do par estéreo e a Figura 24 a adquirida com a translação de $300 \mathrm{~mm}$ segundo uma direção paralela a um dos lados da caixa.

Em seguida, a Figura 25 mostrada a operação de gradiente seguida da transformação da imagem em binária segundo um determinado limiar. A escolha do limiar é muito importante pois a iluminação do ambiente faz com que algumas partes dos objetos, ou mesmo objetos inteiros, não apareçam na imagem e aumenta os efeitos de reflexão na imagem criando bordas inexistentes.

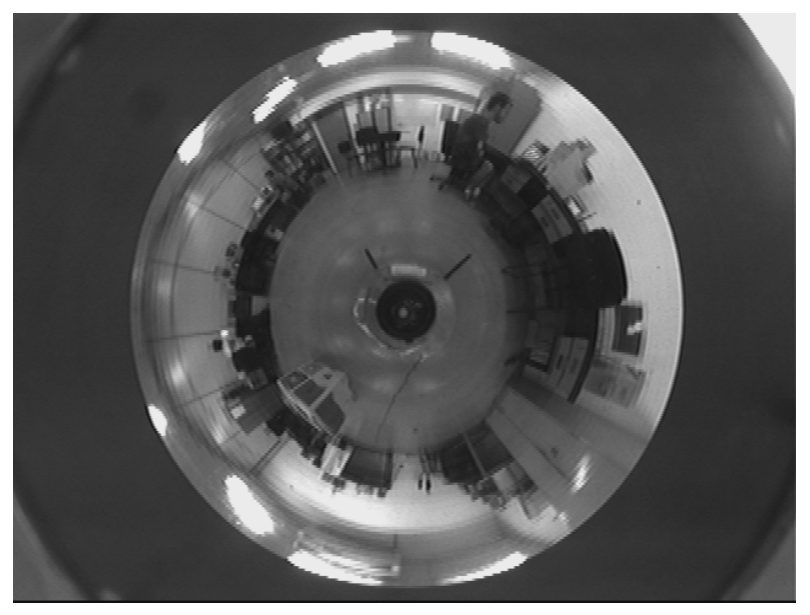

Figura 23. Primeira imagem do par estéreo. 


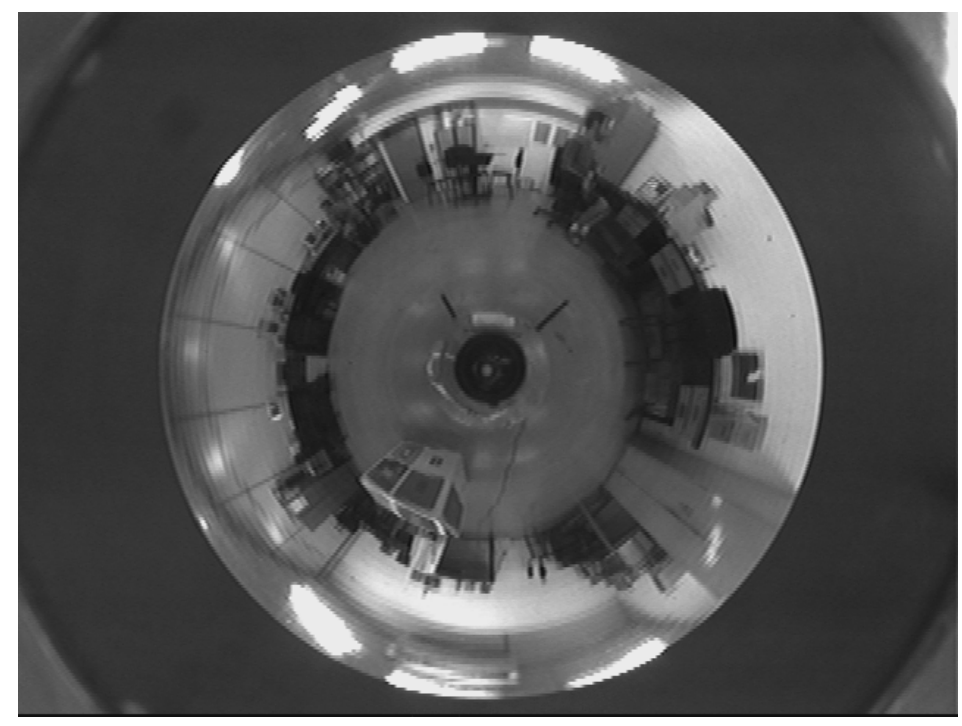

Figura 24. Segunda imagem do par estéreo.

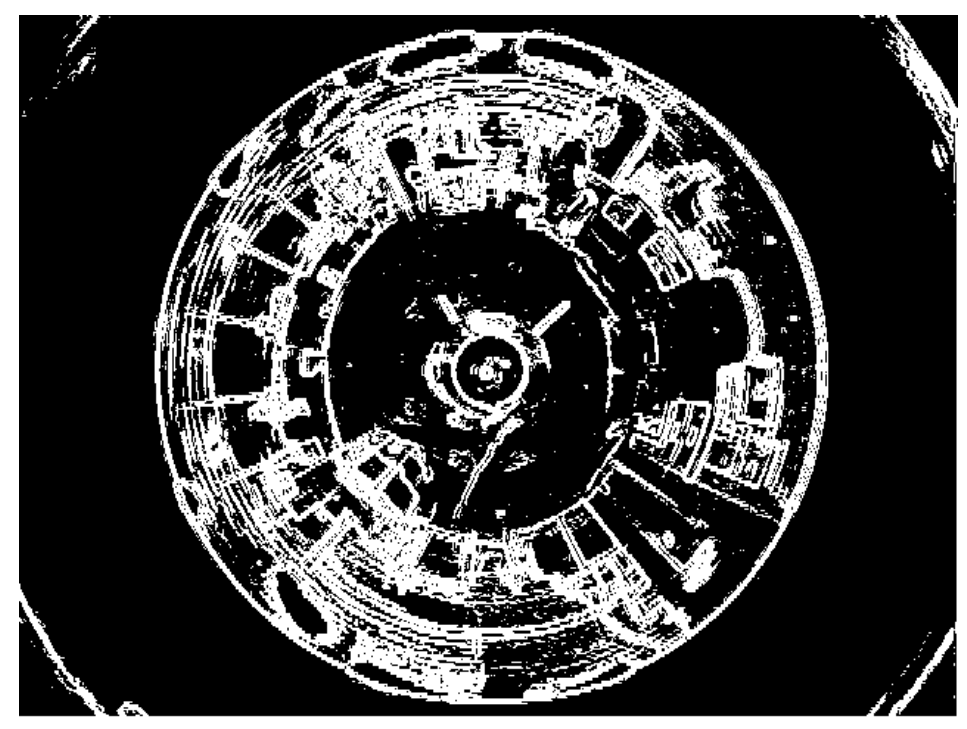

Figura 25. Primeira imagem binária do par.

Algumas curvas epipolares são mostradas na Figura 26 para mostrar a calibração do sistema de visão omnidirecional. Seis pontos foram escolhidos na primeira imagem do par e seus correspondentes foram marcados em vermelho na segunda imagem. Percebe-se que quatro das seis curvas passam sobre os pontos. $\mathrm{O}$ algoritmo de correspondência leva em consideração esse pequeno desvio que ocorre em alguns pontos, procurando por correspondentes numa área próxima à curva epipolar. 


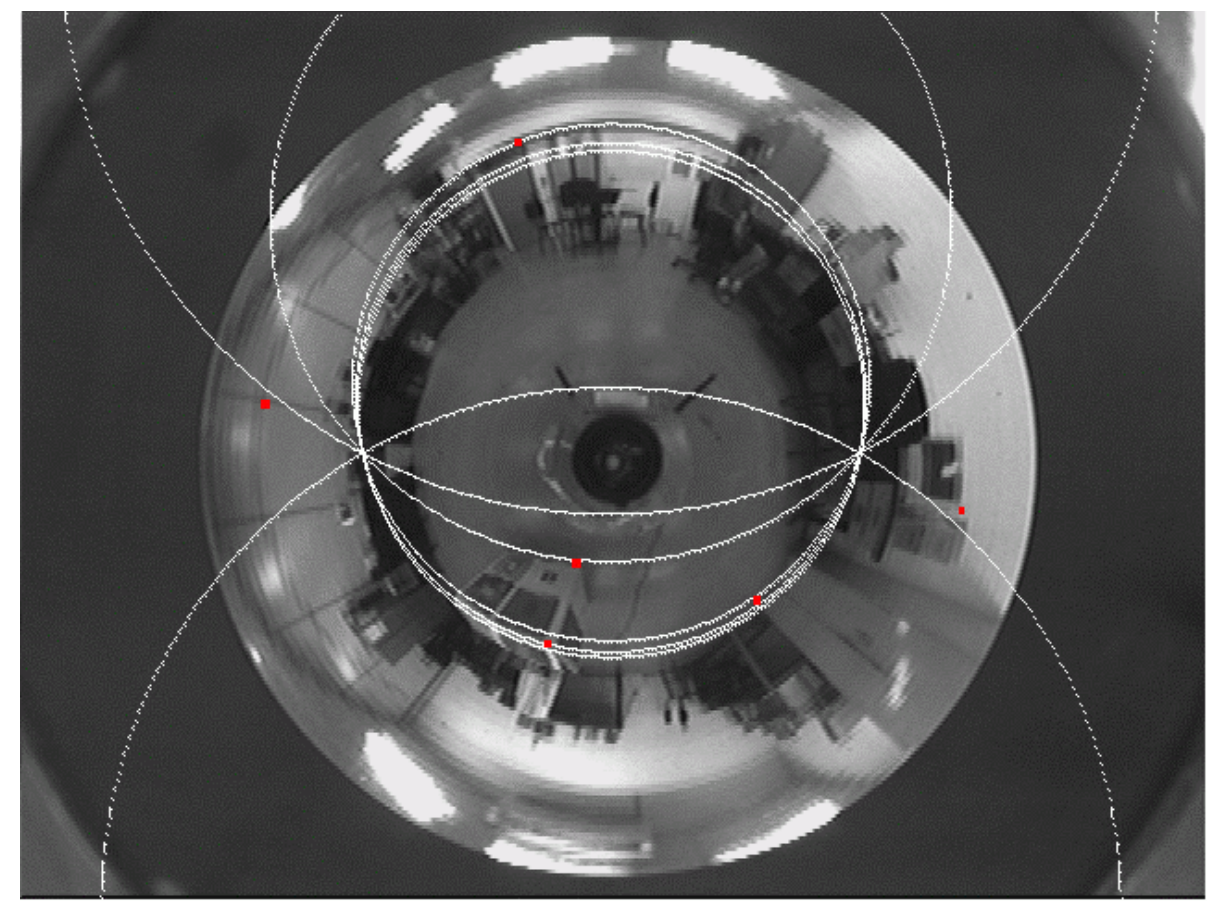

Figura 26. Curvas epipolares.

Os pontos correspondentes encontrados são mostrados na Figura 27 em branco. Analisando esta figura é possível determinar a direção de deslocamento do robô, horizontal na imagem, que é uma área onde não foram encontrados pontos correspondentes. Também é visível que apenas parte da imagem foi processada, restringida aos pontos em que se encontram na mesma altura do robô. Uma representação em escala destes pontos é mostrada na Figura 28. Nesta última figura, cujo referencial é o robô, posição $(0,0)$, a caixa é destacada com um retângulo preto. Nota-se uma concentração de pontos maior na área próxima à caixa do que no resto do ambiente. 


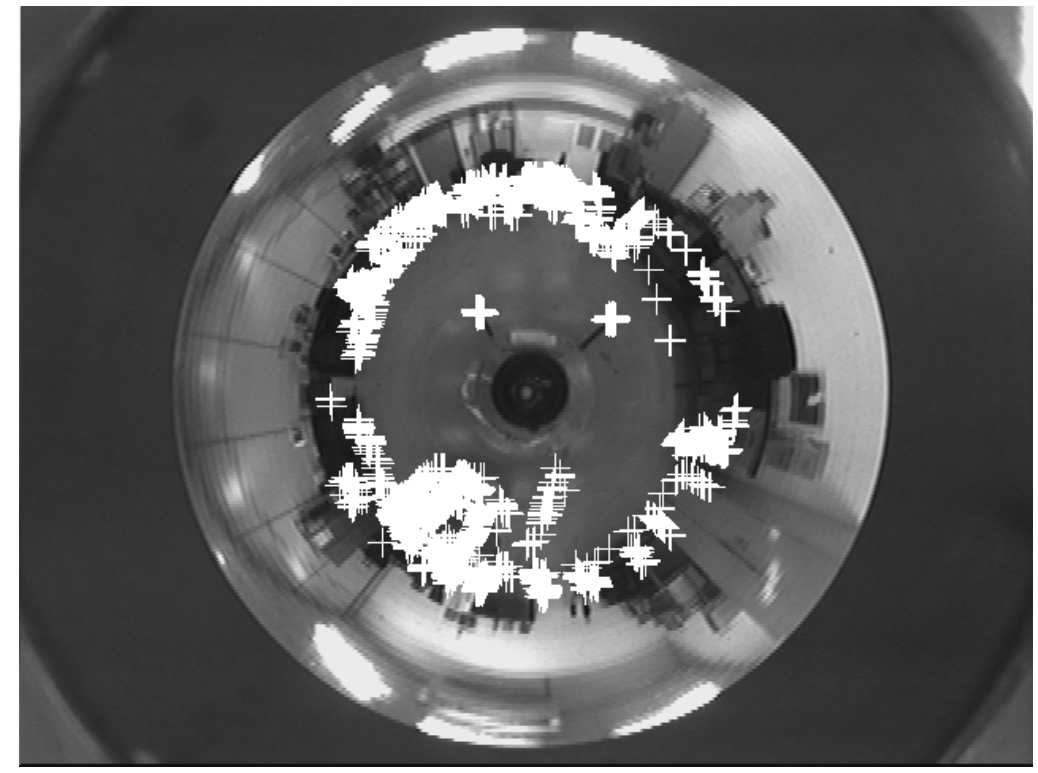

Figura 27. Pontos correspondentes.

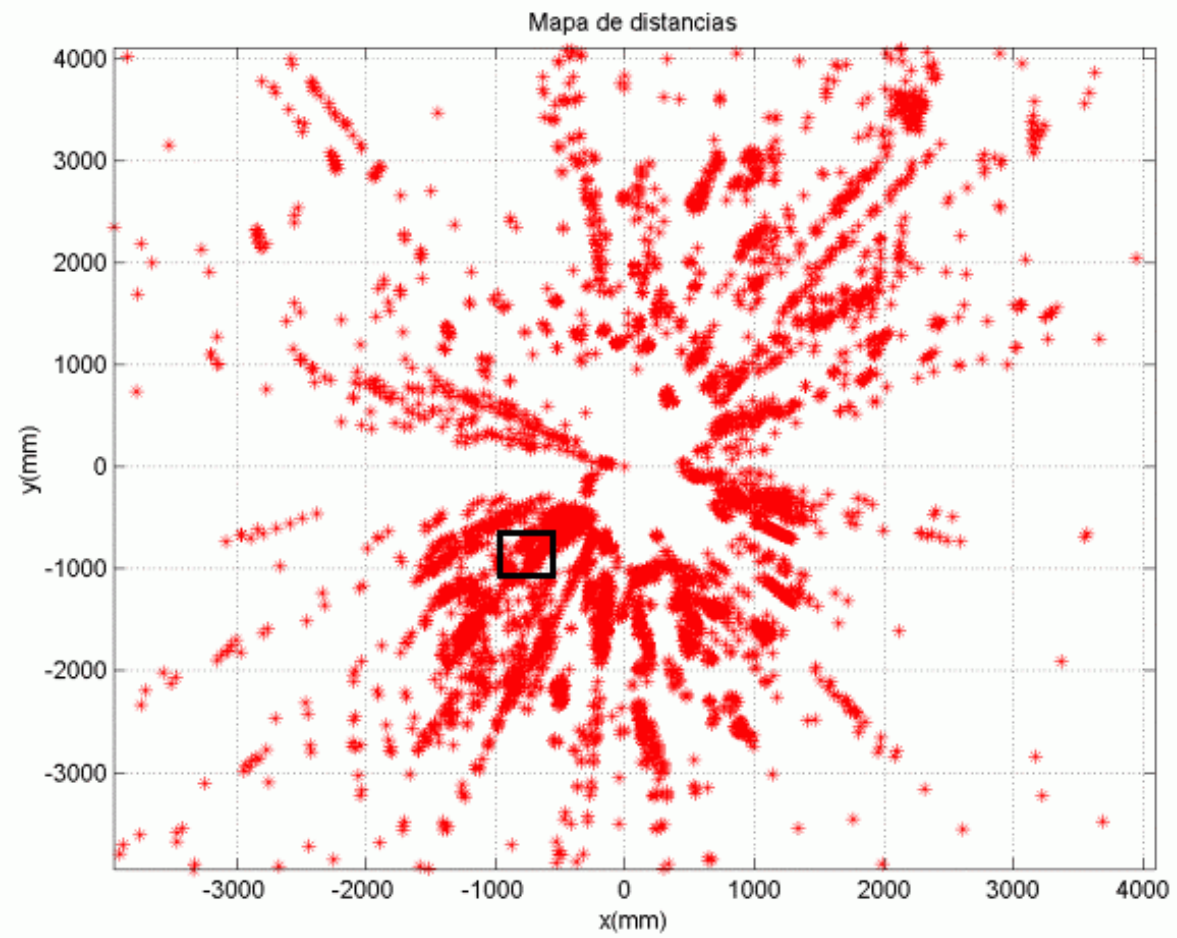

Figura 28. Resultado obtido das distâncias calculadas com a posição da caixa destacada pelo retângulo preto. 


\subsection{Experimentos de mapeamento com as Grades de Evidência}

O resultado do algoritmo estéreo é utilizado para construir as Grades de Evidência com o modelo probabilístico do sensor. As Grades de Evidência têm tamanho de 200 x 200 células, sendo que cada célula representa um espaço de $5 \mathrm{~cm}^{2}$ do ambiente. A Tabela 2 mostra todas as atualizações feitas sobre a Grade de Evidência durante o trajeto do robô ao redor da caixa. Cada representação da Grade de Evidência significa a aquisição de nova informação sensorial. Inicialmente o robô não tem conhecimento nenhum a priori, o que significa atribuir a todas as células da grade o valor 0,5 , correspondendo à incerteza total. Este valor é representado pela cor verde na grade. O robô inicia o trajeto no centro da grade $(100,100)$ e desloca-se paralelo ao eixo inferior da grade para a esquerda da figura. O movimento é no sentido antihorário.

Tabela 2 - Atualizações da Grade de Evidência.

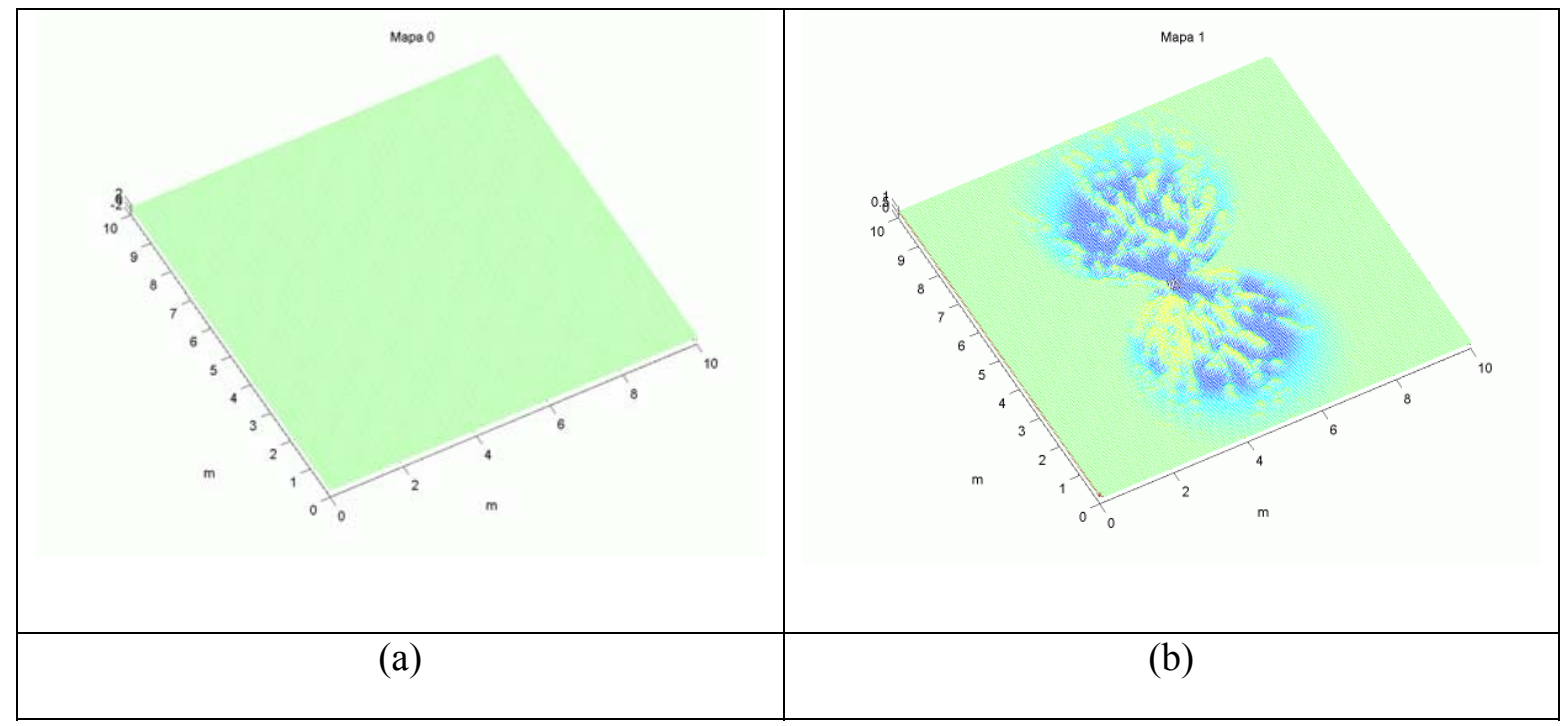




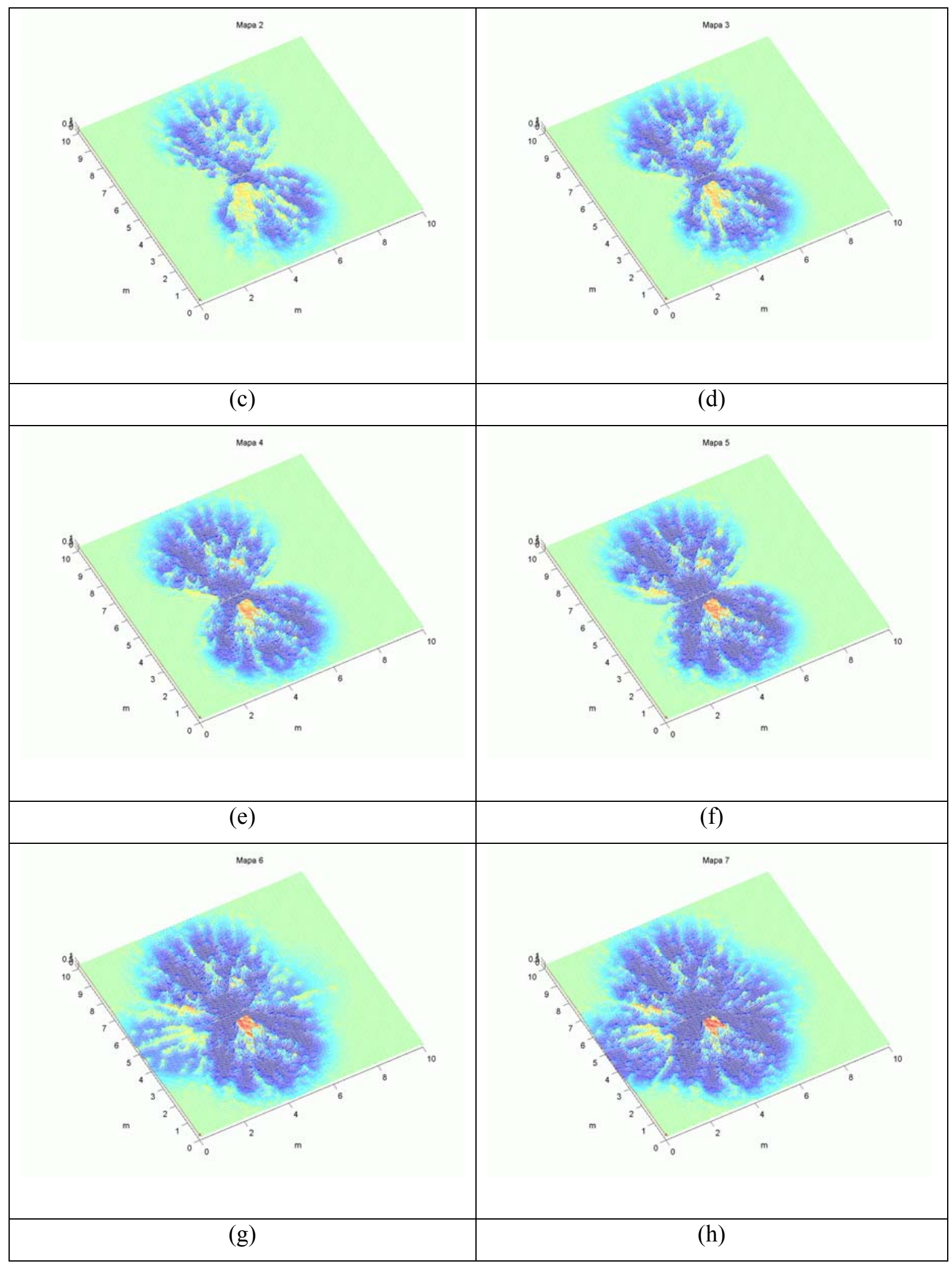




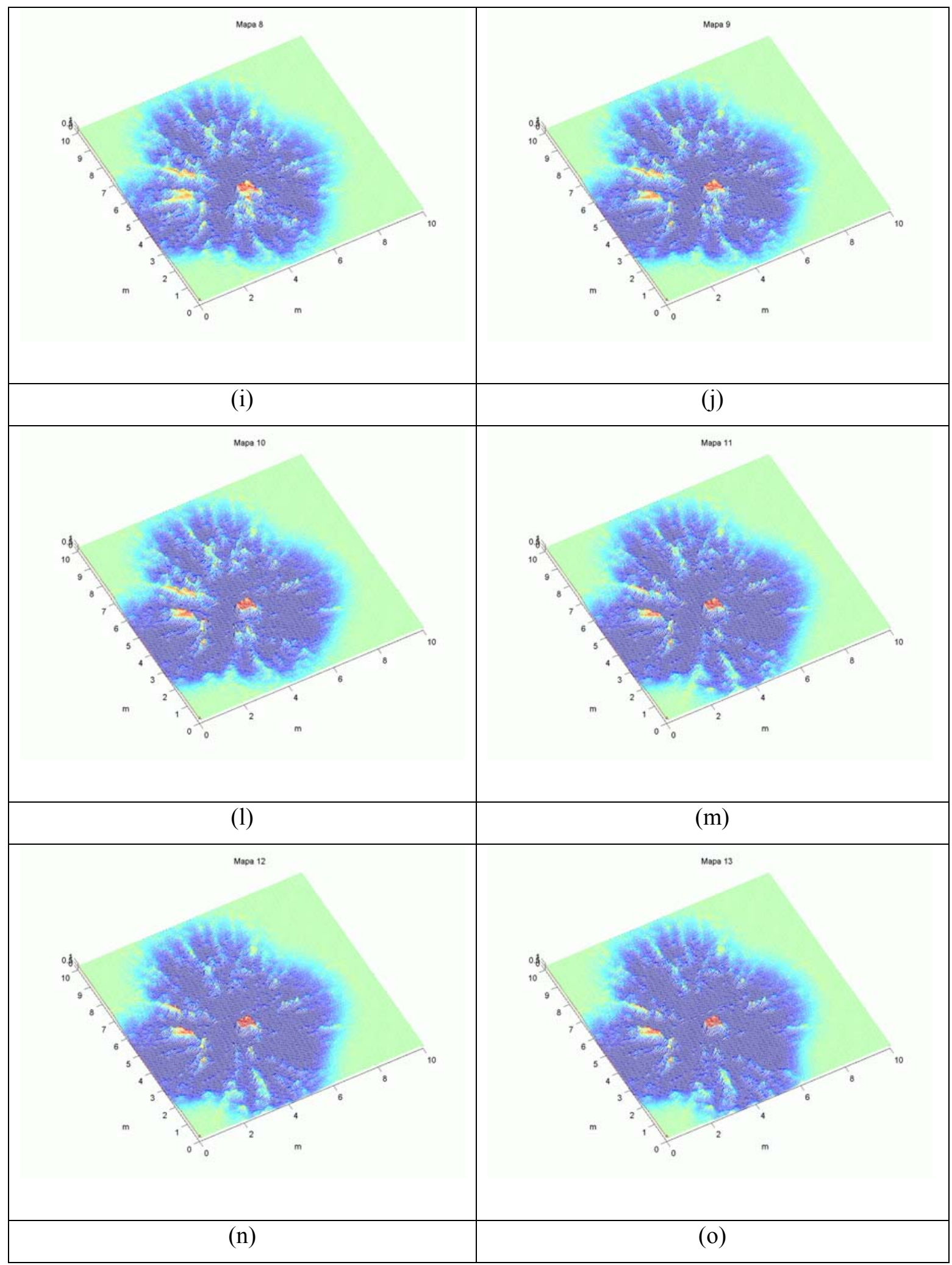




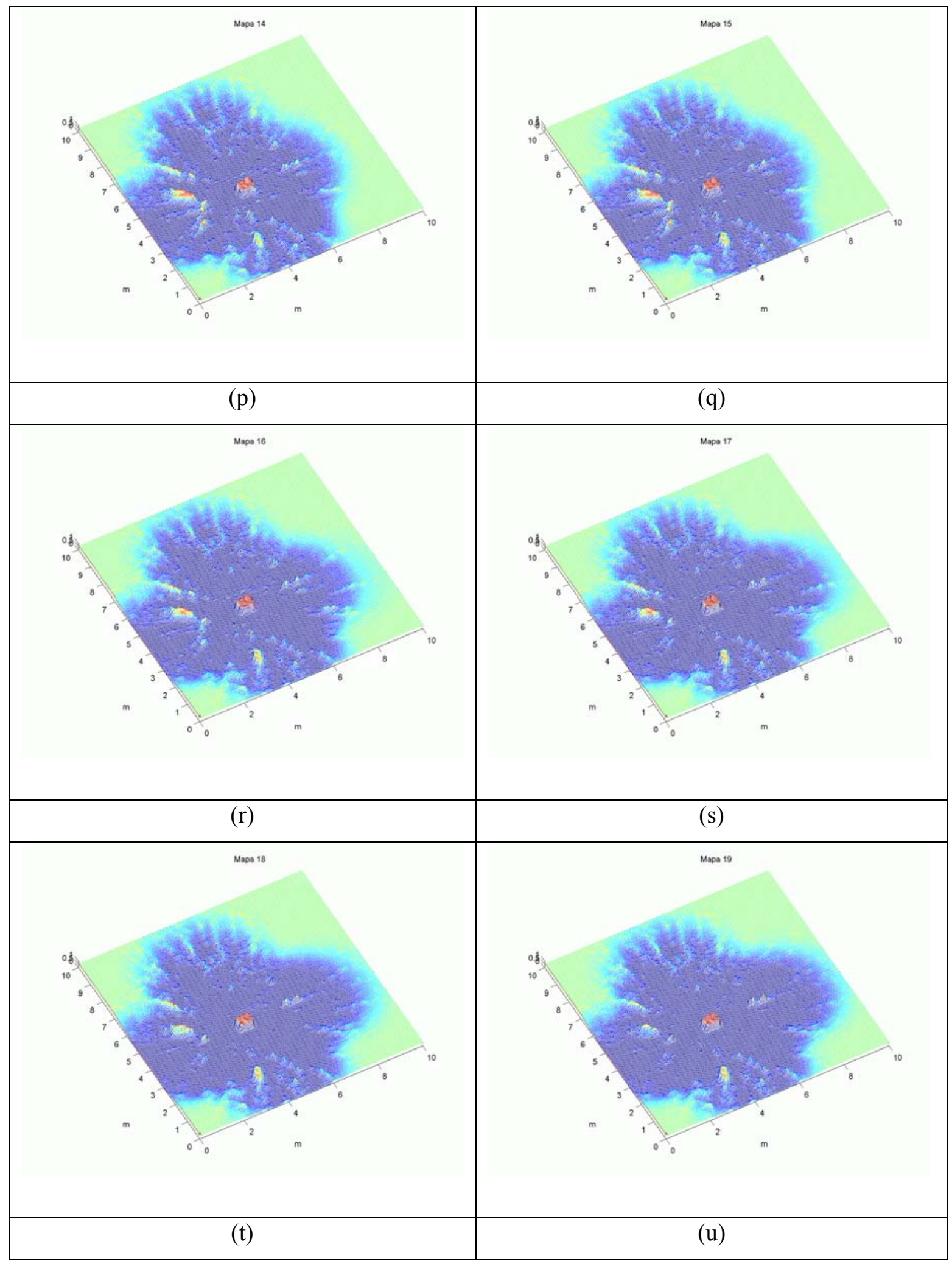




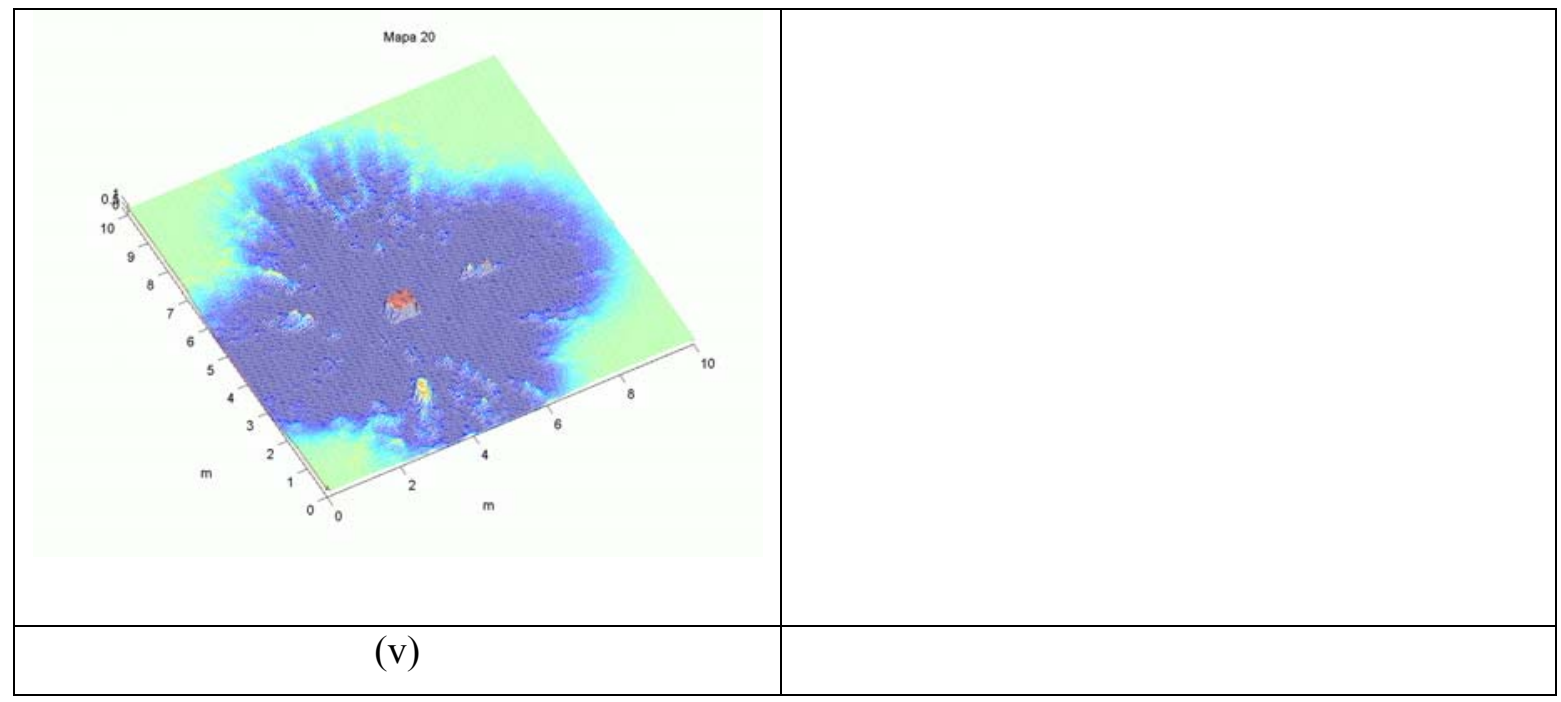

A Figura 29 é uma ampliação da última atualização da Grade de Evidência e mostra a caixa mapeada. Na Figura 30 está representada a mesma Grade de Evidência, uma visão superior do ambiente, numa imagem onde os níveis de cinza correspondem à probabilidade de ocupação de cada pixels. Tonalidades de branco indicam probabilidades baixas de ocupação e de preto, altas.

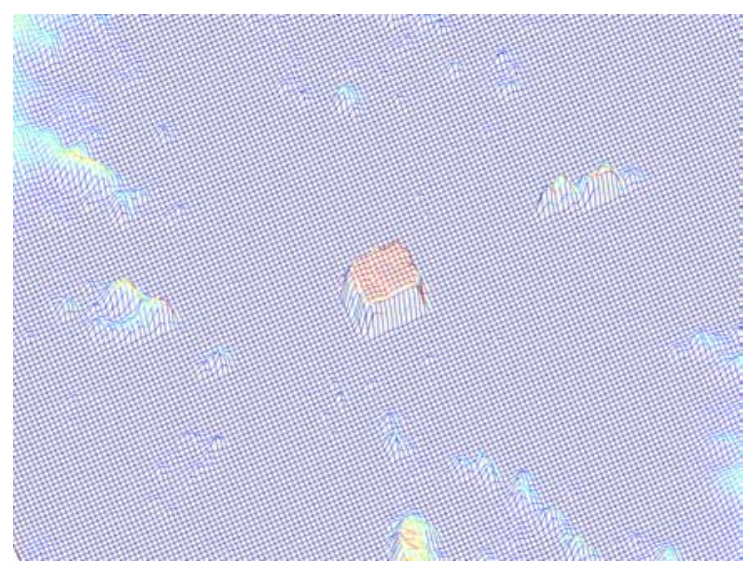

Figura 29 - Ampliação da Grade de Evidência, após todas as atualizações feitas durante o mapeamento, com a caixa em destaque no centro. 


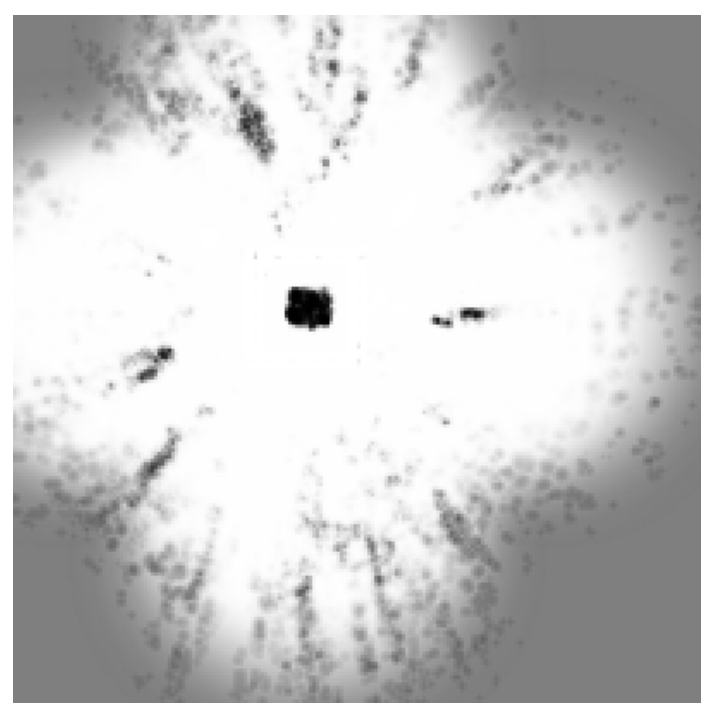

Figura 30 - Outra maneira de representação das Grades.

A representação de uma análise quantitativa deste experimento encontra-se na Figura 31. A célula em verde indica o centro do robô, como se esse fosse um ponto material. O contorno retangular em vermelho representa a caixa no centro do laboratório. As células em preto indicam as células da Grade de Evidência cujo valor estão acima do limite de probabilidade 0,7 evidenciando a ocupação da mesma. Cada célula na figura representa $5 \mathrm{~cm}^{2}$.

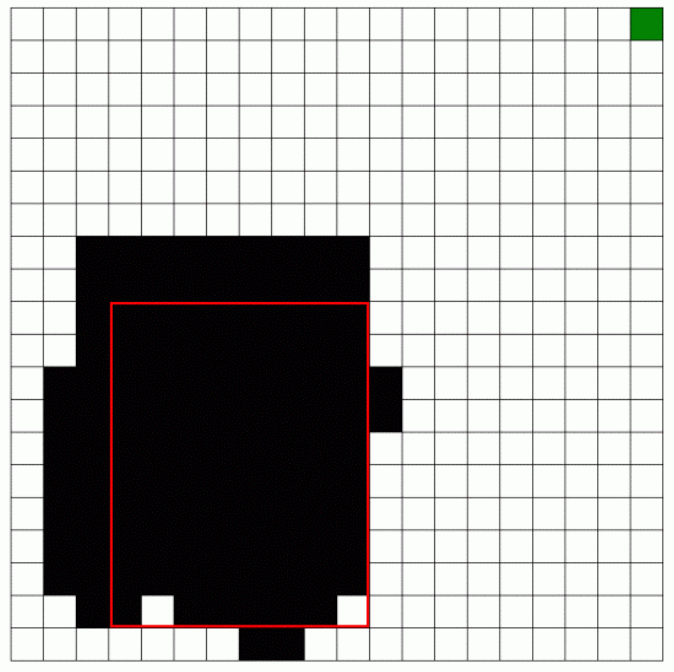

Figura 31 - Análise quantitativa da Grade de Evidência. 
Em outro experimento o robô contorna um objeto triangular como mostrado na Figura 32. A Figura 33 mostra o resultado final da Grade evidenciando o triângulo no centro da figura.

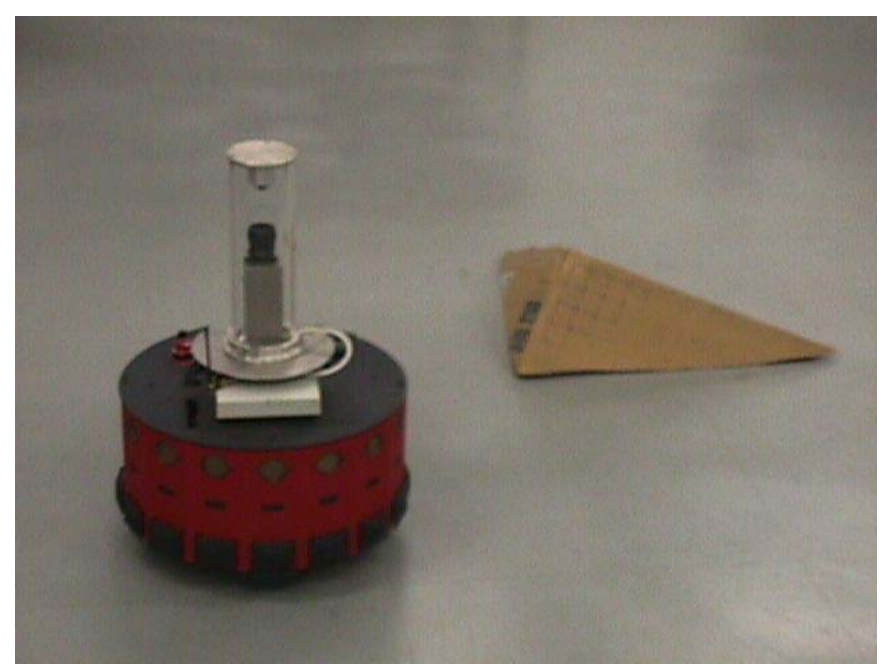

Figura 32 - Um objeto triangular.

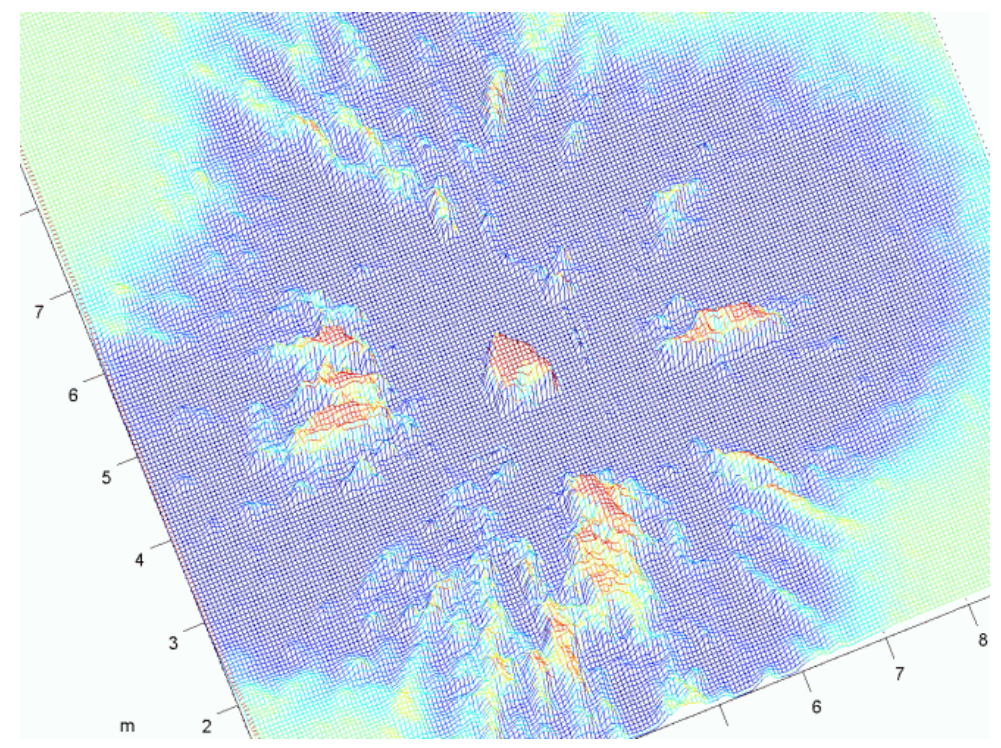

Figura 33 - Triângulo mapeado com as Grades de Evidência.

Nestes dois experimentos o objeto mapeado era visto durante todo o percurso do robô, e por todos os seus lados podendo aparecer no mapa final as suas dimensões reais. 
O experimento a seguir mostra o mapeamento de objetos segundo uma trajetória que não procura circundar objeto algum. Neste exemplo, o robô anda em apenas duas direções, e adquire uma quantidade maior de imagens em cada uma delas. A Figura 34 retrata os obstáculos encontrados durante a trajetória, duas caixas, uma lata de lixo e um livro de capa amarela. Nesta figura o robô encontra-se na posição inicial. Ele irá na direção do lixo à sua frente e virará para a direita da imagem, encontrandose entre os obstáculos no final da trajetória (Figura 35).

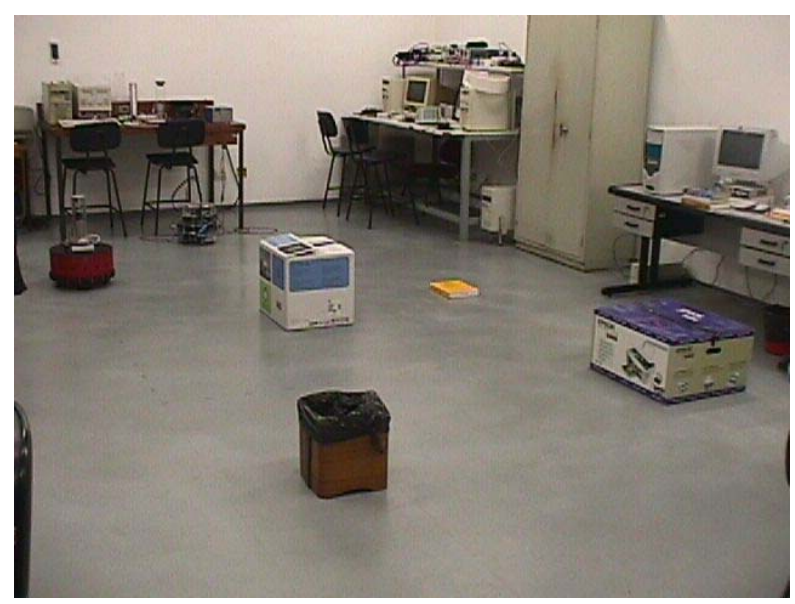

Figura 34 - Posição inicial do robô.

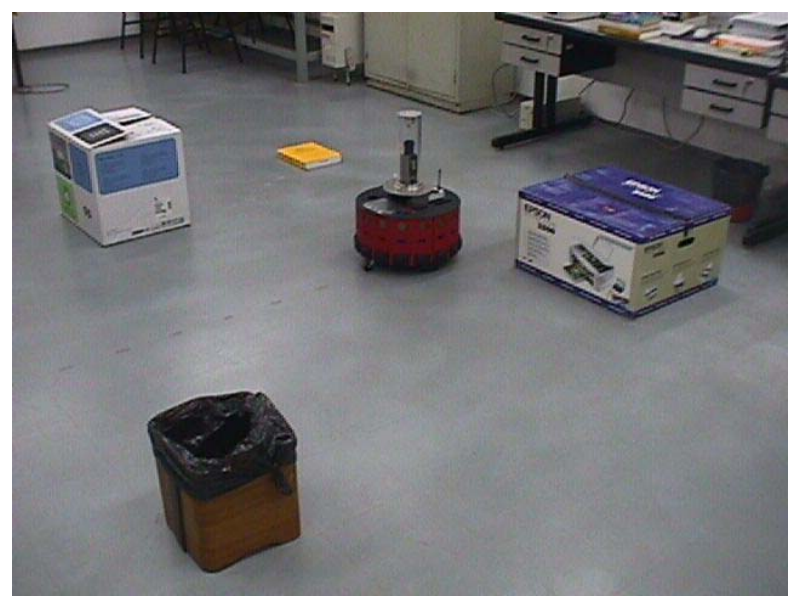

Figura 35 - Posição final do robô. 
A Figura 36 é o resultado da visão estéreo quando o robô está na sua posição final. Os retângulos em preto mostram a posição real dos objetos no ambiente segundo o referencial fixo no robô.

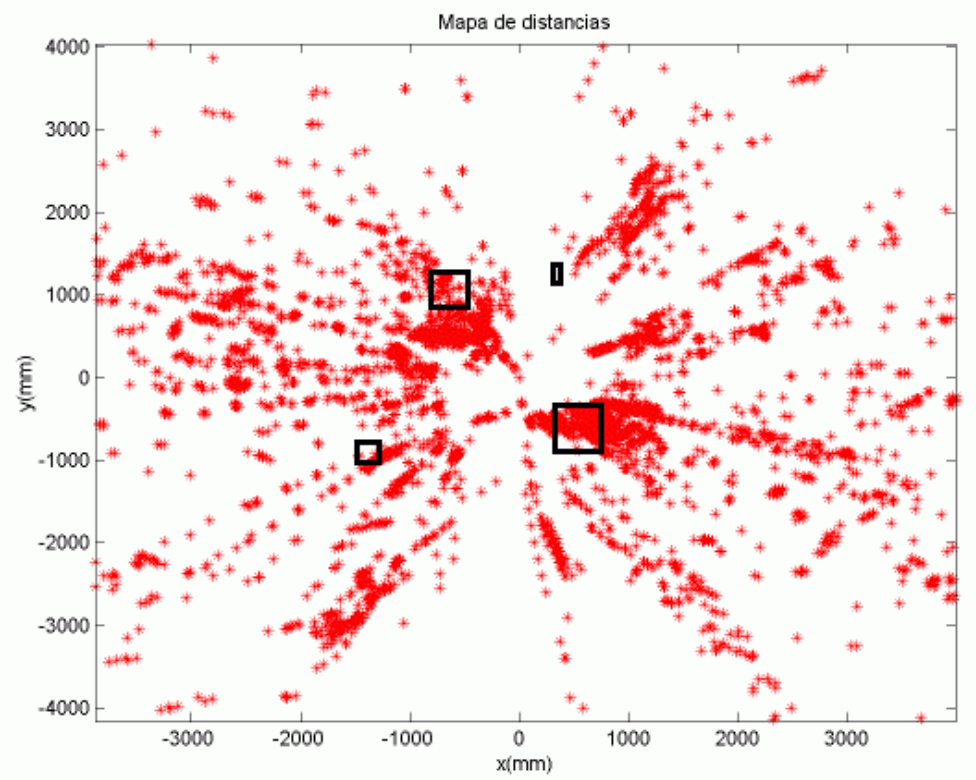

Figura 36 - Informação do algoritmo estéreo na última posição.

O resultado das Grades de Evidência na mesma posição final é mostrado na Figura 37. Os objetos maiores que aparecem na grade, como as duas caixas e o lixo, foram circulados em vermelho e uma indicação da trajetória marcada com duas setas. Constata-se que o tamanho dos objetos não é nítido nas Grades de Evidência quando o robô não os enxerga segundo todos os seus lados. 


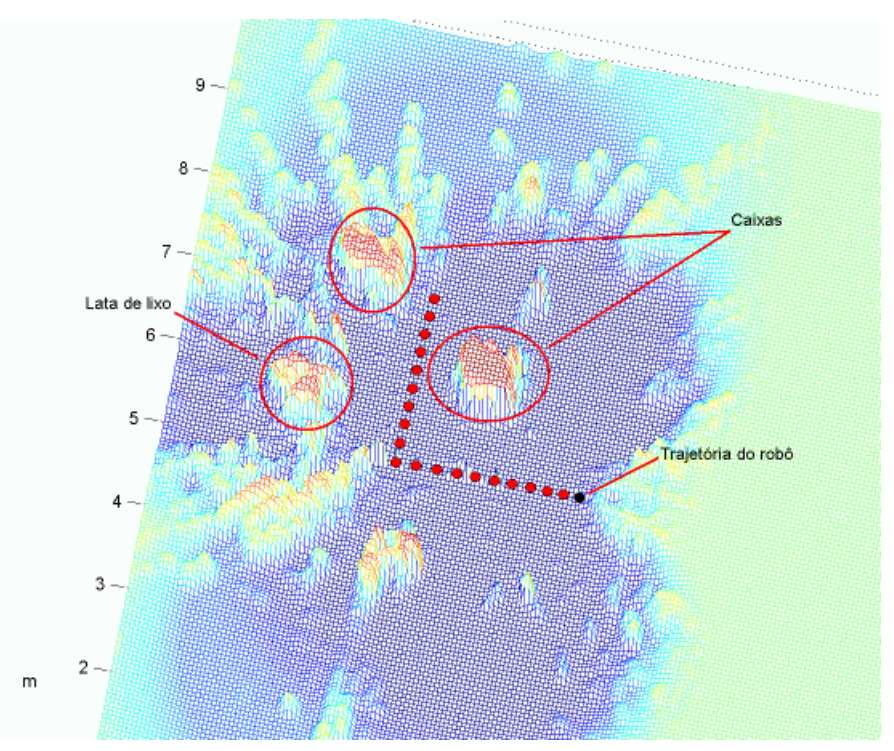

Figura 37 - Distância.

\subsection{Experimentos de navegação autônoma com planejamento de trajetória}

Abaixo encontra-se um dos experimentos realizados em navegação autônoma onde o robô planeja a sua trajetória sobre a Grade de Evidência que vai construindo ao longo da trajetória. Na Figura 38 o robô encontra-se em sua posição inicial e o local de chegada é marcado com um livro de capa amarela. A posição inicial do robô corresponde à célula $(100,100)$ e a posição final é $(100,40)$. O único objeto do qual o robô precisa desviar-se é uma caixa colocada no centro do laboratório.

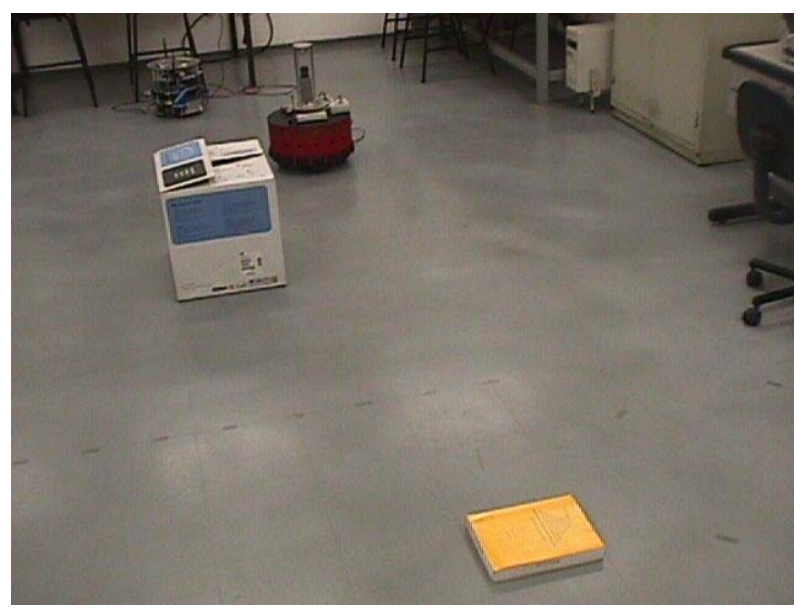

Figura 38 - Posições inicial e de chegada do robô. 
Existe uma linha reta e livre entre as posições inicial e final do robô. O objeto foi colocado ao lado desta trajetória pois o robô desloca-se perpendicularmente à linha que o liga ao objetivo, para adquirir informação suficiente nas Grades e posteriormente iniciar o planejamento da trajetória. O robô locomove-se para a esquerda da Figura 38 em três etapas (Figura 39), quando o cálculo da entropia determina que existe informação suficiente para usar a Grade no planejamento.

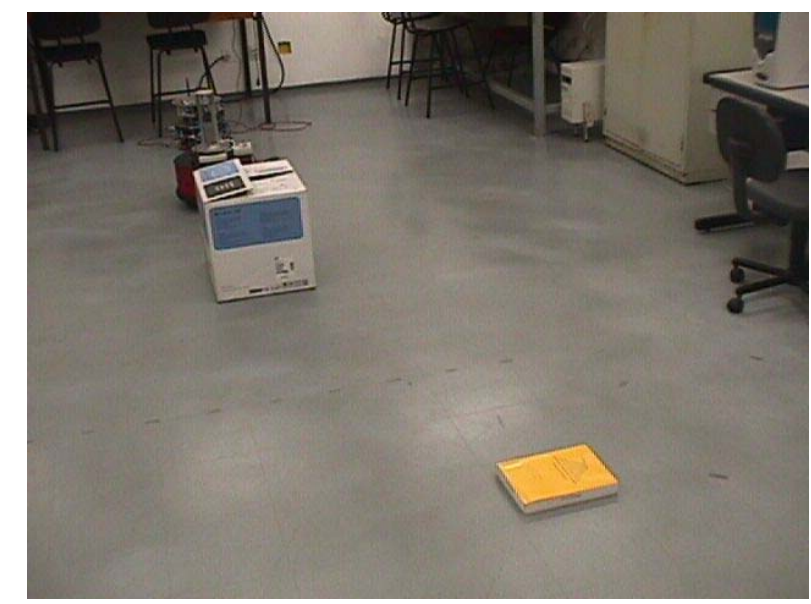

Figura 39 - Posição onde o robô possui informação suficiente para navegar.

A Figura 40 mostra uma etapa intermediária da navegação quando o robô desvia da caixa e a trajetória entre ele e seu objetivo fica desobstruída. A Tabela 3 contém as etapas de atualizações da Grade de Evidência ao longo da navegação autônoma. O robô inicia no centro da imagem, desloca-se três passos para a esquerda, e depois dirige-se ao objetivo que encontra-se na parte superior das imagens da grade. 


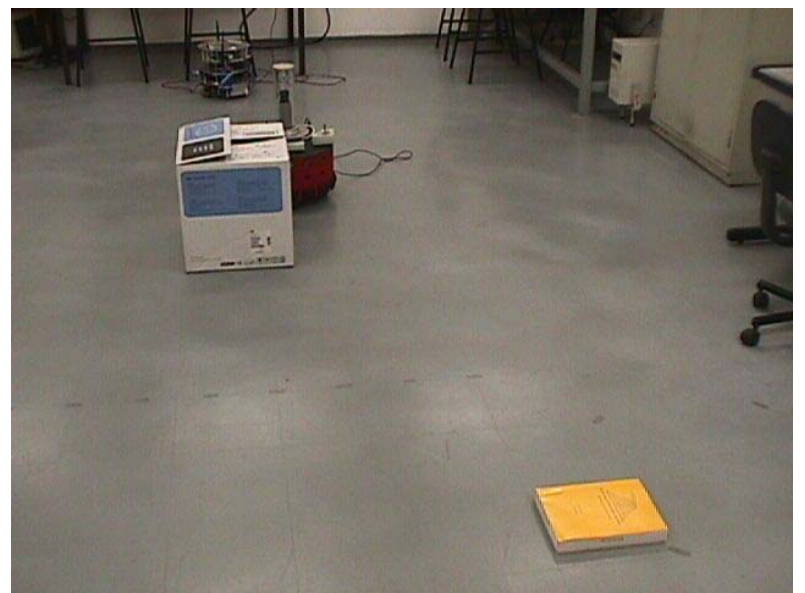

Figura 40 - Posição intermediária na navegação.

Tabela 3 - Atualizações na Grade de Evidência durante navegação autônoma.

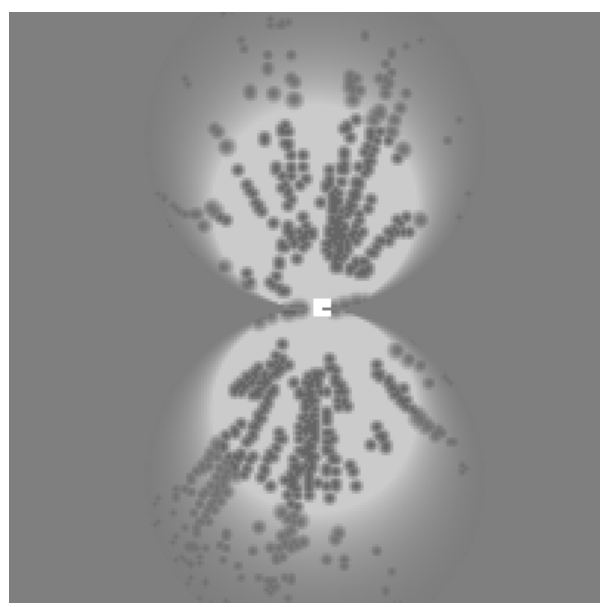

(a)

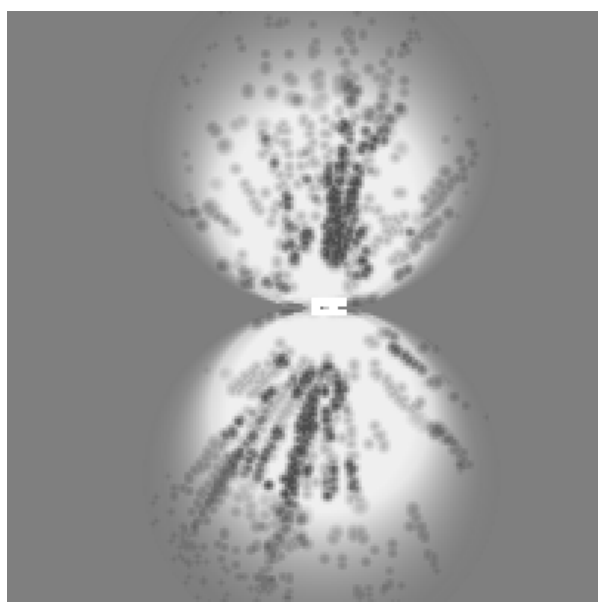

(b) 

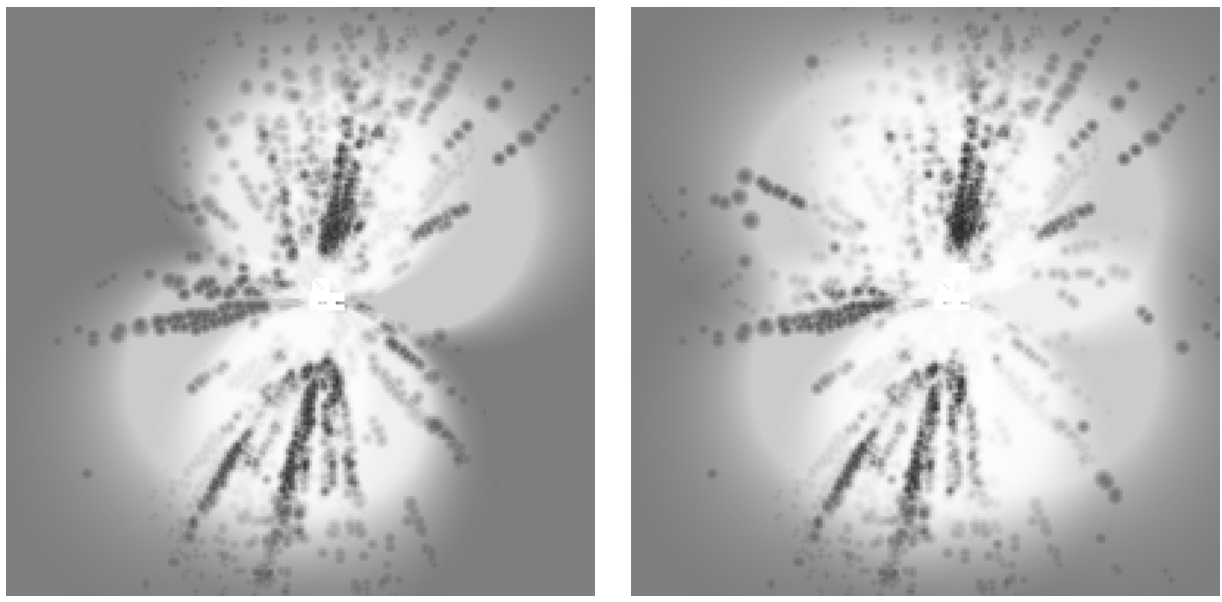

(c)

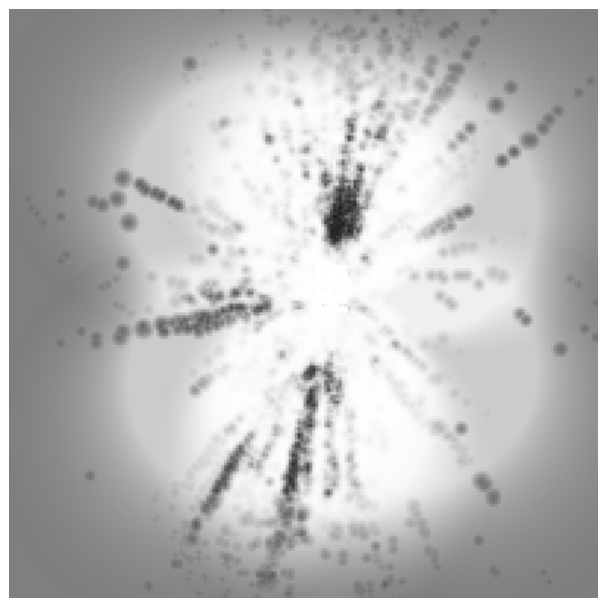

(d)

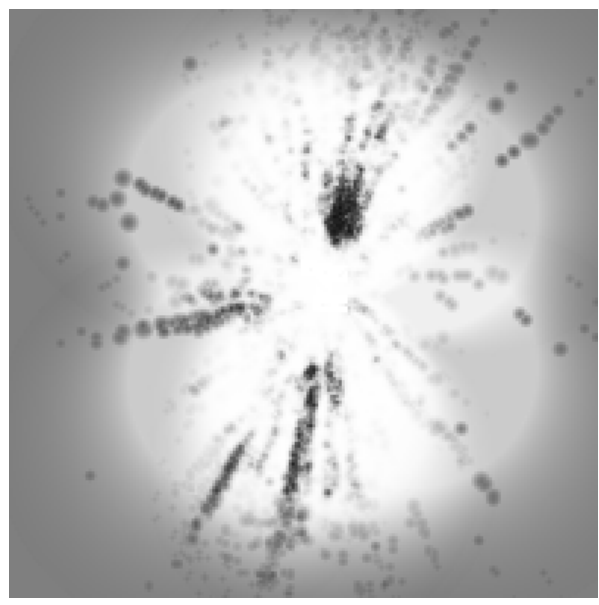

(e)

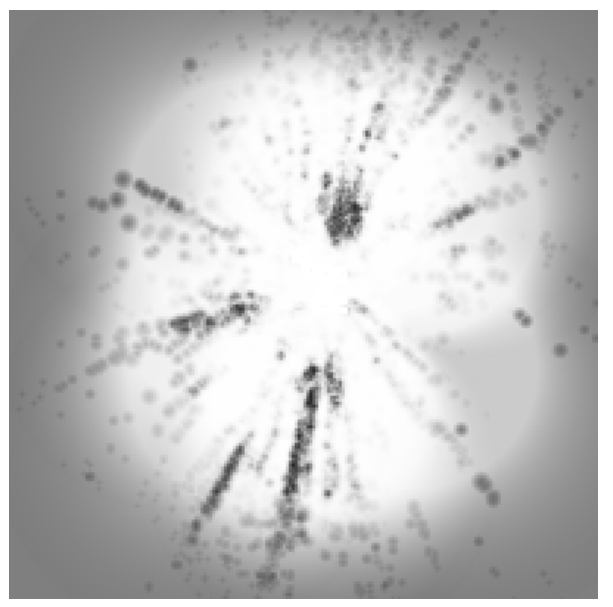

(f)

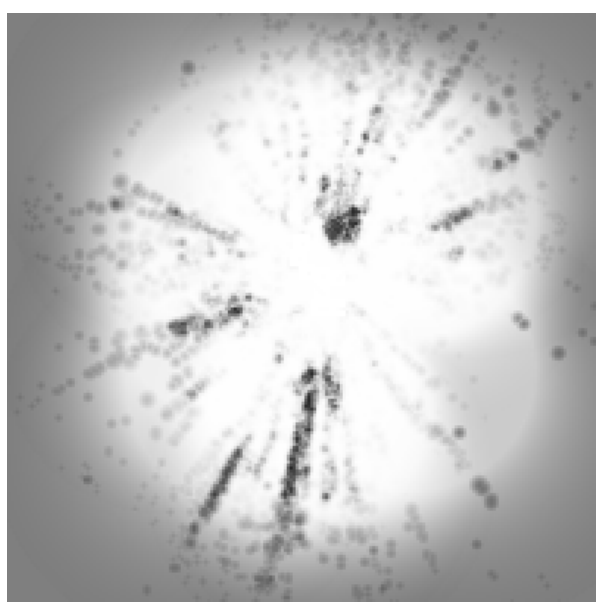

(g)

(h) 

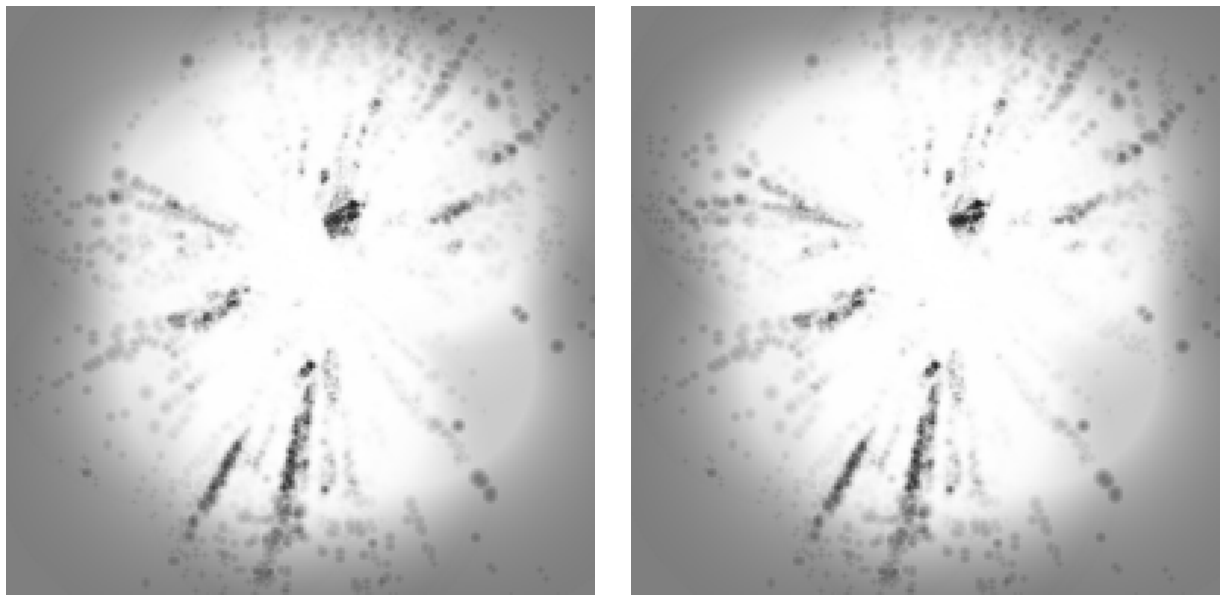

(i)

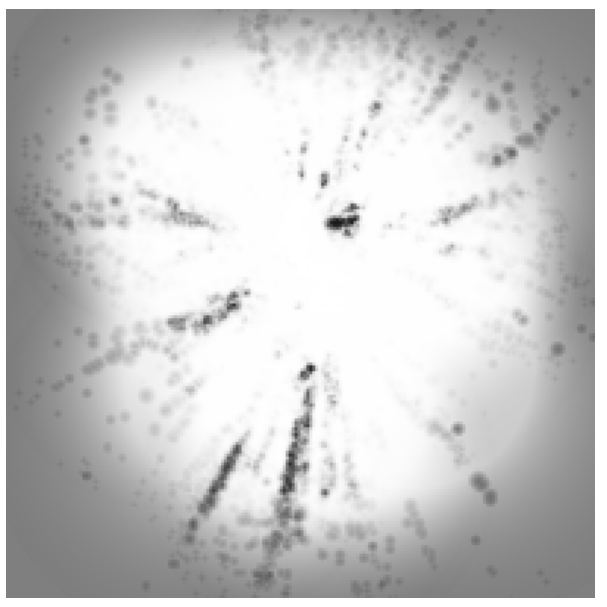

(j)

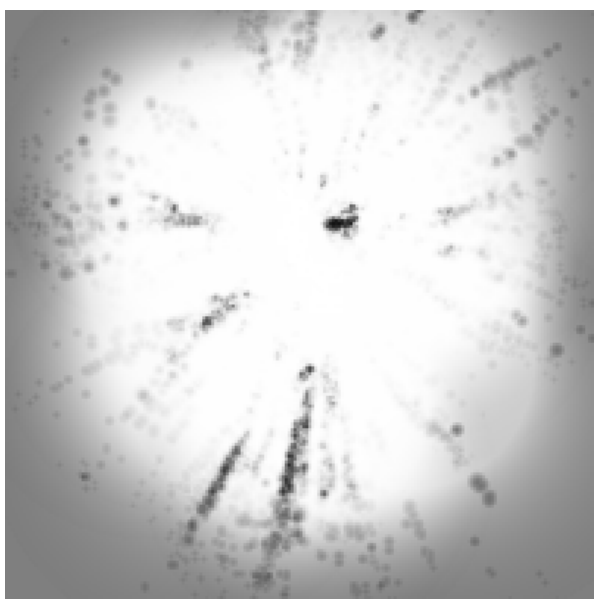

(1)

(m)
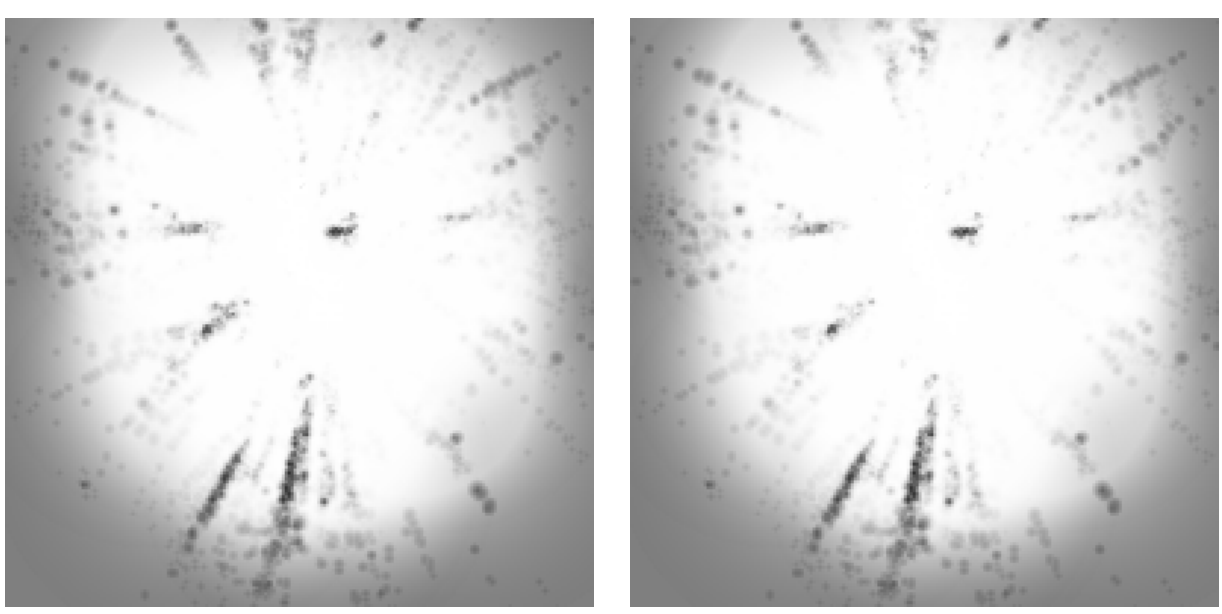

(n)

(o) 


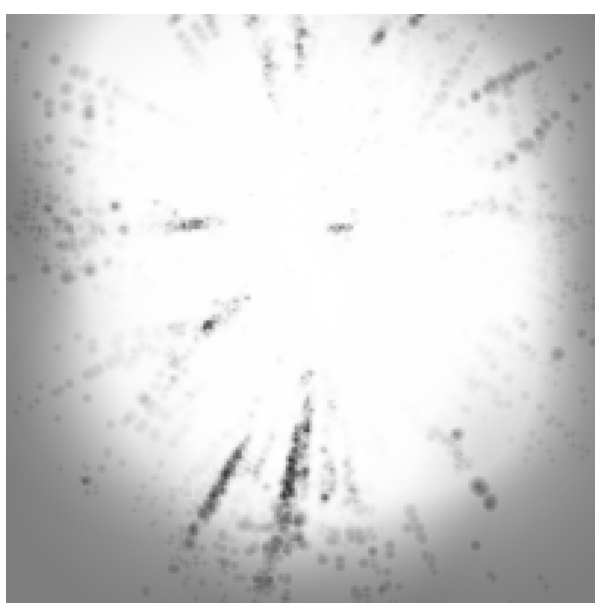

(p)

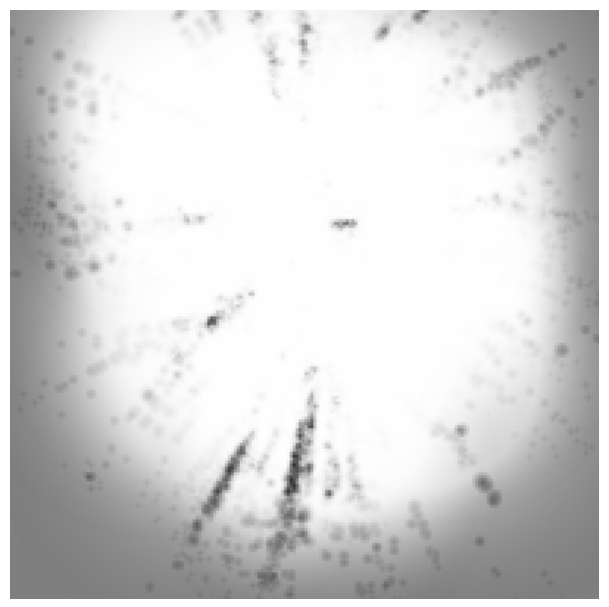

$(\mathrm{r})$

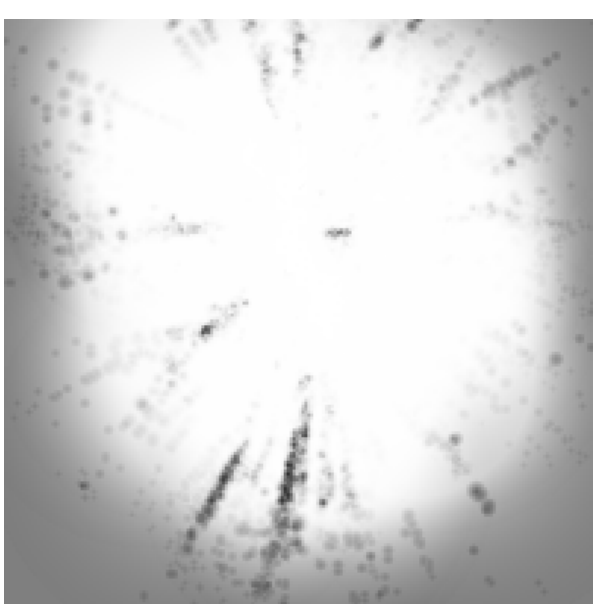

(q)

Nota-se da observação das Grades de Evidência que o obstáculo desaparece após o robô tê-lo passado. A Tabela 4 contém todos os planejamentos que o robô realizou durante a navegação autônoma. O ponto verde é o local de chegada e a outra extremidade da linha preta, a trajetória planejada, indica a posição atual do robô. $\mathrm{O}$ retângulo em azul é o objeto no seu tamanho e posição reais. A trajetória que o robô vai realizando ao longo da navegação é desenhada em vermelho. Os objetos como aparecem nesta representação são os objetos presentes no ambiente depois de aplicado o algoritmo de crescimento de região. 
Tabela 4 - Planejamento da trajetória durante navegação autônoma.

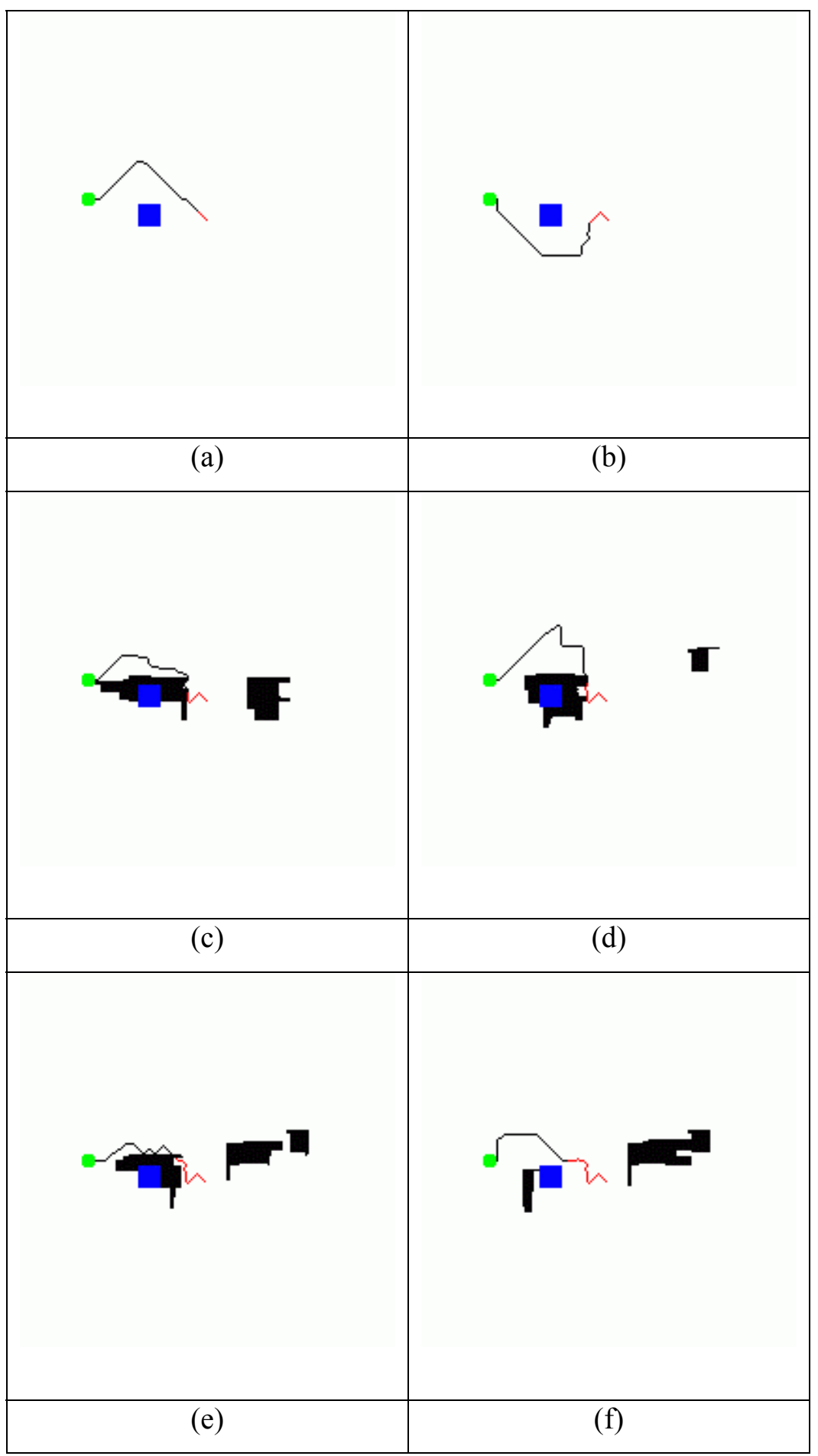




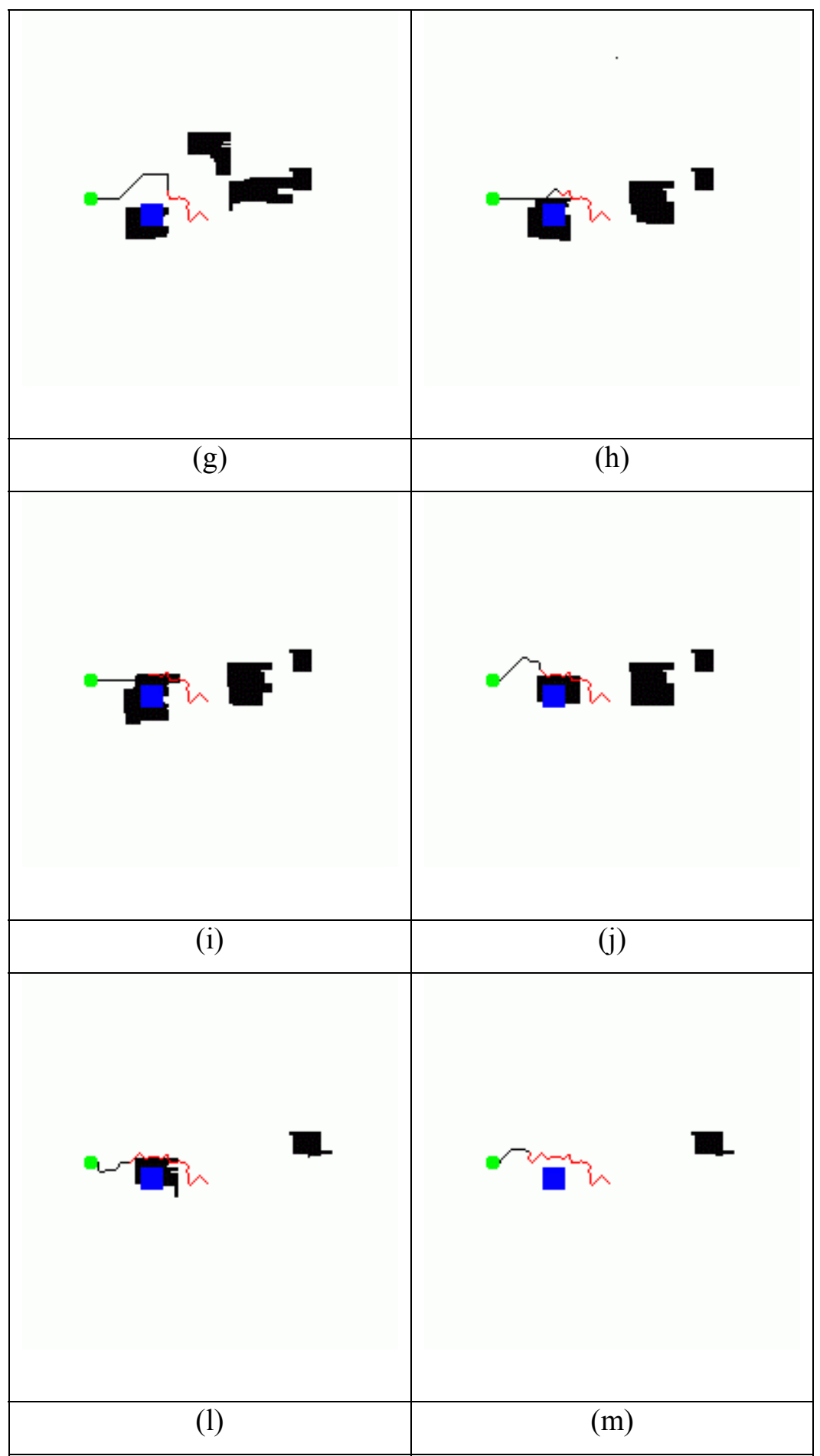




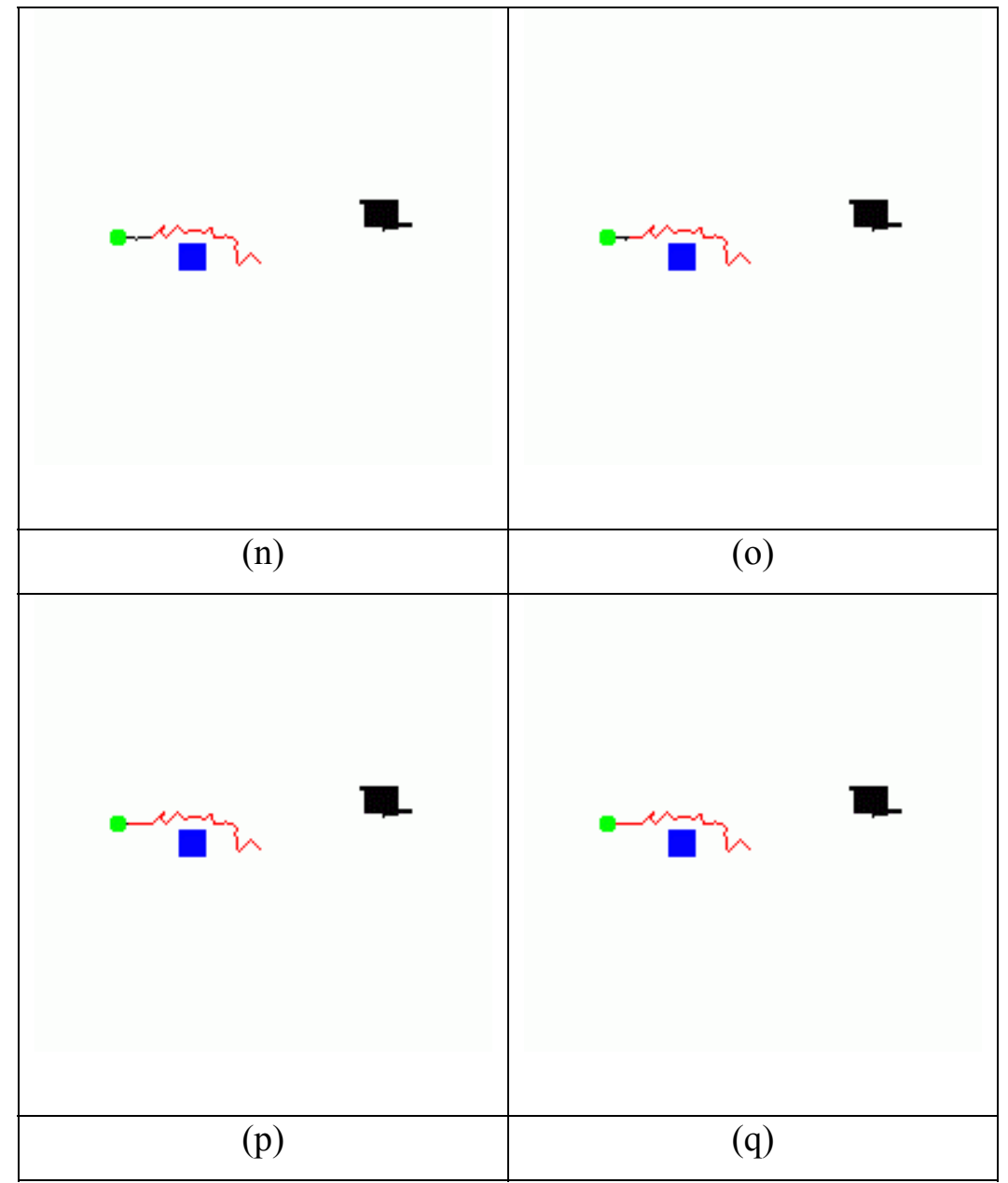

As possibilidades para construção do ambiente sobre o qual é feito o planejamento são duas: ocupado (preto) ou vazio (branco). Os obstáculos retratados nestas figuras do planejamento de trajetória aparecem apenas quando a probabilidade de ocupação é acima de um determinado limite. Os custos para cálculo da trajetória são iguais à Grade de Evidência; no planejamento as células recebem a classificação de vazia ou ocupada. Conforme a probabilidade de cada célula vai variando, alguns objetos ultrapassam o limiar e as células se tornam ocupadas. Valores de probabilidade próximos ao limiar fazem com que os objetos apareçam e desapareçam da imagem de um quadro pro outro. 


\subsection{Experimentos de auto-localização com as Grades de Evidência}

Os resultados dos experimentos anteriores utilizaram apenas a estimativa da posição do robô obtida da odometria. Nestes casos, o deslocamento do robô era pequeno e os erros acumulados não significaram grandes distorções no mapa adquirido.

Usando os mapas globais obtidos nas diversas iterações do mapeamento de uma caixa no centro do laboratório, foi usada a técnica de motion-solving em cada iteração para determinar uma melhor estimativa para a real posição do robô. A Tabela 5 mostra o resultado deste algoritmo aplicado às Grades de Evidência. As linhas da tabela representam novos conjuntos de informação vindos do sistema de visão estéreo. Cada novo conjunto, depois de empregado o modelo probabilístico do sensor, era correspondido com a grade mais atual. Mas vale ressaltar que as grades foram atualizadas segundo o odômetro e não com a estimativa do motion-solving. A técnica de motion-solving foi utilizada aqui apenas para verificar a qualidade desta alternativa para estimar a posição real do robô e mostrar que é possível obter uma estimativa a partir da correspondência entre Grades de Evidência.

Tabela 5 - Resultado do motion-solving. 


\begin{tabular}{|c|c|c|c|c|c|c|}
\cline { 2 - 7 } \multicolumn{1}{c|}{} & \multicolumn{3}{c|}{ Motion solving } & \multicolumn{3}{c|}{ Odometria } \\
\cline { 2 - 7 } \multicolumn{1}{c|}{} & $\mathrm{x}(\mathrm{mm})$ & $\mathrm{y}(\mathrm{mm})$ & $\begin{array}{c}\text { phi } \\
\text { (graus })\end{array}$ & $\mathrm{x}(\mathrm{mm})$ & $\mathrm{y}(\mathrm{mm})$ & $\begin{array}{c}\text { phi } \\
\text { (graus })\end{array}$ \\
\hline $\mathrm{d} 1$ & 300 & 150 & 0 & 300 & 0 & 0 \\
\hline $\mathrm{d} 2$ & 450 & -150 & 1 & 300 & 0 & 0 \\
\hline $\mathrm{d} 3$ & 150 & 150 & -1 & 300 & 0 & 0 \\
\hline $\mathrm{d} 4$ & 150 & 150 & -1 & 300 & 0 & 0 \\
\hline $\mathrm{d} 5$ & -150 & 400 & 0 & 0 & 300 & 0 \\
\hline $\mathrm{d} 6$ & -150 & 350 & -1 & 0 & 300 & 0 \\
\hline $\mathrm{d} 7$ & -150 & 150 & -1 & 0 & 300 & 0 \\
\hline $\mathrm{d} 8$ & -150 & 150 & 1 & 0 & 300 & 0 \\
\hline $\mathrm{d} 9$ & -100 & 200 & 1 & 0 & 300 & 0 \\
\hline $\mathrm{d} 10$ & 150 & 150 & -1 & 300 & 0 & 0 \\
\hline $\mathrm{d} 11$ & 150 & 150 & -1 & 300 & 0 & 0 \\
\hline $\mathrm{d} 12$ & 150 & -50 & -1 & 300 & 0 & 0 \\
\hline $\mathrm{d} 13$ & 300 & 0 & -1 & 300 & 0 & 0 \\
\hline $\mathrm{d} 14$ & 200 & 0 & -1 & 300 & 0 & 0 \\
\hline $\mathrm{d} 15$ & 150 & 150 & 1 & 0 & 300 & 0 \\
\hline $\mathrm{d} 16$ & 150 & 150 & 1 & 0 & 300 & 0 \\
\hline $\mathrm{d} 17$ & 150 & 150 & 1 & 0 & 300 & 0 \\
\hline $\mathrm{d} 18$ & 150 & 250 & 1 & 0 & 300 & 0 \\
\hline $\mathrm{d} 19$ & 0 & 300 & 1 & 0 & 300 & 0 \\
\hline
\end{tabular}

Analisando a Tabela 5 percebe-se que nos dois primeiros trechos do mapeamento, não existe muita informação nas Grades de Evidência e a estimativa obtida através do motion-solving não é muito precisa. Também nota-se que apenas após algumas atualizações na grades feitas numa mesma direção é que os resultados são bastante satisfatórios (linhas d13,14,d18,d19 na Tabela 5). A combinação desta estimativa com a odometria, e a adoção de uma estratégia de utilização da correspondência entre Grades de Evidência faz-se necessária para melhor utilização desta técnica. 
Capitulo 6

\section{CONCLUSÃO}

A navegação de robôs móveis em ambientes desconhecidos continua sendo um desafio aos pesquisadores da área. O emprego de sistemas de visão nesta tarefa, principalmente aqueles com amplo campo visual, vendo sendo cada vez mais freqüente. Suas imagens podem ser aproveitadas para diferentes finalidades, como a obtenção da movimentação da câmera entre a aquisição de duas imagens, de informação em todas as direções ao redor do sistema em tempo-real e das distâncias entre o sistema e os objetos em cena para a reconstrução do ambiente em duas ou três dimensões.

O foco principal deste trabalho foi a implementação das Grades de Evidência como forma de representação do conhecimento que o robô adquire através de seus sensores. Foi escolhida como única fonte de informação para o robô a visão estéreo com o sistema de visão omnidirecional. Esta implementação teve como objetivo possibilitar a navegação de um robô móvel num ambiente interno, desconhecido (sem nenhum conhecimento a priori), não-estruturado e estático (não são tratados eventuais objetos móveis no ambiente). O planejamento e a auto-localização, problemas que precisam ser resolvidos em uma navegação autônoma, são feitos diretamente sobre a Grade de Evidência.

O sistema de visão estéreo omnidirecional foi aperfeiçoado neste trabalho com relação à implementações anteriores. Os resultados obtidos com o sistema possuem informação suficiente para a construção de mapas de distância quando empregados em conjunto com as Grades de Evidência. No entanto, o algoritmo de visão estéreo necessita de mudanças para produção de um mapa mais denso e consistente do ambiente.

O modelo probabilístico do sistema de visão estéreo omnidirecional mostrou-se adequado para ser utilizado nas Grades de Evidência. Algumas características do 
sistema real ainda podem ser incorporadas no modelo. Como esta forma de representação é utilizada para navegação em ambientes desconhecidos, as Grades de Evidência dependem da qualidade do modelo do sensor utilizado, apresentando informação pouco precisa sobre o ambiente no início da tarefa. No entanto, todo algoritmo que envolva um certo aprendizado do ambiente no início da tarefa apresenta resultados semelhantes.

O planejamento de trajetórias foi implementado com a finalidade de mostrar que é possível, com a quantidade de informação que o robô possui por meio das Grades de Evidência, realizar uma navegação autônoma. Os resultados dependem também da qualidade do algoritmo estéreo.

A utilização das Grades de Evidência para determinar uma estimativa do real deslocamento do robô é uma fonte auxiliar aos dados da odometria. As duas informações podem ser combinadas, ou prevalecerem uma sobre a outra em determinado instante. Mostrou-se que o algoritmo de correspondência entre as grades resultado em melhores estimativas de posição quando mais de três atualizações são realizadas na mesma direção de movimento. Nos primeiros movimentos do robô o resultado deve-se utilizar apenas a estimativa do odômetro, pois as Grades de Evidência não possuem muita informação. Mas é nesta etapa inicial onde os dados do odômetro são mais confiáveis. Após certo trecho percorrido, a posição pode ser corrigida com este algoritmo de correspondência entre as grades.

A principal idéia deste trabalho diz respeito ao aspecto deliberativo em robôs móveis. Para que um robô tome decisões sobre o que fazer a cada passo, é necessária uma forma de representação do conhecimento que o robô vai adquirindo através de seus sensores conforme ele navega no ambiente. Os estudos futuros procurarão analisar melhores formas de representar o conhecimento garantindo um melhor desempenho do robô.

Quanto ao algoritmo estéreo, o processo de correspondência escolhido embora simples e computacionalmente eficiente resulta em mapas imprecisos devido à presença de falsos correspondentes. Este processo poderia ser aperfeiçoado através do emprego de janelas de correspondência de tamanhos e formatos variáveis segundo 
o formato do espelho. A utilização de programação dinâmica é uma das soluções para eliminar as falsas correspondências. Ainda, um estudo mais detalhado do cálculo das distâncias levando em consideração a limitação do próprio sistema de visão permitiria a construção de um modelo do erro existente no processo.

Uma limitação do emprego da visão estéreo neste trabalho está na formação de uma região não visível do espaço, na direção do movimento, como já foi mencionado no modelo por arcos capazes. A existência de apenas uma câmera e a necessidade da obtenção de pelo menos duas imagens de posições distintas para aquisição de informação estéreo determinou este tipo de implementação. Embora a solução adotada possa ser utilizada em navegação de robôs móveis, como foi mostrado neste trabalho, está-se desenvolvendo um espelho com dois lobos para resolver esta limitação. Com este novo espelho não há a necessidade de deslocar o robô, pois o ambiente é retratado de duas formas diferentes nos lobos. A Figura 41 é uma imagem obtida por um espelho deste tipo criado virtualmente através do software POV-Ray, de domínio público. O ambiente é representado em duas áreas distintas na imagem: o círculo central onde o ambiente inteiro é retratado e a coroa circular onde apenas parte do ambiente é visível. Os cubos presentes no ambiente aparecem nas duas partes da imagem.

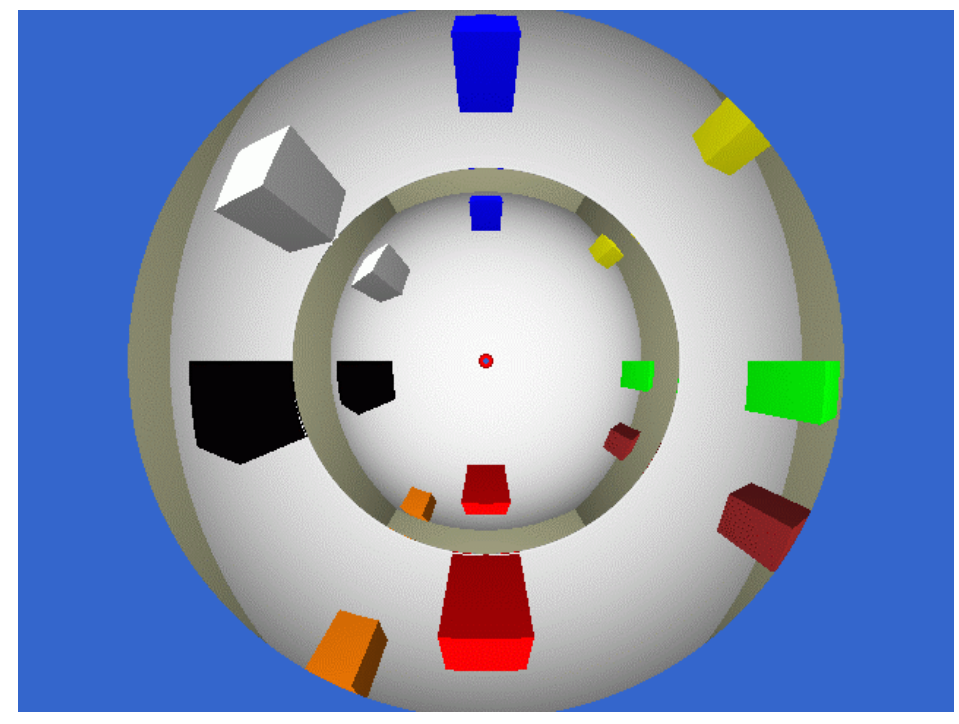

Figura 41 - Imagem do novo espelho. 
A Figura 42 representa o perfil deste espelho de dois lobos com o qual a imagem anterior foi feita. $\mathrm{O}$ foco do lobo inferior está marcado em vermelho na figura e o do superior em azul.

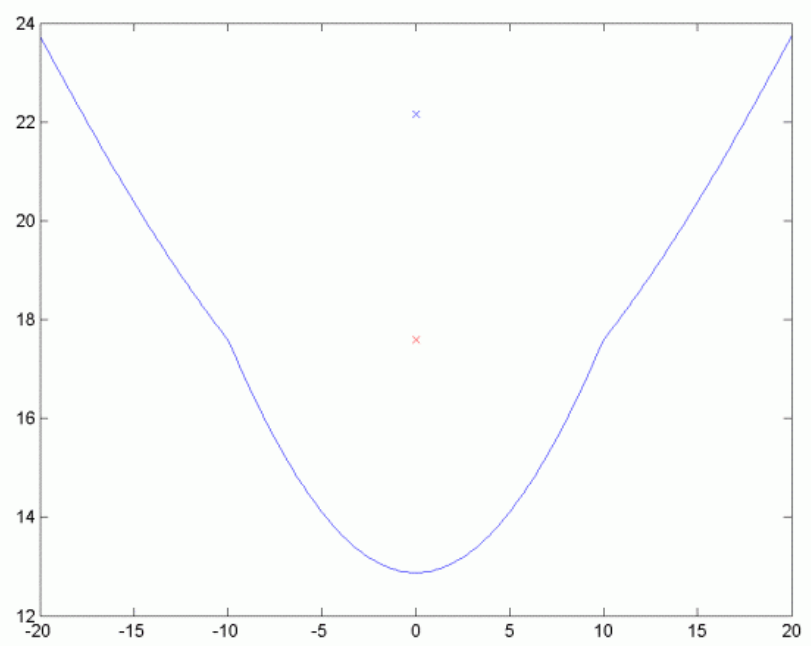

Figura 42 - Perfil do espelho de dois lobos. 


\section{REFERÊNCIAS BIBLIOGRÁFICAS}

ARGYROS, A.A.; BEKRIS, E.; ORPHANOUDAKIS, S.C. Robot homing based on corner tracking in a sequence of panoramic images. In: COMPUTER AND VISION PATTERN RECOGNITION CONFERENCE (CVPR 2001), Hawaii, 2001.

CHEESEMAN, P.; SMITH, R.C.; SELF, M. Estimating uncertain spatial relationships in robotics. Autonomous Robot Vehicles, pp. 167-193, 1990.

CORREA, F.R.; DECCÓ, C.C.G.; OKAMOTO, J. Obtaining range information with an omnidirectional vision system. In: CONGRESSO BRASILEIRO DE ENGENHARIA MECÂNICA (COBEM), XVII, São Paulo, 2003.

DESOUZA, G.N.; KAK, A.C. Vision for mobile robot navigation: a survey. IEEE Transactions on Pattern Analysis and Machine Intelligence, v.24, n.2, p.237267, February 2002.

DROCOURT, C. et al. Simultaneous localization and map building paradigm based on omnidirectional stereoscopic vision. In: IEEE WORKSHOP ON “OMNIDIRECTIONAL VISION APPLIED TO ROBOTICS ORIENTATION AND NONDESTRUCTIVE TESTING” OF THE INTERNATIONAL CONFERENCE ON ADVANCED ROBOTICS (ICAR'01), 10th, Budapest, 2001. Proceedings. p. 73-79.

ELFES, A. Occupancy Grids: a probabilistic framework for robot perception and navigation. Pittsburgh, 1989. Ph.D. Thesis - Carnegie-Mellon University.

FAUGERAS, O. Three-dimensional computer vision: a geometric viewpoint. Massachusetts: MIT Press, 1999. 
GRASSI JR, V. et al. Desenvolvimento de um sistema de visão omnidirecional. In: CONGRESSO BRASILEIRO DE ENGENHARIA MECÂNICA (COBEM), XVI, Uberlândia, 2001. Anais.

KOYASU, H.; MIURA, J.; SHIRAI, Y. Recognizing moving obstacles for robot navigation using real-time omnidirectional stereo vision. Journal of Robotics and Mechatronics, vol. 14, 2002.

HAGER, G.; TOYAMA, K. The "XVision” system: A general purpose substrate for real-time vision applications. Computer Vision and Image Understanding, v.69, n.1, p.23-27, 1998.

LEE, J. W.; YOU, S.; NEUMANN, U. Large motion estimation for omnidirectional vision. In: IEEE WORKSHOP ON OMNIDIRECTIONAL VISION (OMNIVIS'00), Hilton Head, 2000.

MARTIN, M.C.; MORAVEC, H.P. Robot evidence grids. Pittsburgh: The Robotics Institute, Carnegie Mellon University, March 1996. (Technical Report CMU-RI-TR-96-06).

MATSUMOTO, Y. et al. Visual navigation using omnidirectional view sequence. In: IEEE/RSJ INTERNATIONAL CONFERENCE ON INTELLIGENT ROBOTS AND SYSTEMS (IROS'99), 1999. Proceedings, pp.317-322, 1999.

MIURA, J.; NEGISHI, Y.; SHIRAI, Y. Mobile robot map generation by integrating omnidirectional stereo and laser range finder. In: INTERNATIONAL CONFERENCE ON INTELLIGENT ROBOTS AND SYSTEMS (IROS), Lausanne, 2002. Proceedings, pp. 250-255, 2002.

MORAVEC, H.; ELFES, A. High resolution maps from wide angle sonar. In: IEEE INTERNATIONAL CONFERENCE ON ROBOTICS AND AUTOMATION, St. Louis, 1985. Proceedings, pp 116-121, 1985. 
MORAVEC, H. P. Robot spatial perception by stereoscopic vision and 3D evidence grids. Pittsburgh: The Robotics Institute, Carnegie Mellon University, September 1996. (Technical Report CMU-RI-TR-96-34).

MORIYA, K.; OHBA, K. Image projection criteria with epipolar line for a precise correlation with omni images. In: ASIAN CONFERENCE ON COMPUTER VISION, 4th, 2000. Proceedings, pp. 152-157, 2000.

MURPHY, R.R. Introduction to AI robotics. Massachusetts: MIT Press, 2000.

OLLIS, M.; HERMAN, H.; SINGH, S. Analysis and design of panoramic stereo vision using equi-angular pixel cameras. Pittsburgh: The Robotics Institute, Carnegie Mellon University, January 1999. (Technical Report CMU-RI-TR-9904).

PAJDLA, T. Robot localization using shift invariant representation of panoramic images. November 1998. (Report Research no. k335/98/170).

PALETTA, L.; FRINTROP, S.; HERTZBERG, J. Robust localization using context in omnidirectional imaging. In: IEEE INTERNATIONAL CONFERENCE ON ROBOTICS AND AUTOMATION (ICRA 2001), Seoul, Korea, May 21-26, 2001. Proceedings, pp. 2072-2077.

PATEL, S. et al. Sensor based door navigation for a nonholonomic vehicle. In: INTERNATIONAL CONFERENCE ON ROBOTICS \& AUTOMATION, Washington, 2002. Proceedings.

SHAKERNIA, O.; VIDAL, R.; SASTRY, S. Omnidirectional egomotion estimation from back-projection flow. In: IEEE WORKSHOP ON OMNIDIRECTIONAL VISION, June 2003.

STRATMANN, I.; SOLDA, E. Omnidirectional vision and inertial clues for robot navigation. In: INTERNATIONAL CONFERENCE ON ADVANCED ROBOTICS (ICAR '03), 11th, Coimbra, Portugal, 2003. Proceedings, pages 1915 - 1921, ISBN 972-96889-9-0, June 2003. 
SVOBODA, T.; PAJDLA, T.; HLAVÁC, V. Epipolar geometry for panoramic cameras. In: EUROPEAN CONFERENCE ON COMPUTER VISION, 5th, Freiburg, Germany, 1998. Proceedings, p. 218-232.

SVOBODA, T.; PAJDLA, T. Matching in catadioptric images with appropriate windows, and outliers removal. In: INTERNATIONAL CONFERENCE ON COMPUTER ANALYSIS OF IMAGES AND PATTERNS, 9th, Warsaw, Poland, 2001. Proceedings, September 2001.

THRUN, S. Robotic mapping: a survey. Pittsburgh: School of Computer Science, Carnegie Mellon University, February 2002. (Technical Report CMU-CS-02$111)$.

YAGI, Y. Omnidirectional sensing and its applications. IEICE Transactions on Information and Systems, v.E82-D, n.3, p.568-579, 1999.

YAGI, Y.; NISHIZAWA, Y.; YACHIDA, M. Map-based navigation for a mobile robot with omnidirectional image sensor COPIS. IEEE Transactions on

Robotics and Automation, vol. 11, no. 5, October 1995.

YAMAZAWA, K.; YAGI, Y.; YACHIDA, M. Obstacle detection with omnidirectional image sensor HyperOmni Vision. In: IEEE INTERNATIONAL CONFERENCE ON ROBOTICS AND AUTOMATION, 1995. Proceedings, pages 1062-1067, 1995.

WEI, S. K.; URBAN, M.; PAJDLA, T. Stereo matching of catadioptric panoramic images. Prague: Center for Machine Perception, Czech Technical University, March 2000. (Research Report CTU-CMP-2000-08).

WINTERS, N. et al. Omni-directional vision for robot navigation. In:

INTERNATIONAL IEEE WORKSHOP ON OMNIDIRECTIONAL VISION (CVPR 2000), 1st, Hilton Head Island, USA, June 2000. Proceedings, 2000. 